\title{
A Systematic Review up to 2018 of HIV and Associated Factors Among Criminal Justice-Involved (CJ) Black Sexual and Gender Minority Populations in the United States (US)
}

\author{
Russell Brewer ${ }^{1}$ (D) Santhoshini L. Ramani ${ }^{1}$ - Aditya Khanna ${ }^{2} \cdot$ Kayo Fujimoto ${ }^{3}$ • John A. Schneider ${ }^{1}$. Anna Hotton ${ }^{1}$. \\ Leo Wilton $^{4,5}$ - Tania Escobedo ${ }^{1}$ - Nina T. Harawa ${ }^{6,7}$
}

Received: 22 February 2021 / Revised: 24 May 2021 / Accepted: 26 May 2021 / Published online: 22 July 2021

(C) W. Montague Cobb-NMA Health Institute 2021

\begin{abstract}
Black men who have sex with men (BMSM) and Black transgender women (BTW) are impacted by dual epidemics of HIV and incarceration. We advanced understanding of the relationship between criminal justice involvement, HIV, and other key HIVrelated characteristics among these key populations in the US. We conducted a systematic review up to 2018 and 47 articles met the inclusion criteria of scientific publications involving quantitative findings of US-based HIV-related studies focused on criminal justice-involved (CJI) BMSM and BTW. Overall, there was a dearth of studies focused specifically on BTW. Criminal justice involvement was relatively high among BMSM and BTW and more pronounced among BTW. The current evidence favors no association between incarceration and HIV acquisition among BMSM with limited information about BTW. Criminal justice involvement was associated with a greater likelihood of STIs among BMSM with mixed results for sexual risk behaviors. Criminal justice settings served as an important venue for HIV testing/diagnosis for both BMSM and BTW. However, these settings were not conducive for subsequent stages of the HIV care continuum. Studies pointed to an independent association between criminal justice involvement, substance use, housing instability, and greater odds of incarceration among BMSM who were unemployed and had limited education. Future incarceration was associated with high levels of perceived racism among BMSM. Among young BMSM, high network criminal justice prevalence was also associated with sexual risk behaviors, poorer mental health outcomes, drug use, and housing instability. CJI BMSM and BTW represent a critical subpopulation to end the HIV epidemic in the US.
\end{abstract}

Keywords HIV · Criminal justice-involved · Corrections · Black men who have sex with men · Black transgender women

Russell Brewer

rbrewer@medicine.bsd.uchicago.edu

1 Department of Medicine, University of Chicago, 5837 S. Maryland Ave, MC5065, Chicago, IL 60637, USA

2 Department of Behavioral and Social Science, Brown University, Providence, RI, USA

3 Division of Health Promotion and Behavioral Sciences, University of Texas Health Science Center at Houston, Houston, TX, USA

4 State University of New York at Binghamton, Binghamton, NY, USA

5 Faculty of Humanities, University of Johannesburg, Johannesburg, South Africa

6 David Geffen School of Medicine, General Internal Medicine and Health Services Research, University of California Los Angeles, Los Angeles, CA, USA

7 College of Medicine, Department of Psychiatry, Charles R. Drew University of Medicine and Science, Los Angeles, CA, USA

\section{Introduction}

Black sexual and gender minority individuals are disproportionately impacted by HIV in the United States (US) [1-9]. In 2017, Black men who have sex with men (BMSM) nationally accounted for more than a quarter of all new HIV diagnoses in the US, with a majority of new HIV diagnoses occurring among younger BMSM aged 13-34 [1]. Among transgender individuals, an estimated $14 \%$ of transgender women were living with HIV in 2017, with the highest prevalence estimate (i.e., 44\%) being among Black transgender women (BTW) [10].

High incarceration rates have also been identified among BMSM and BTW in the US $[11,12]$. A landmark longitudinal study, the HIV Prevention Trials Network (HPTN) 061 study conducted in six urban US cities (i.e., District of Columbia, San Francisco, Los Angeles, Boston, Atlanta, and New York City), highlighted the disproportionate burden of incarceration 
among sexual and gender minority populations. Consisting of primarily cisgender BMSM, the HPTN 061 study showed an elevated lifetime history of incarceration $(60 \%)$ and high incarceration incidence $(35 \%, 95 \% \mathrm{CI}=[31 \%, 38 \%])$ among sexual and gender minority participants. Furthermore, BTW had a greater odds (3.26) of incarceration history compared with cisgender BMSM [12]. However, to date, there is not a comprehensive understanding of the impact of incarceration among these priority populations and there remains a dearth of information about the connection between criminal justice involvement and HIV among BMSM and BTW who sit at the intersection of multiple marginalized identities (i.e., Black race, gender identity, sexual orientation) [3, 5]. Thus, in the current systematic review, we sought to expand understanding of the burden of incarceration as well as the relationship between HIV and criminal justice involvement among Black sexual and gender minority populations in the US [11, 12].

Previous studies have shown that network characteristics (e.g., high sexually transmitted infection [STI] rates among sexual partners), psychosocial characteristics (e.g., mental health and substance use/misuse), and socio-structural factors (e.g., unstable housing, racism/stigma, unemployment) contribute to HIV vulnerability and poor access to HIV services for Black sexual and gender minority populations [1, 13-25]. What is less understood are the reasons surrounding why these characteristics may or may not be more pronounced and/or exacerbated among criminal justice-involved (CJI) BMSM and BTW. To address this gap, we focus our systematic review on quantitative studies that have examined the various intersections between criminal justice involvement, HIV, and key characteristics (e.g., network, psychosocial, socio-structural) known to be associated with HIV vulnerability and poor access to HIV services (i.e., HIV care and treatment). We use the term CJI to include those who are currently detained or under criminal justice supervision (probation or parole) or who have a history of arrest, incarceration, or supervision. We also highlight epidemiological studies focused on YBMSM given that they account for the majority of new HIV diagnoses among all men who have sex with men (MSM) and the need to fully engage this population in order to reach HIV elimination $[1,14]$.

Pre-detention, detention, and post-release incarceration periods have been identified as important intervention opportunities for evidence-based and informed HIV interventions [15, 16]. A recent systematic review found that the most common interventions within criminal justice settings consisted of HIV/STI screenings as well as educational interventions [17]. In addition, relatively few interventions were focused on MSM and TW, perhaps, because this approach may expose these populations to unwarranted attention and violence within criminal justice settings [17]. Of the 58 studies identified in this review, only one was focused specifically on CJI among
BMSM [17]. The information gathered from the current systematic review can be used to inform gaps in existing research focused on CJI BMSM and BTW in the US and guide the development of future research and interventions.

\section{Methods}

The final systematic review search was completed on September 6, 2018, and included all articles up to that date. Relevant keywords and Medical Subject Headings (MeSH) terms based on a priori knowledge and manuscript goals were used to search the PubMed, PsychINFO, and SocINDEX databases. The finalized terms inputted into these databases are available in the appendix. The search yielded a total of 393 articles that were then exported into an Endnote library [18]. Seventy-four (74) duplicate articles were removed and the remaining articles were assessed for eligibility.

\section{Article Eligibility}

The systematic review was focused on quantitative epidemiological studies conducted in the US that provided data for individuals 18 and older. Thus, qualitative and non-US studies were excluded. Studies had to (1) report criminal justice involvement estimates (e.g., previous incarceration history or incidence) that were specific to BMSM and/or BTW participants and/or (2) contain CJI estimates specific to BMSM and/ or BTW within the context of at least one of the following conditions: (a) HIV, (b) STIs, (c) sexual risk behaviors, (d) mental health outcomes, (e) substance use/misuse, and (f) socio-structural experiences (including stigma/discrimination, housing status, education levels, and employment history). Articles were reviewed for inclusion or exclusion in an Endnote library. Detailed information on article identification and selection, including exclusion criteria, is available in Fig. 1 (PRISMA diagram). Each ineligible article was categorized by a single exclusion reason. An initial review of titles, abstracts, and full texts of articles was conducted by a member of the research team, and uncertainties related to eligibility were resolved with input from the primary author. In total, 47 articles were identified for inclusion.

\section{Data Abstraction}

General article characteristics (e.g., location, type of study, primary outcomes) are described in Table 1. All relevant point estimates from the eligible articles were abstracted and described in Tables 2-4. Within Tables 2-4, each article with qualifying data is presented along with article-specific estimates and organized according to variables of interest. Table 2 includes articles with HIV/STI estimates. Table 3 includes articles involving sexual behavior, substance use, and 
Fig. 1 PRISMA flow diagram: systematic review of US-based studies among CJI BMSM and BTW
Total articles found from PubMed, databases using keywords/MESH terms $(n=393)$
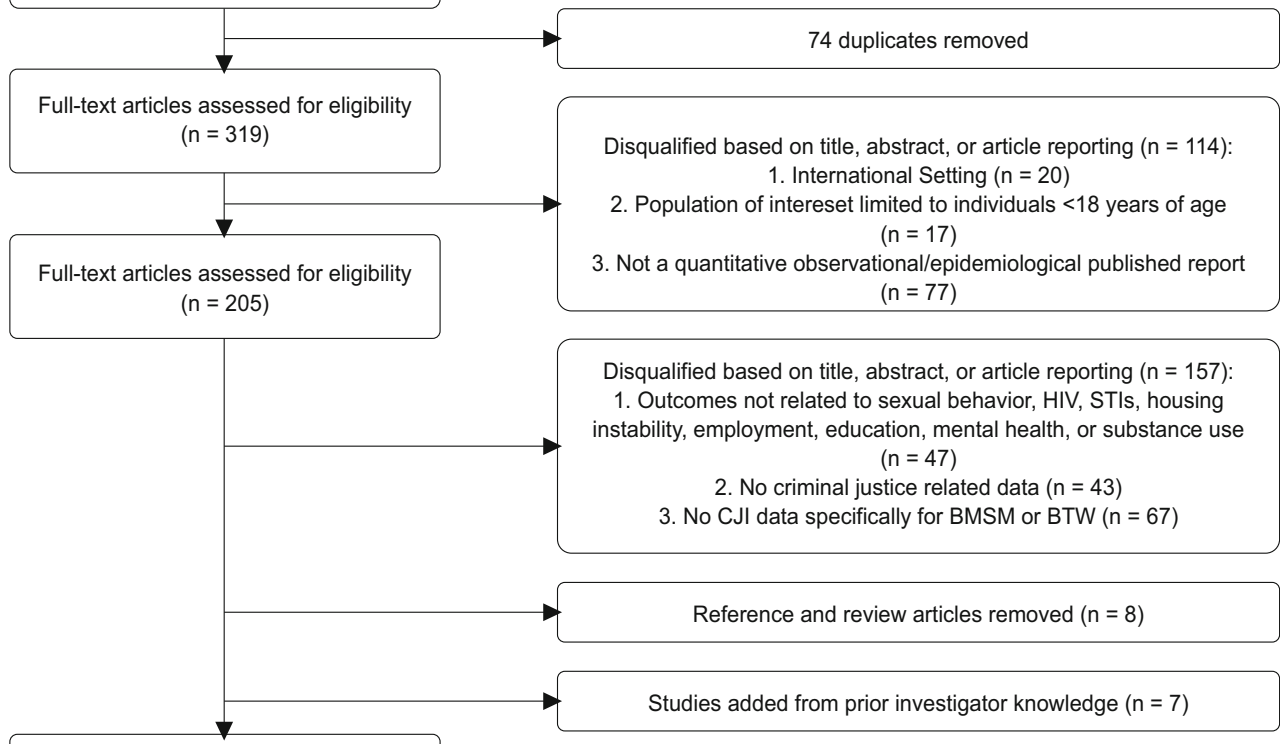

Included studies $(n=47)$ mental health. Table 4 includes all articles that assessed and provided information about socio-structural characteristics to include stigma/discrimination, education, employment, and housing.

\section{Quality Assessment}

Eligible studies were assessed for quality using a ten-item risk of bias tool developed by Hoy et al. [19] for population-based prevalence studies (range: 0 , worst-10, best). The risk of bias tool included domains such as the method of sample selection, non-response bias, and reliability and validity of the study instrument. Some limitations with applicability of the scale existed due to its intended use to rate observational studies of clinical disease prevalence. The scale was modified to more appropriately assess the quality of included articles based on the senior investigator's knowledge of epidemiological studies of sexual and gender minorities and based on previous work [26]. Initially, 5 articles were scored independently to assess interrater reliability. A member of the research team generated a quality score for each article using the scale items with input from senior investigators.

We organize our findings in the following order: (1) a summary of the studies included in the systematic review; (2) studies describing criminal justice involvement estimates among BMSM and BTW; (3) studies focused on the intersection of HIV and criminal justice involvement to include the
HIV care continuum; (4) studies focused on criminal justice involvement and STIs; (5) studies focused on criminal justice involvement and sexual risk behaviors; (6) studies focused on criminal justice involvement and substance use/misuse; (7) studies focused on criminal justice involvement and mental health outcomes; and finally (8) studies focused on criminal justice involvement and socio-structural factors.

\section{Results}

\section{Summary of Included Articles}

A total of 47 eligible articles published over a span of 18 years were identified for inclusion. Aggregate characteristics of the included articles are summarized in Table 1 to include studies by region, design, and primary outcomes (e.g., HIV, STIs, mental health, and substance use). Tables 2-4 containing all abstracted article data are available as part of the supplementary materials. The mean rating for article quality based on the risk of bias tool [19] was $7.04(\mathrm{SD}=2.00)$, with scores ranging from 4 to 9 .

Notably, 25 published articles $(53.2 \%)$ were analyzed utilizing datasets similar to at least one other article (i.e., based on the same local cohort or from the same multi-site study such as the HPTN 061 study and the National HIV Behavioral Surveillance survey). Information on usage of 
Table 1 Characteristics of included studies focused on criminal justiceinvolved (CJI) Black men who have sex with men (BMSM) and Black transgender women (BTW), 2000-2018

\begin{tabular}{|c|c|}
\hline United States Region & 6 \\
\hline South & 4 \\
\hline Northeast & 14 \\
\hline West & 5 (all Chicago, IL) \\
\hline Midwest & 11 \\
\hline Multiple regions & 7 \\
\hline \multicolumn{2}{|l|}{ National/web-based/other } \\
\hline HIV estimates & 18 \\
\hline STI estimates & 7 \\
\hline $\begin{array}{l}\text { Substance-misuse estimates (e.g., alcohol and } \\
\text { drugs) }\end{array}$ & 9 \\
\hline $\begin{array}{l}\text { Sexual behavior estimates (e.g., condomless sex, } \\
\text { multiple partners, unknown HIV status) }\end{array}$ & 11 \\
\hline Mental health estimates & 5 \\
\hline Social/structural estimates & 0 \\
\hline HIV stigma & 6 \\
\hline Housing & 3 \\
\hline Employment & 5 \\
\hline Education & 47 (39 estimates)* \\
\hline \multicolumn{2}{|l|}{ Incarceration } \\
\hline Study type & 3 \\
\hline Randomized clinical trial (RCT) & 0 \\
\hline Quasi RCT & $36^{* *}$ \\
\hline Cross-sectional study (CS) & 6 \\
\hline Longitudinal study (LS) & 1 \\
\hline Case-control study & 1 \\
\hline \multicolumn{2}{|l|}{ Meta-analysis } \\
\hline Inclusion of BTW & $\begin{array}{l}18 \text { total trans } \\
\text { inclusive studies }\end{array}$ \\
\hline $\begin{array}{l}\text { Study sample includes BTW but combines } \\
\text { reported estimates with BMSM }\end{array}$ & 7 \\
\hline $\begin{array}{l}\text { Study sample includes BTW but combines } \\
\text { reported estimates with non-Black TW }\end{array}$ & 3 \\
\hline $\begin{array}{l}\text { Study samples includes Black transgender } \\
\text { persons, but does not specify MTF or FTM }\end{array}$ & 2 \\
\hline Study provides specific estimates for BTW & 6 \\
\hline
\end{tabular}

*39 explicit estimates on incarceration prevalence, frequency, duration, etc. +8 additional articles with $100 \%$ CJI population containing relevant socio-demographic or other information on detainees/CJI populations; **4 studies analyzed baseline data from a RCT, 7 analyzed baseline data from a longitudinal study

similar datasets is detailed in a separate column for each applicable article in Table 4. Nearly all studies were implemented in urban settings, with just one article providing specific estimates for a rural location [27]. All studies in the Midwest $(\mathrm{n}=5)$ were conducted in Chicago, IL. More than a quarter $(n=13)$ of all studies were conducted in the West Coast, primarily in Los Angeles County, CA.

\section{Criminal Justice Involvement Estimates Among BMSM and BTW}

All included articles described criminal justice involvement estimates for BMSM and BTW. However, the type (e.g., prior history, arrest, currently detained) and measures used varied substantially across studies. The most common measure, reported by 28 studies $(60 \%)$, was prevalence of incarceration history. Of these, 19 articles reported lifetime incarceration history estimates $[11,12,28-44]$. Eleven of these articles had estimates focused on BMSM of all ages (i.e., samples of all or primarily BMSM) [11, 28-31, 34-36, 40, 42, 43], five particularly among YBMSM [33, 37-39, 44], one among BTW only [41], and two among both BMSM and BTW [12, 32]. Incarceration estimates focused on BMSM had values ranging from 25.5 to $84 \%$, while those on YBMSM ranged from 2.4 to $53.5 \%$ [32, 33, 37-39, 44]. The three estimates among BTW of all ages had relatively small sample sizes, but estimates were uniformly high in contrast to estimates among BMSM of all ages, ranging from 46.9 to $80 \%$ [12].

Seven studies ( $15 \%$ of total) assessed more recent estimates of incarceration prevalence ranging from the past 2 months to 2 years [22, 35, 45-49]. Among these, two articles contained estimates specific to BTW $[45,46]$ and one among YBMSM in particular [49]. Six articles described prevalence estimates for history of arrest [25, 39, 50-53], varying from lifetime history to the past 6 or 12 months, though one had an unspecified window [50], Two analyses based on the same sample of YBMSM broadly assessed lifetime criminal justice involvement (inclusive of both arrest and incarceration) [13, 54].

Incarceration frequency and duration were relatively uncommon variables of interest with only three articles providing estimates of incarceration duration [29, 55, 56], four on incarceration frequency $[11,25,32,55]$, one on arrest frequency [51], and one on length of time since release [57]. Two estimates among these were specific to BTW $[32,55]$. Only one analysis explored incarceration incidence, reporting an annualized incidence rate of $35 \%$ [31, 38] among a sample of 1278 BMSM [11]. Twelve articles (25.5\%) also contained comparative incarceration estimates by race and/or ethnicity [22, 27, 30, 31, 33, 39, 41, 46, 47, 52, 53, 58]. Seven (14.9\%) studies were conducted among detainees in a jail setting $[56$, 59-64], and an additional four reported on a post-incarcerated population in which all participants had been recently released from jail or prison $[55,57,65,66]$.

\section{Key Findings Related to the Intersection Between HIV and Criminal Justice Involvement Among BMSM and BTW}

Seventeen (17) studies examined the intersection between HIV and criminal justice involvement among BMSM and BTW. These articles are described in Table 2. Among these, 14 were focused primarily on BMSM [11, 13, 22, 28, 34, 37, $40,44,54,56,57,62,64,67]$, two primarily on BTW [45, 65], and one on both BMSM and BTW [46]. We describe the specific studies in detail below by four categories of interest. 


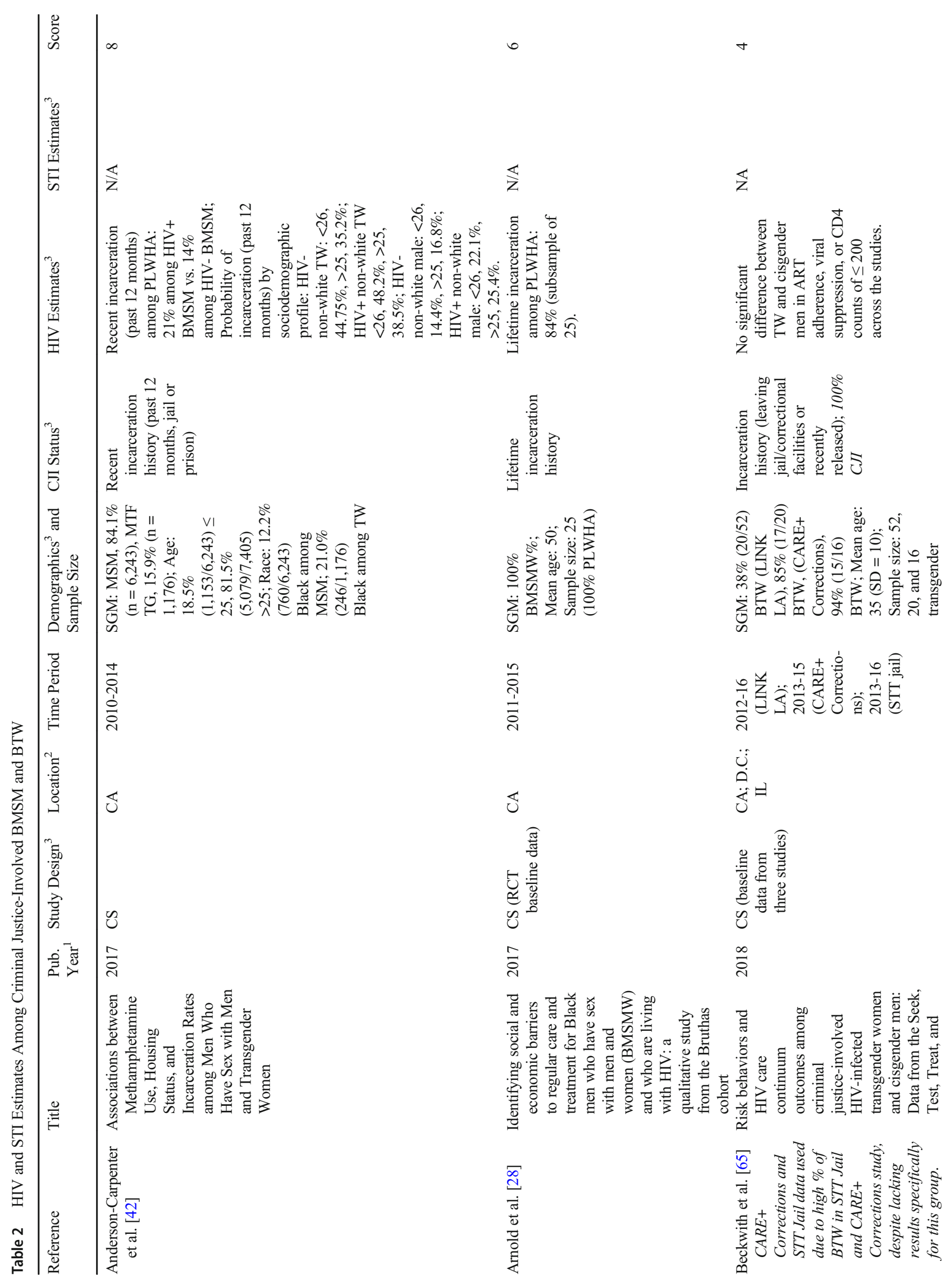




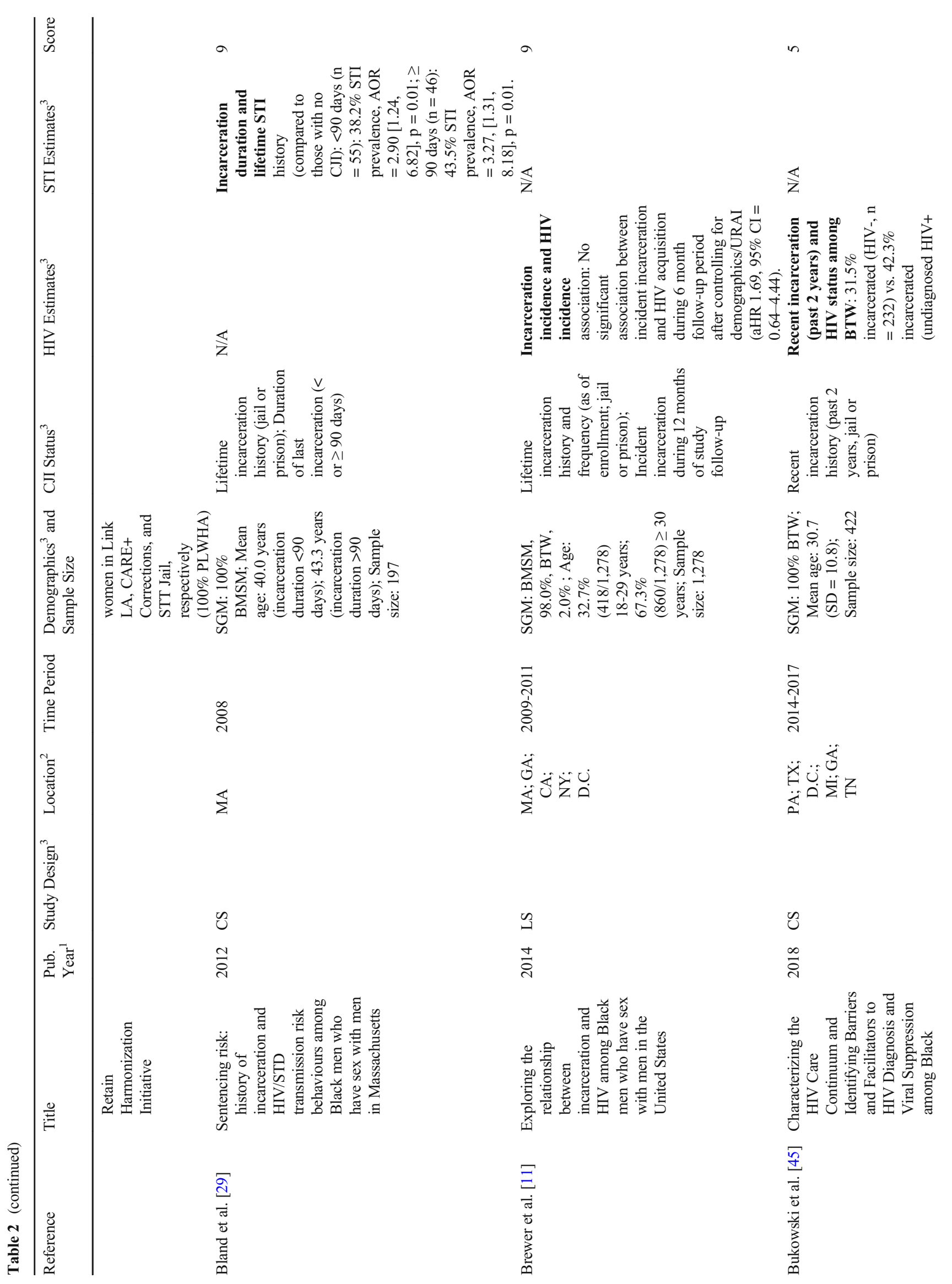




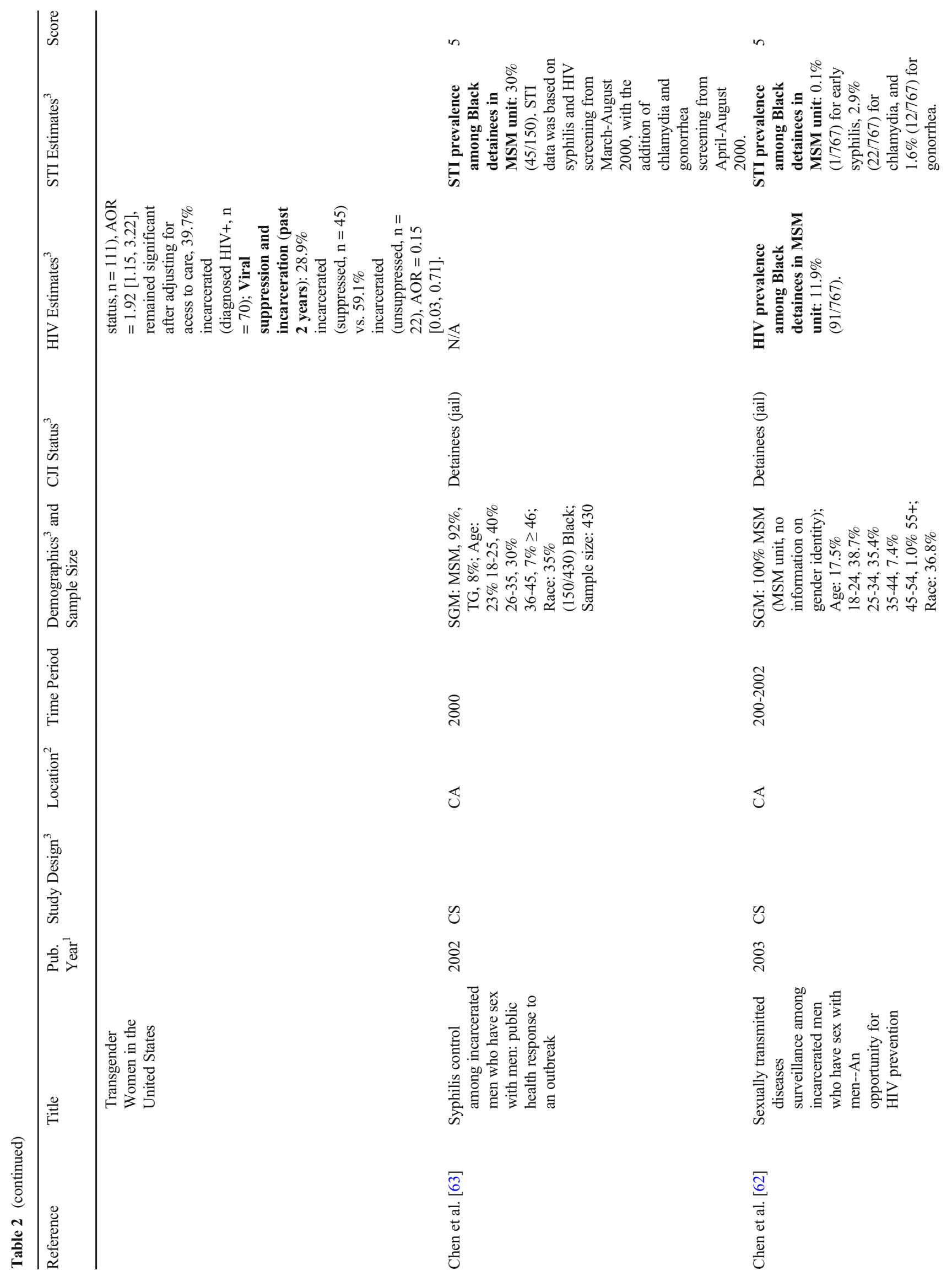




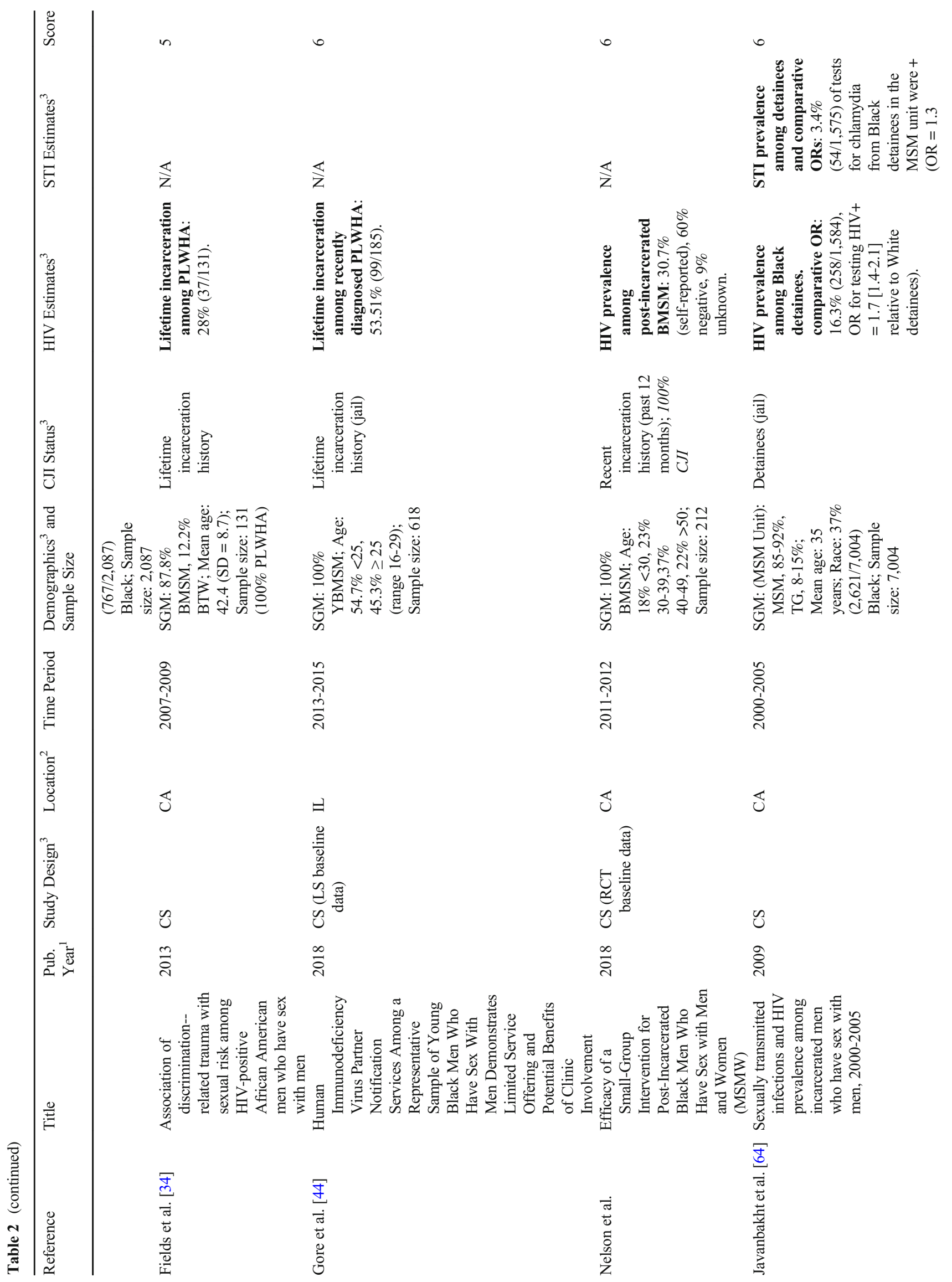




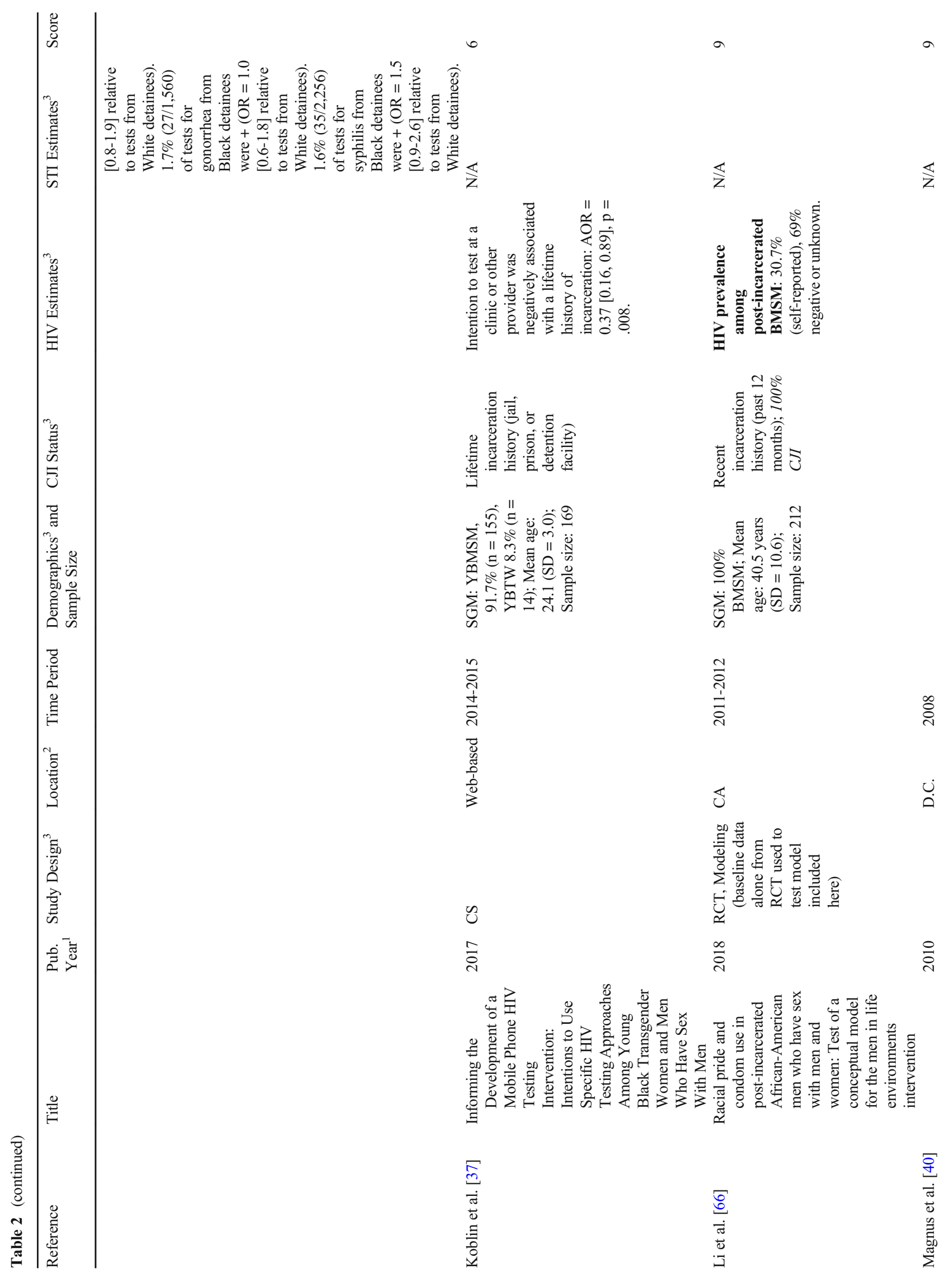




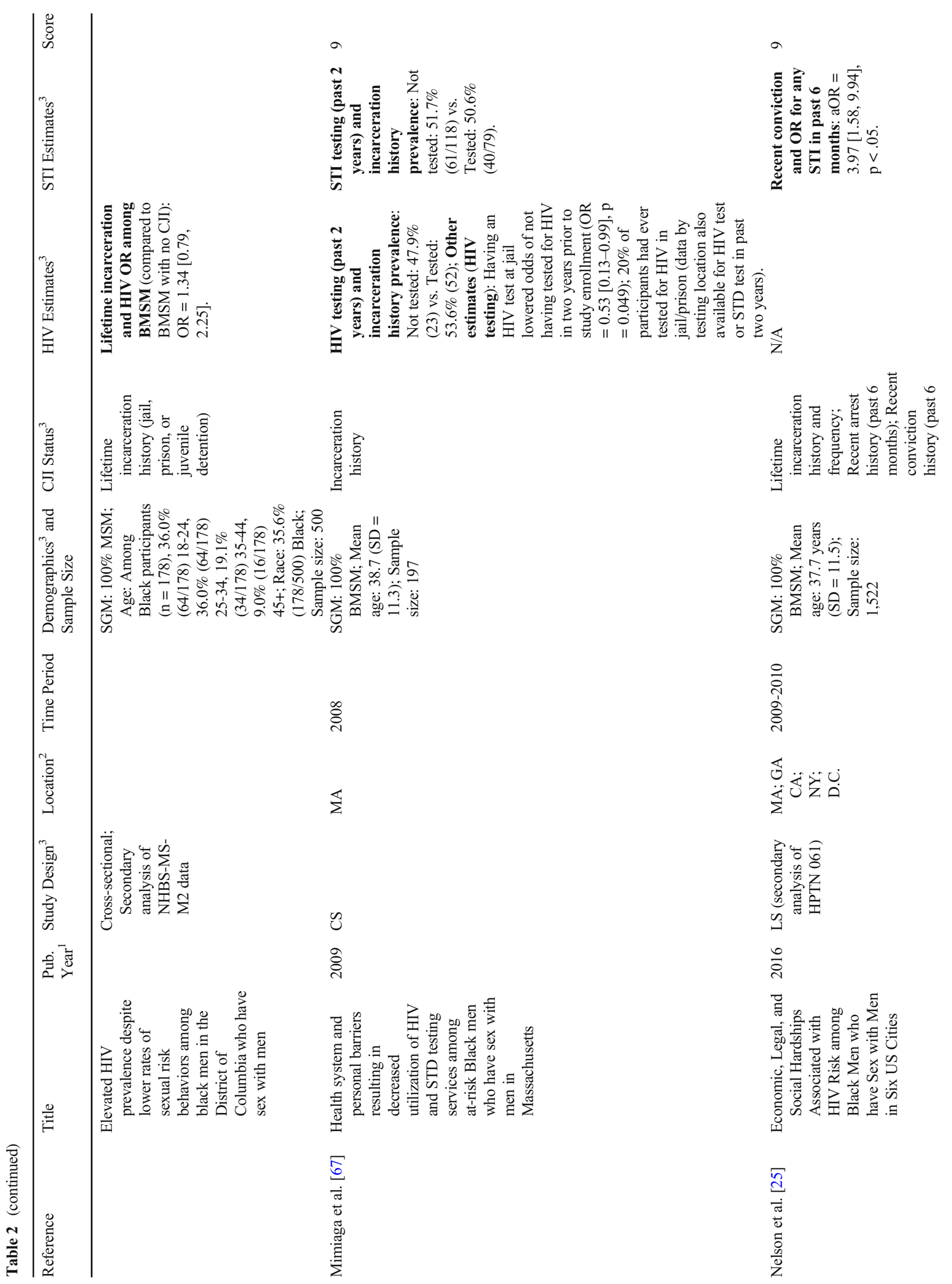




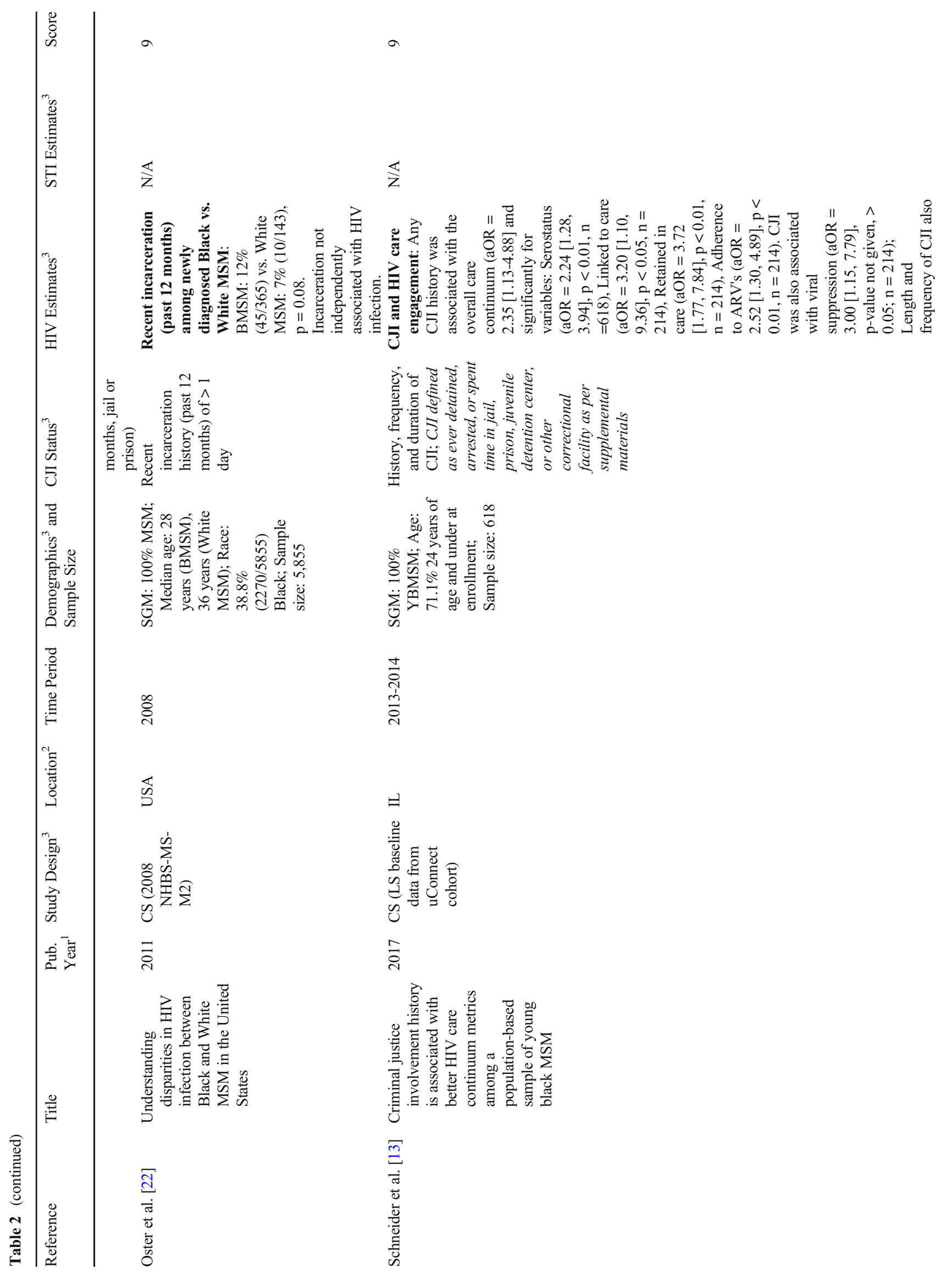




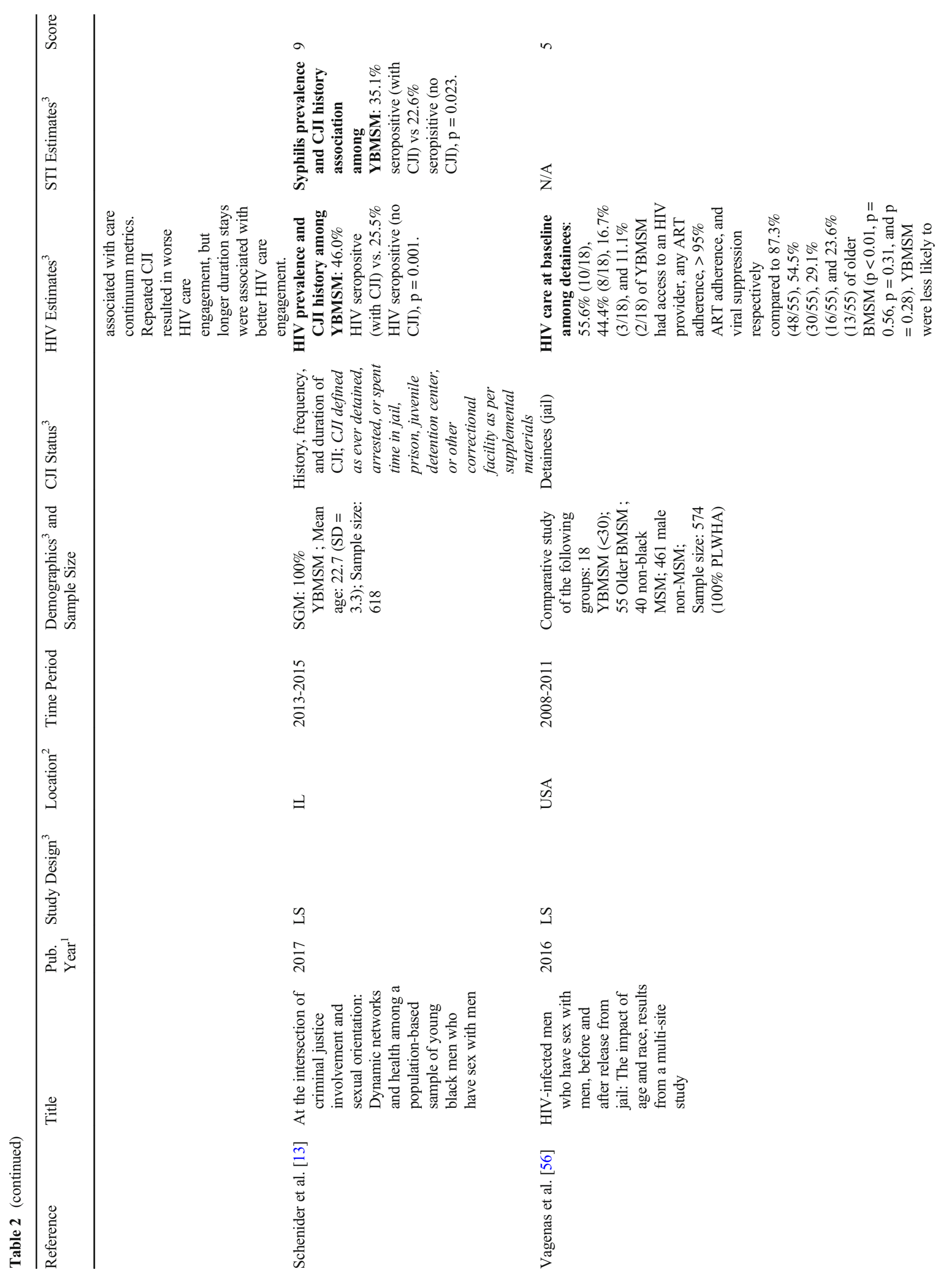




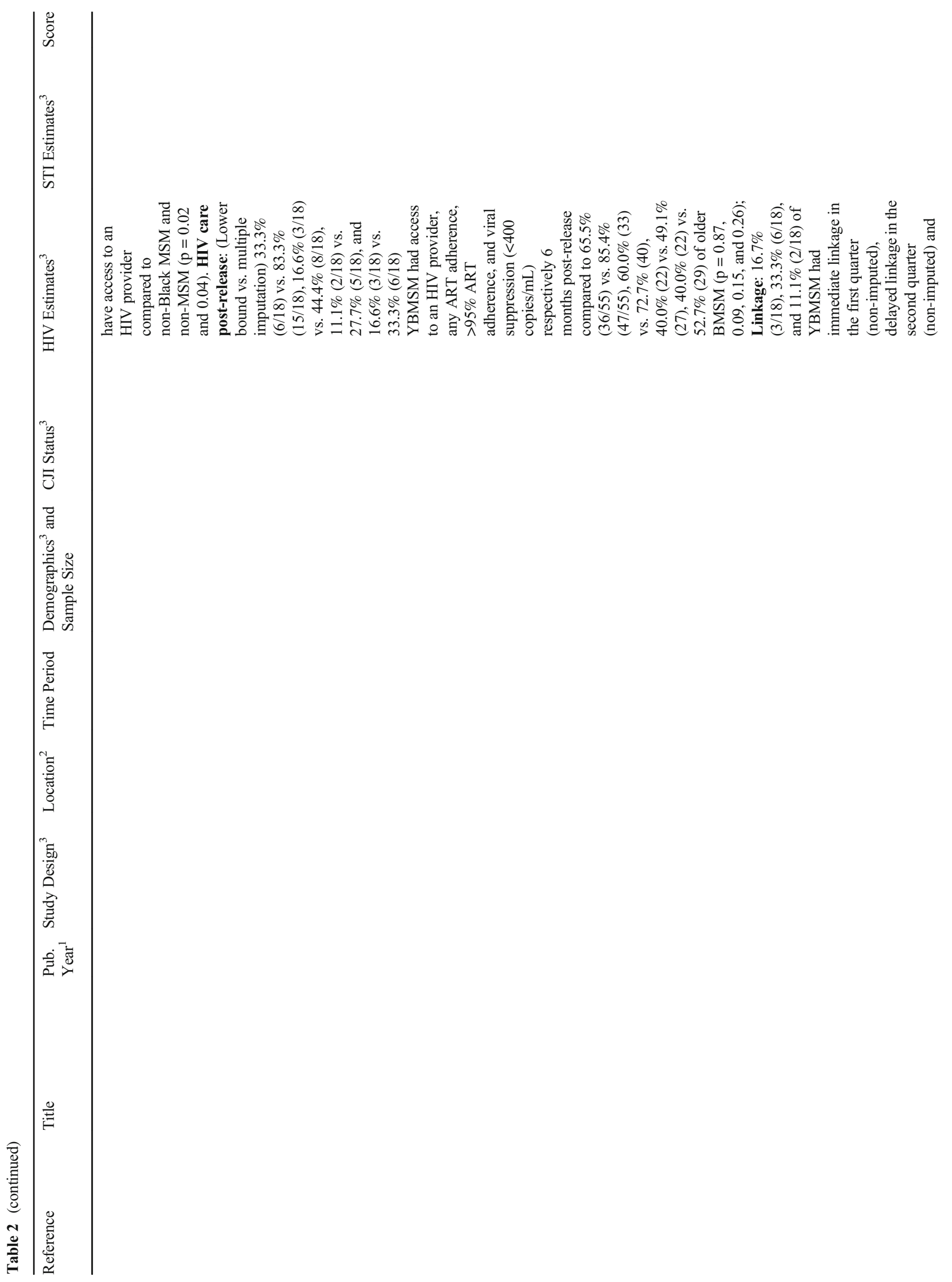




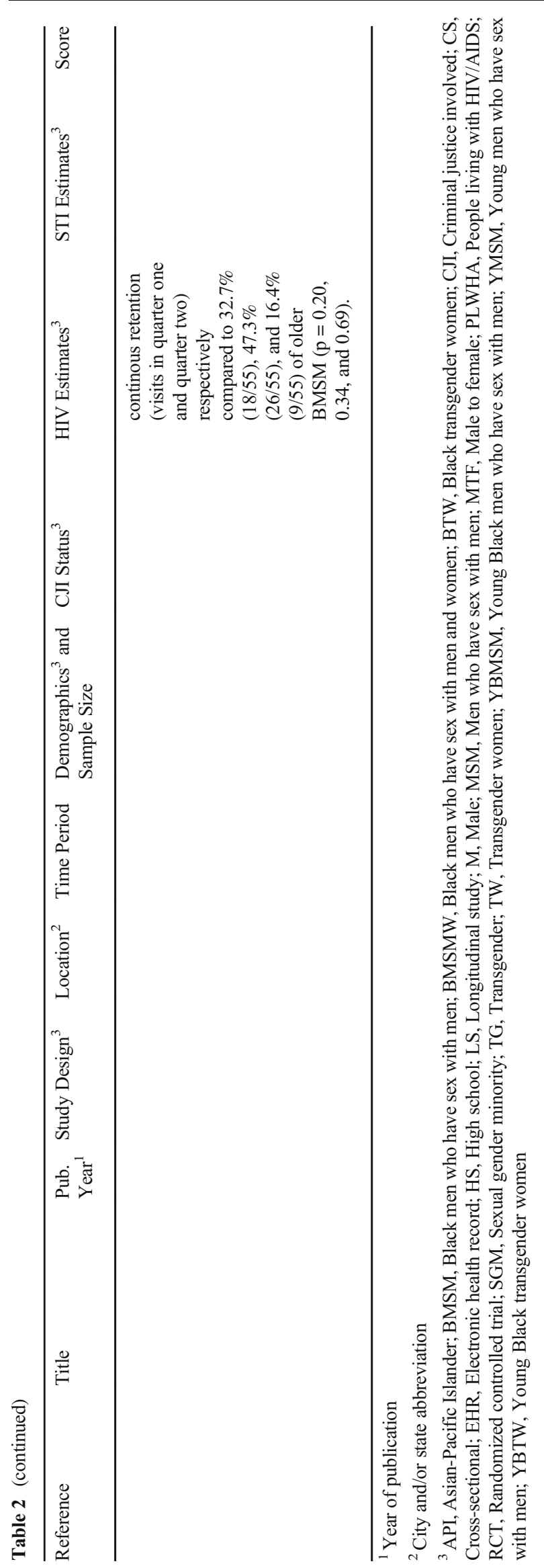




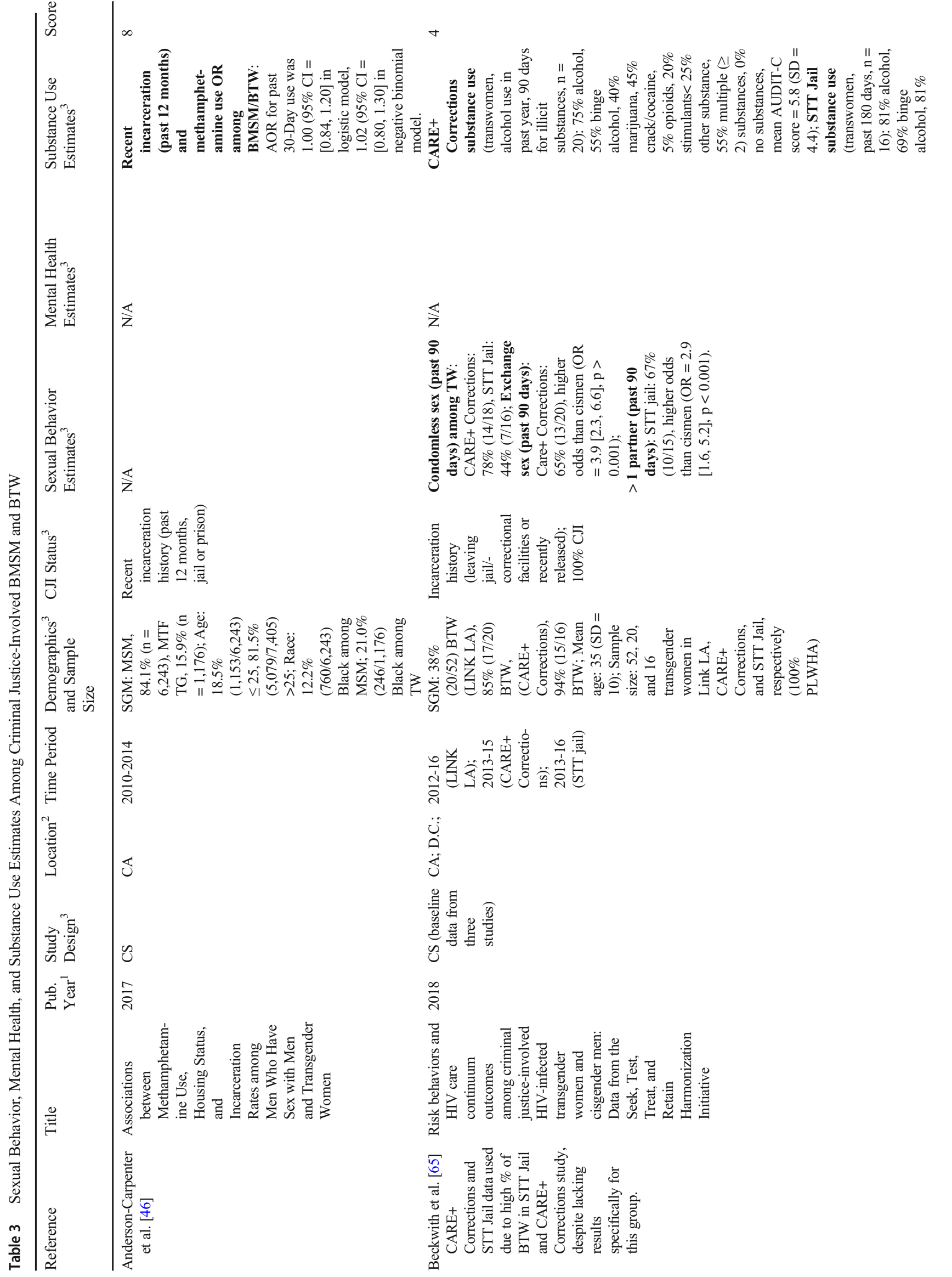




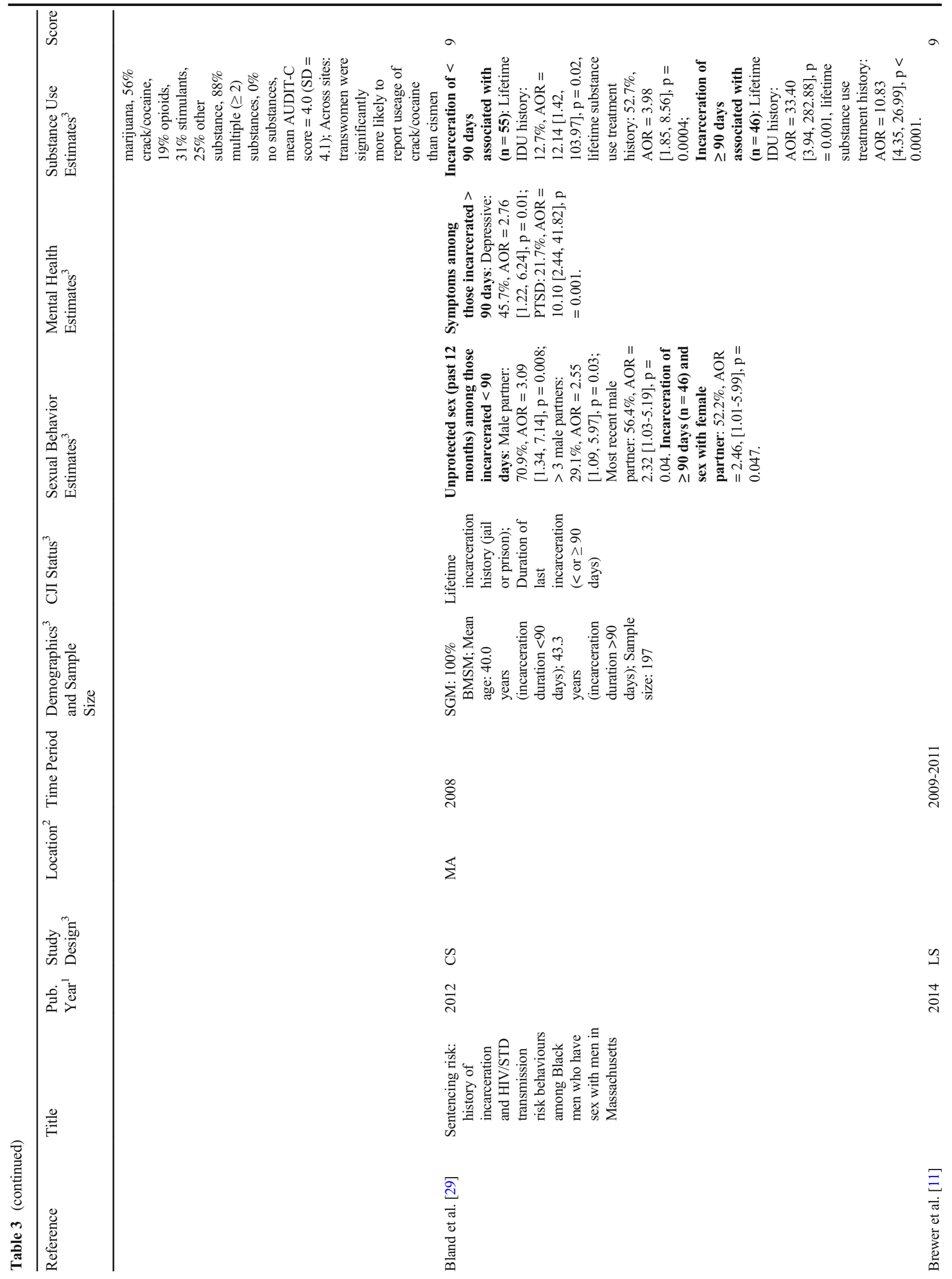




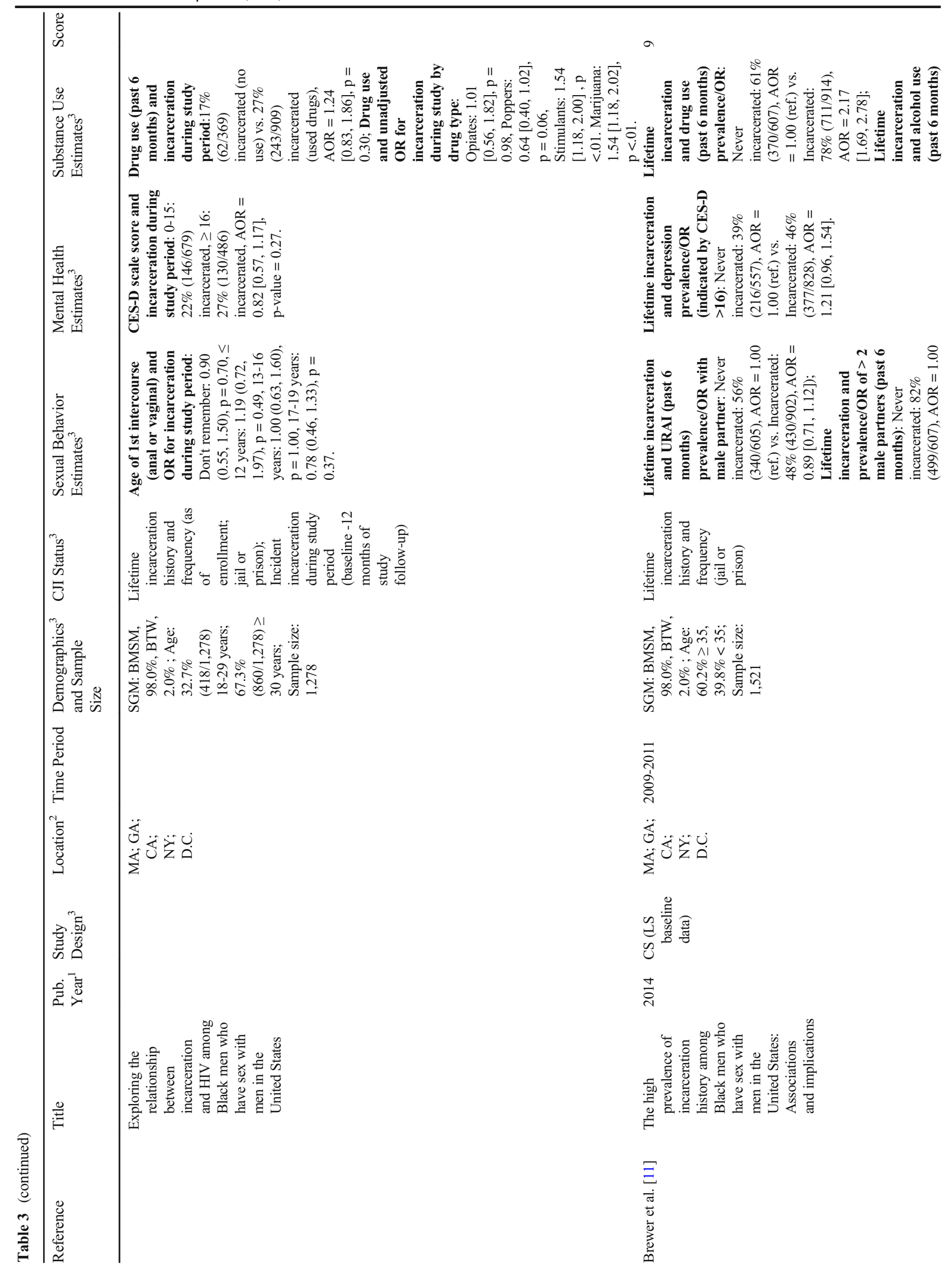




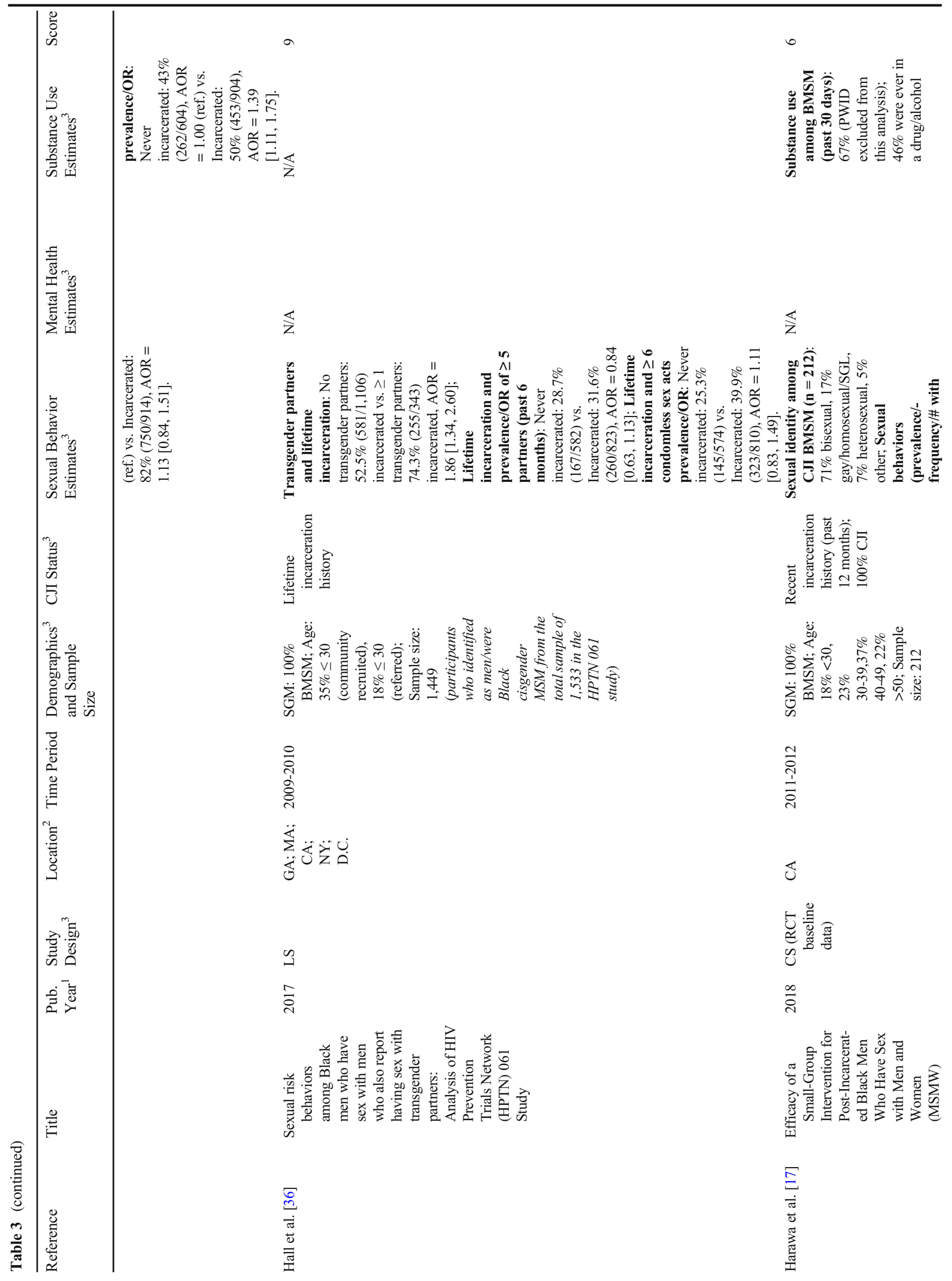




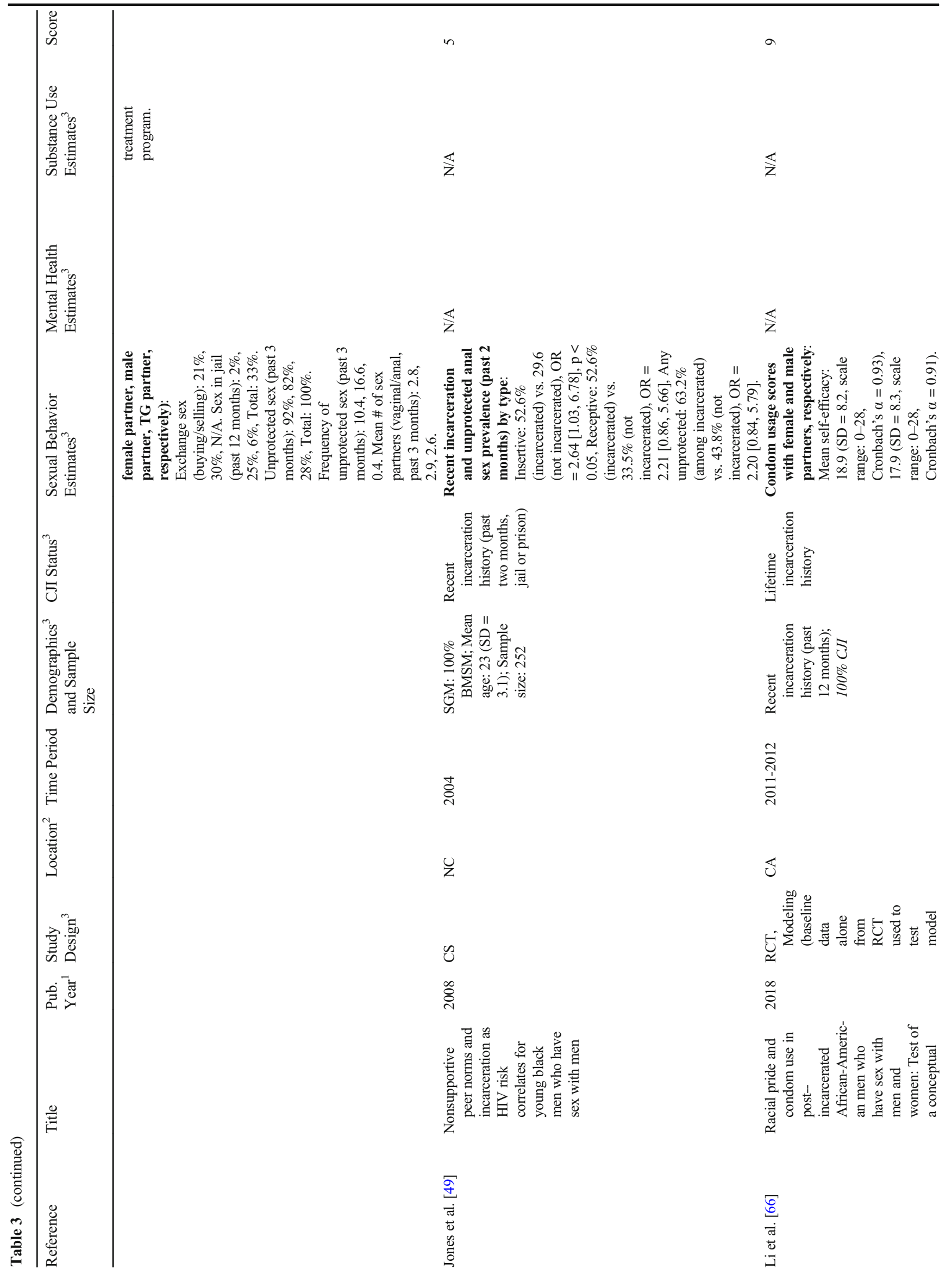




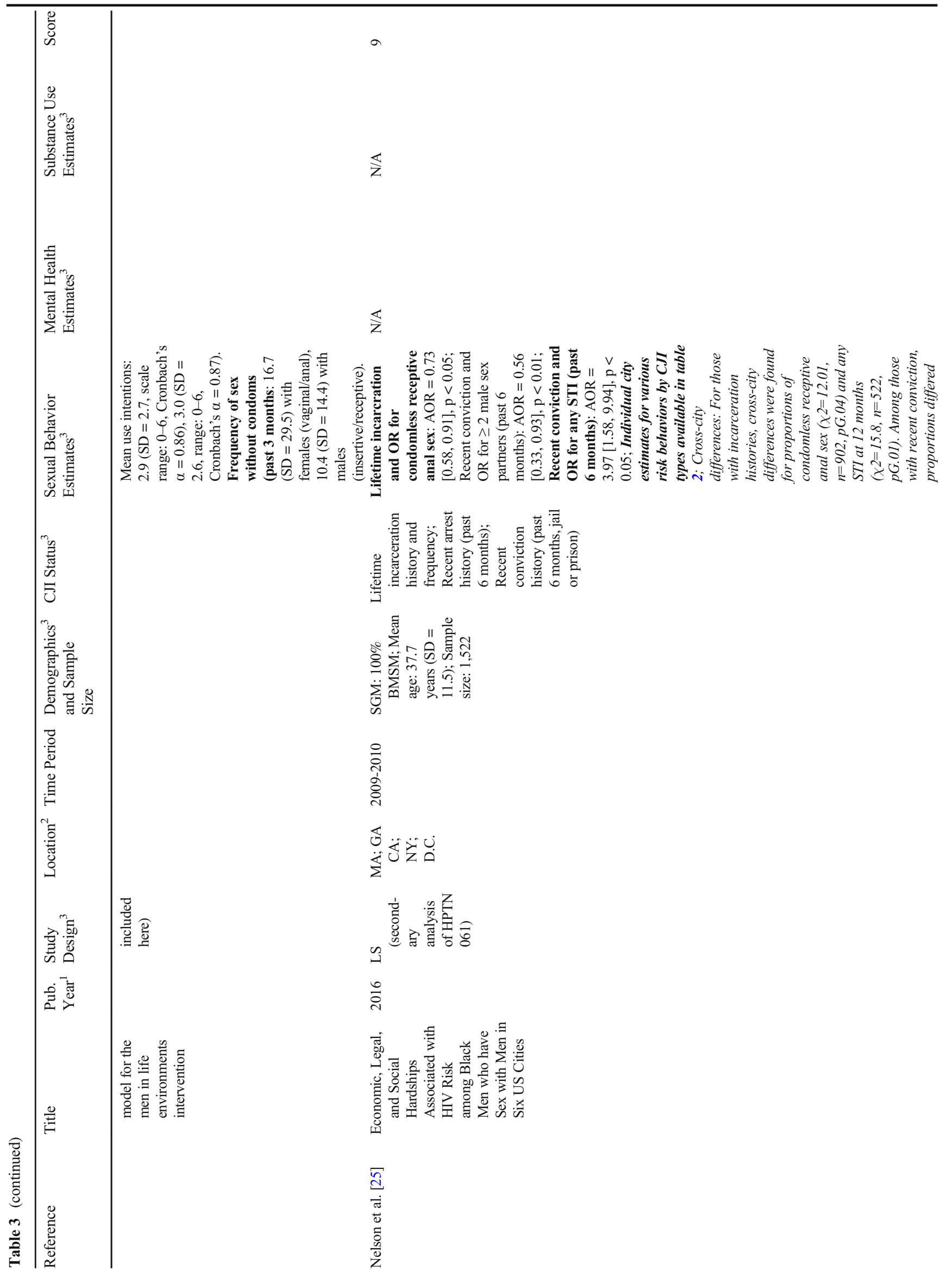




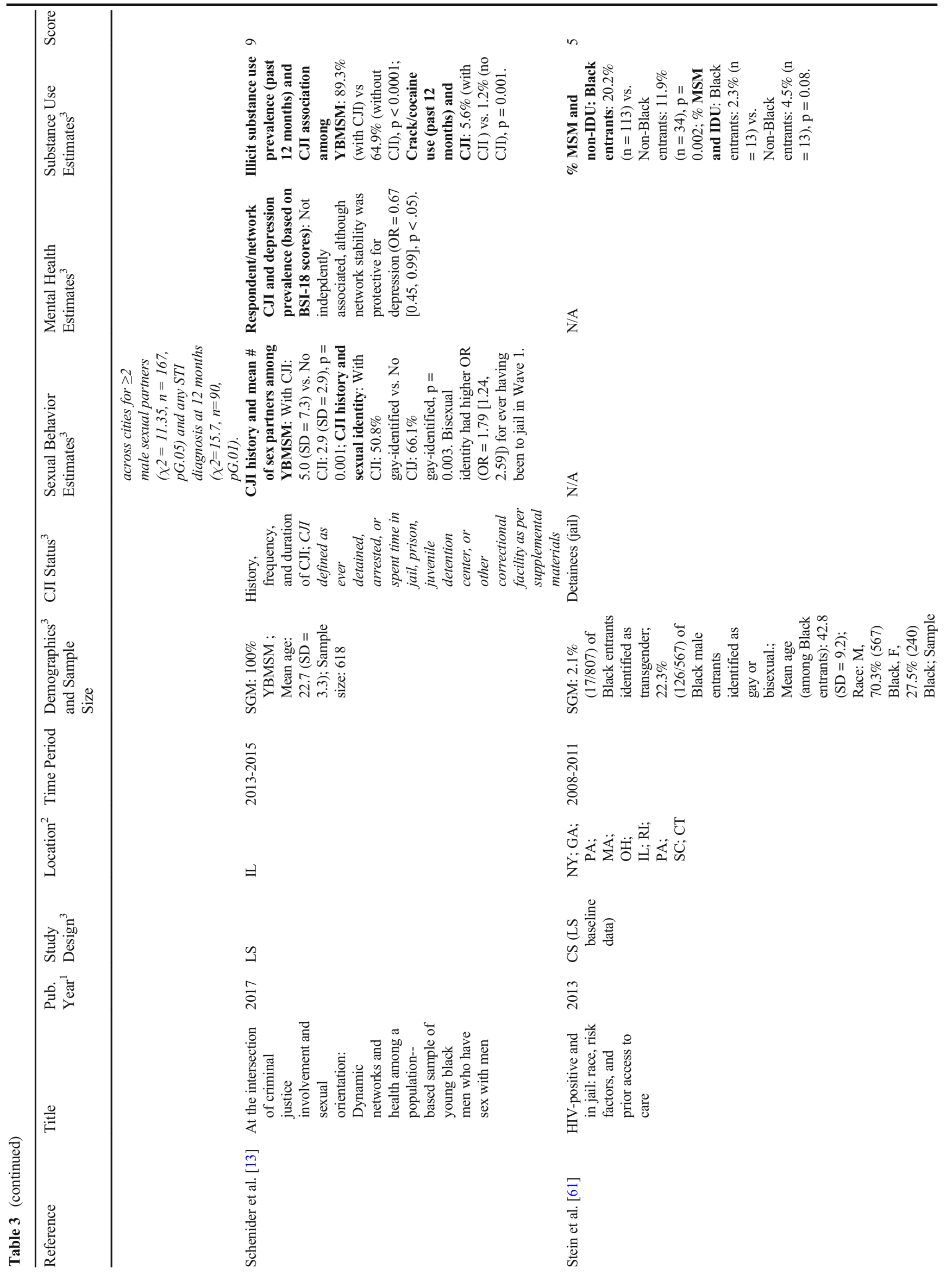




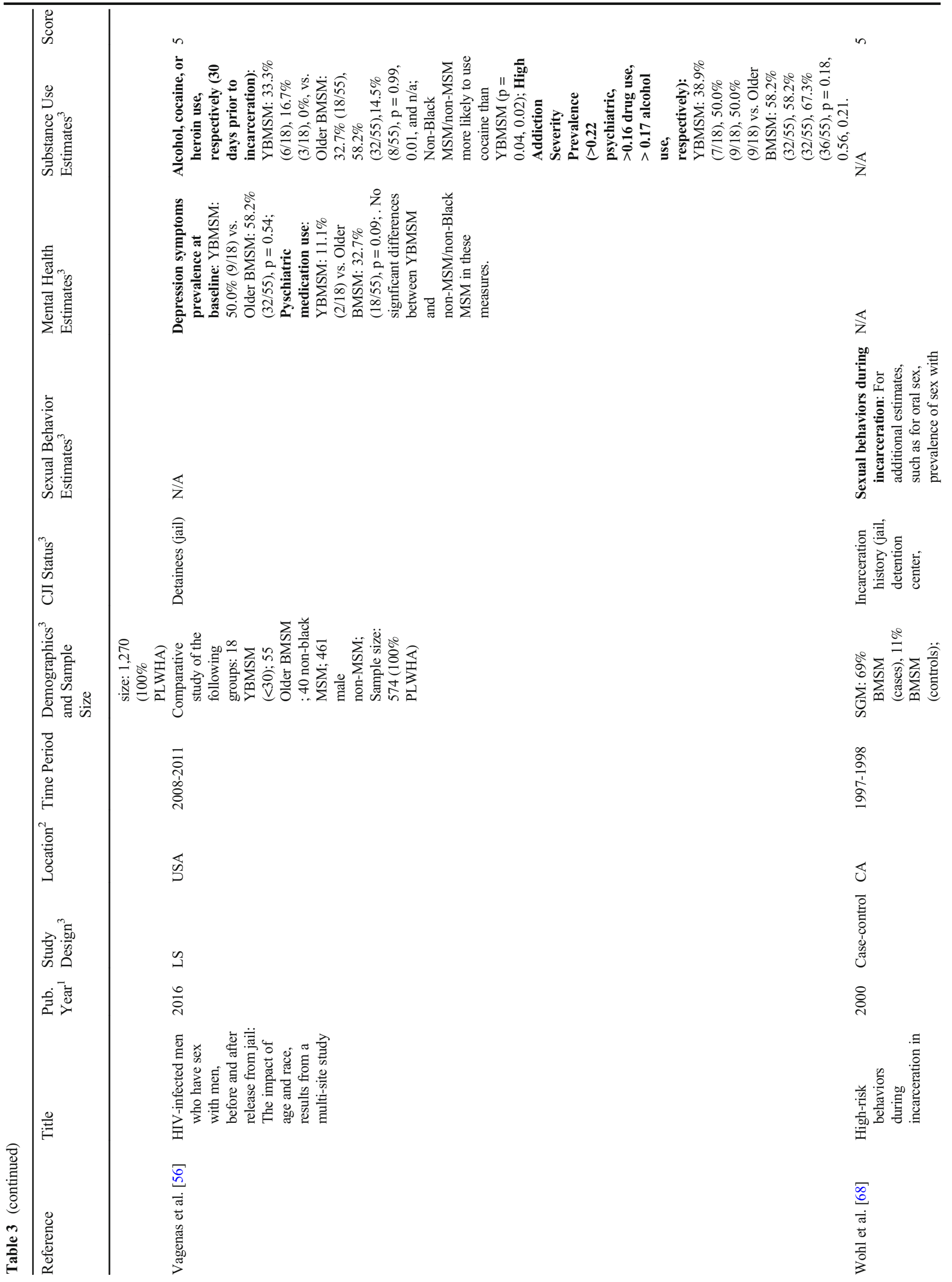




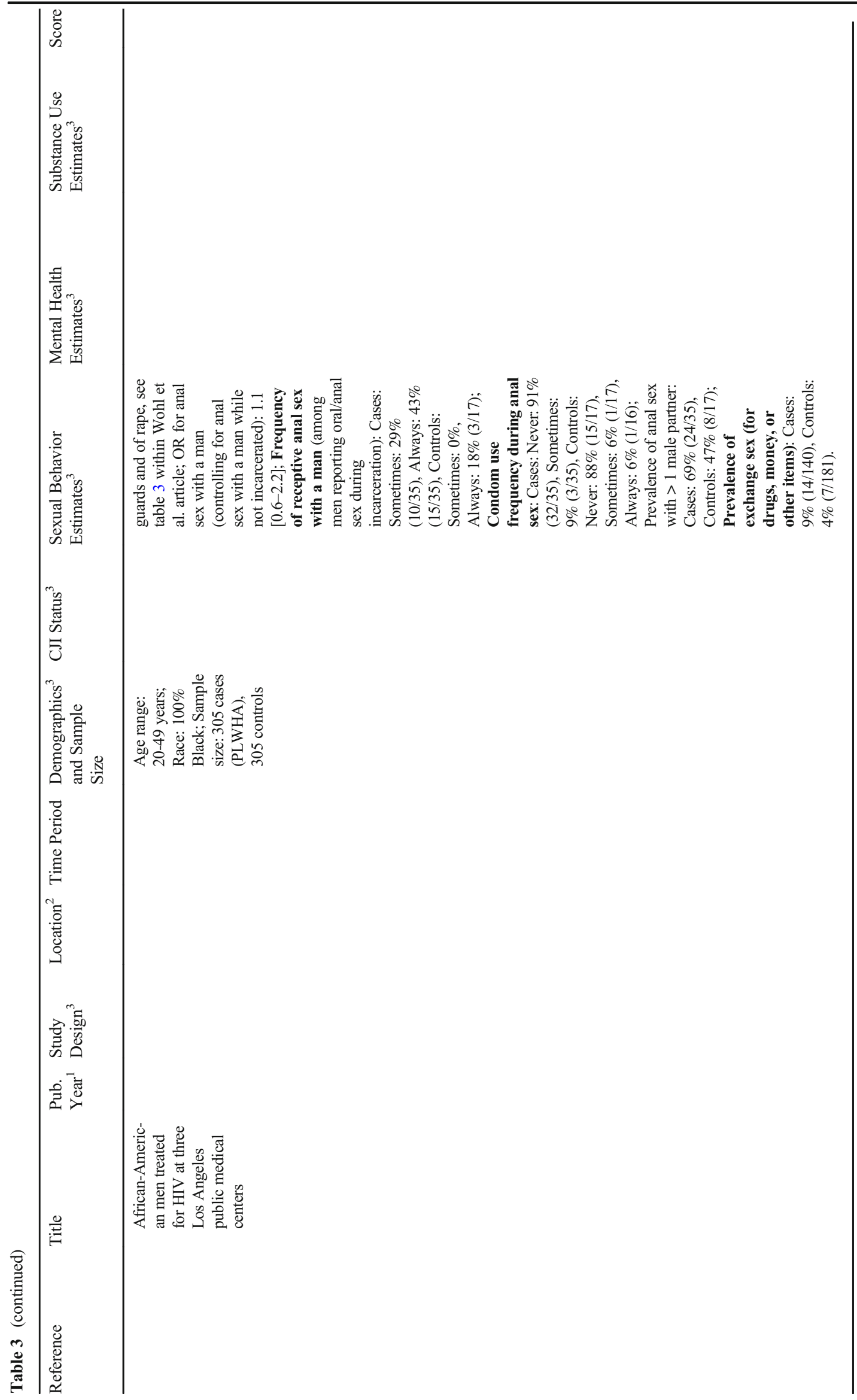




\section{HIV Prevalence Among Current and Recently Incarcerated BMSM and BTW}

Two studies reported HIV prevalence estimates among a large sample of Black detainees receiving HIV testing in the same protected jail unit for MSM and transgender women (consisting of primarily MSM), reporting prevalence estimates of $11.9 \%(91 / 767)$ and $16.3 \%(258 / 1,584)$ respectively $[62,64]$. These estimates were somewhat low because detainees with diagnosed HIV disease generally were not screened for HIV. Three studies reported HIV prevalence estimates among criminal justice-involved BMSM. Harawa et al. [57] and Li et al. [66] both provided a self-reported HIV positivity estimate of $30.7 \%$ based on the same RCT sample of 212 BMSM with a recent 12-month incarceration. Schneider et al. [13] reported a higher HIV prevalence in a sample of YBMSM reporting a history of incarceration, among which $46.0 \%$ were HIV seropositive $(n=285)$.

\section{Incarceration History Among BMSM and BTW Living with HIV}

Four studies reported a high prevalence of incarceration among BMSM living with HIV [28, 34, 44, 46]. Three of these analyses reported lifetime incarceration history estimates ranging from 28 to $84 \%$ [28, 34, 44]. The fourth article examined the prevalence of recent incarceration among BMSM by HIV serostatus, reporting a prior 12-month incarceration prevalence of $21 \%$ among BMSM living with HIV compared to $14 \%$ among BMSM who were not living with HIV $(\mathrm{n}=760)$ [46]. Only one article, by Bukowski et al. [45], provided estimates on incarceration prevalence specific to BTW living with HIV, finding that $42.3 \%(n=111)$ of BTW with previously undiagnosed HIV were incarcerated in the past 2 years, compared to $31.5 \%$ of BTW who were not living with HIV ( $\mathrm{n}=$ $232), \mathrm{aOR}=1.92[1.15,3.22]$, and $39.7 \%$ of BTW with diagnosed HIV $(n=70)$. In summary, a high percentage of BMSM and BTW living with HIV have a high frequency of contact with the criminal justice system.

\section{Independent Associations Between Criminal Justice Involvement and HIV}

Four studies explicitly examined the independent associations between HIV and criminal justice involvement among BMSM and BTW [11, 22, 40, 46]. Three of those analyses utilized cross-sectional data $[22,40,46]$ and one utilized longitudinal data [11]. Anderson-Carpenter et al. [46] found that recent incarceration history was associated with HIV-positive status $(\mathrm{aOR}=1.69, \mathrm{CI}=[1.31,2.16], \mathrm{p} \leq .001)$. Oster et al. [22] found that $12 \%$ of newly diagnosed BMSM living with HIV were incarcerated in the past 12 months but did not find an independent association between incarceration and HIV infection. Similarly, Magnus et al. [40] did not find an independent association between HIV infection and incarceration history among 178 BMSM. The study by Brewer et al. [11] was the only analysis to longitudinally explore the relationship between incident incarceration and HIV acquisition. Brewer et al. [11] did not find an association between incarceration (last 6 months) and HIV acquisition (adjusted hazard ratio $1.69, \mathrm{CI}=[0.64-4.44]$ ) among a sample of $1278 \mathrm{BMSM}$ followed for 12 months after controlling for demographics and unprotected receptive anal intercourse (URAI). In summary, findings related to the independent association between HIV and criminal justice involvement are mixed, but the current evidence favors no association between incarceration and HIV.

\section{Criminal Justice Involvement and the HIV Care Continuum Components Among BMSM and BTW}

Five studies examined the relationship between criminal justice involvement and the HIV care continuum, with four focused on BMSM and one on BTW [37, 45, 54, 56, 67]. Koblin et al. [37] found that intention to test for HIV was negatively associated with lifetime incarceration history $(\mathrm{aOR}=0.37, \mathrm{CI}$ $=[0.16,0.89], p=.008)$ in a sample of 169 consisting of 91.7\% YBMSM and 8.3\% YBTW. Yet Mimiaga et al. [67] found that in a sample of 197 BMSM, those who had not received an HIV test in the past 2 years were less likely to report a history of incarceration. This is likely due to an increased likelihood of receiving an HIV test during incarceration, as those who had ever obtained HIV testing in jail had a lower odds of not testing for HIV in the 2 years prior to study enrollment relative to those who were never tested in jail (OR $=0.53, \mathrm{CI}=[0.13-0.99], \mathrm{p}=.049)$ [67]. The sole article focused exclusively on BTW showed that incarceration was significantly and positively associated with undiagnosed HIV and negatively associated with viral suppression in multivariable models such that BTW who were virally suppressed had significantly lower odds of incarceration compared to those who were virally unsuppressed $(\mathrm{aOR}=0.15, \mathrm{CI}=[0.03$, $0.71], \mathrm{p}<.05) .{ }^{45}$ Thus, criminal justice settings may serve as an important venue for the first step (i.e., HIV testing/diagnosis) of the HIV care continuum and not subsequent stages (e.g., viral suppression) among BTW.

The findings from Schneider et al.'s [54] examination of the associations between criminal justice involvement and the HIV care continuum broadly aligned with those of Mimiaga et al. [67]. Such that, any history of criminal justice involvement was associated with engagement in the overall care continuum $(\mathrm{aOR}=2.35, \mathrm{CI}=[1.13-4.88])$, as well as linkage and retention to care, adherence to anti-retroviral treatment, and viral suppression. Although longer incarceration duration events were associated with improved engagement, repeated incarceration events were associated with poorer HIV care engagement [54]. In contrast, Vagenas et al. [56] highlighted 


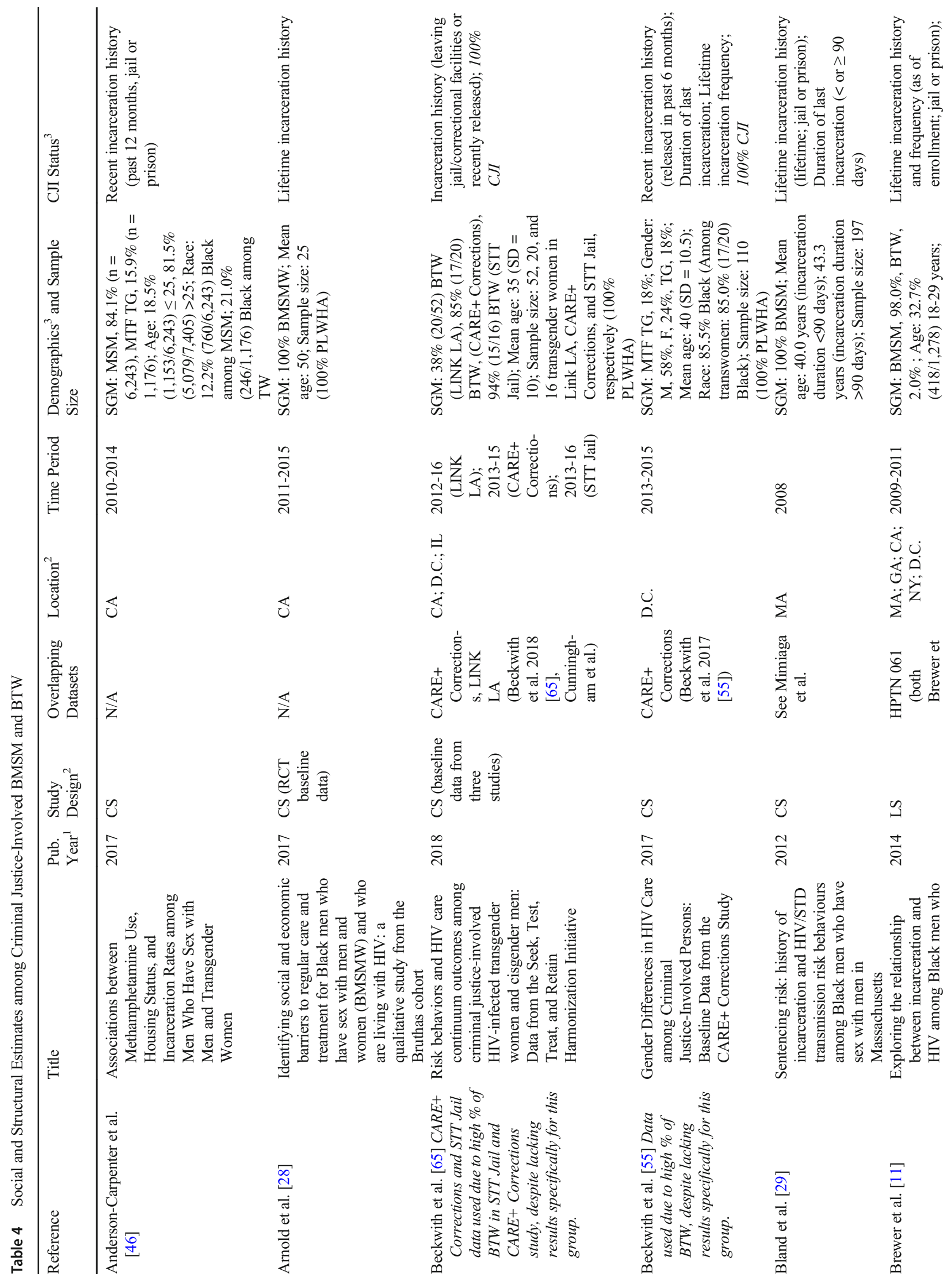




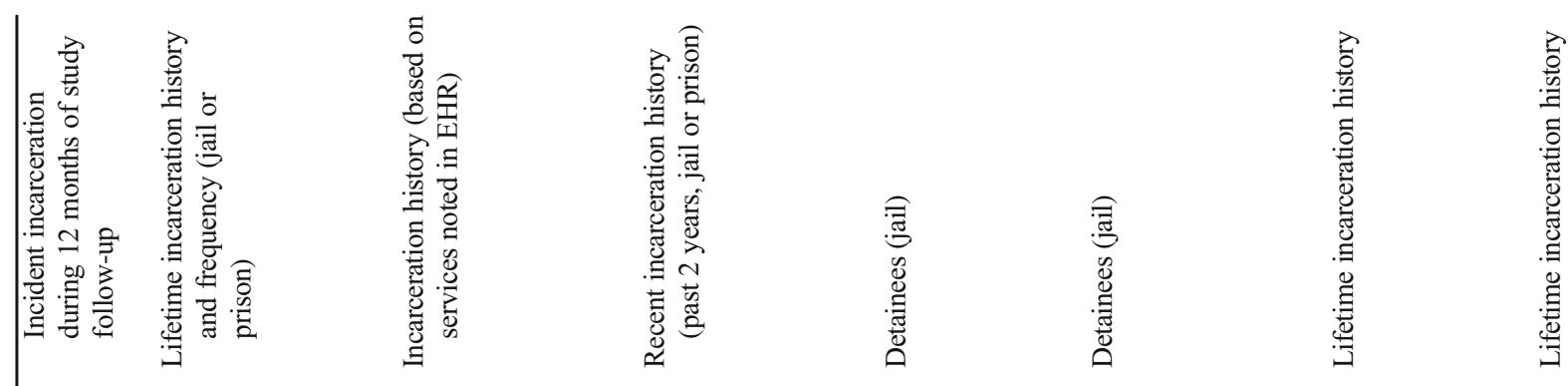

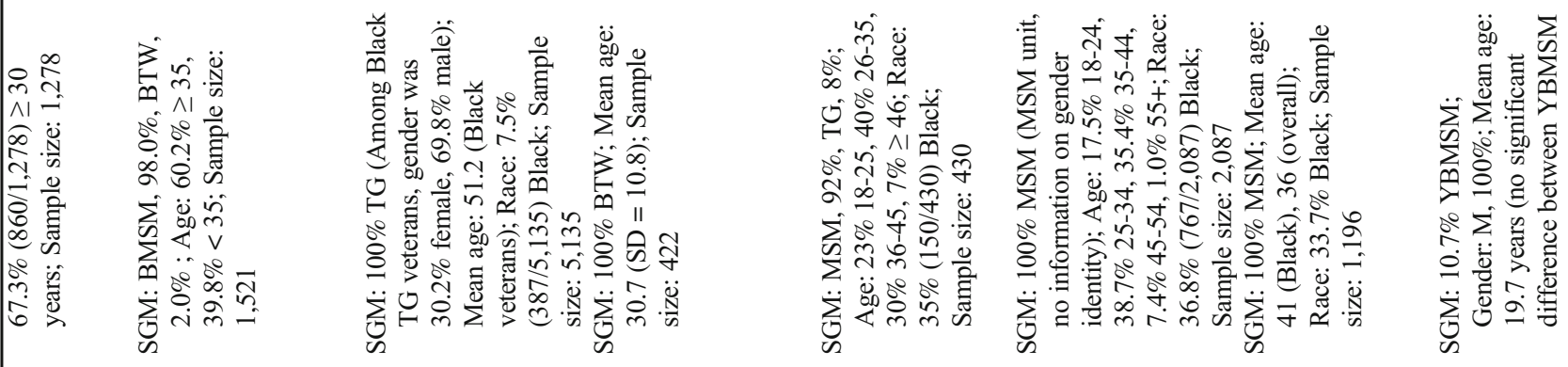

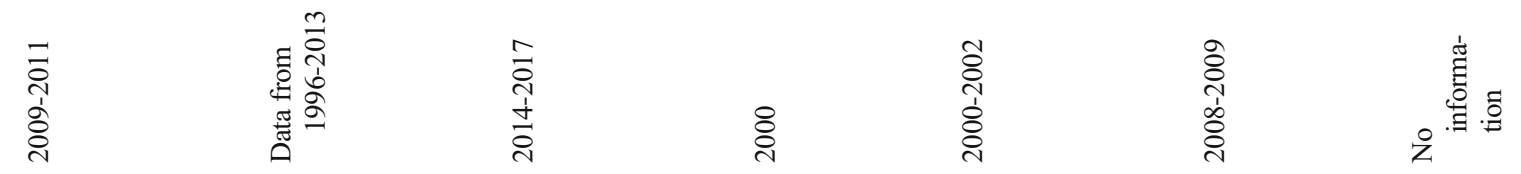

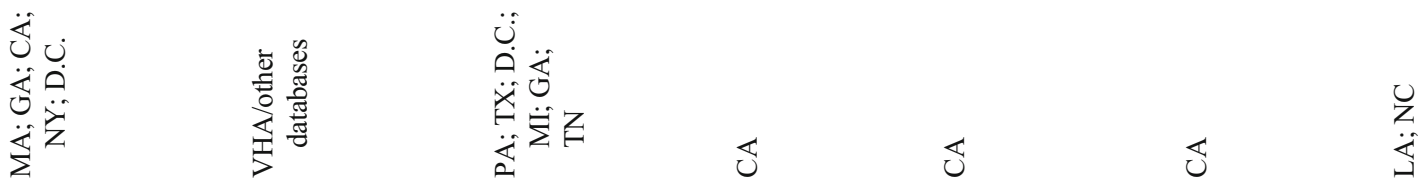

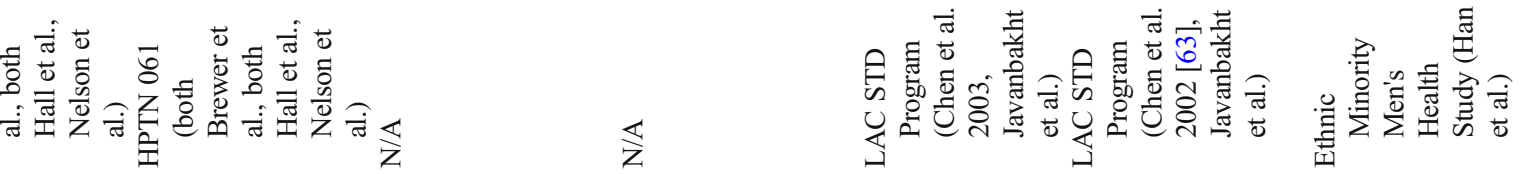

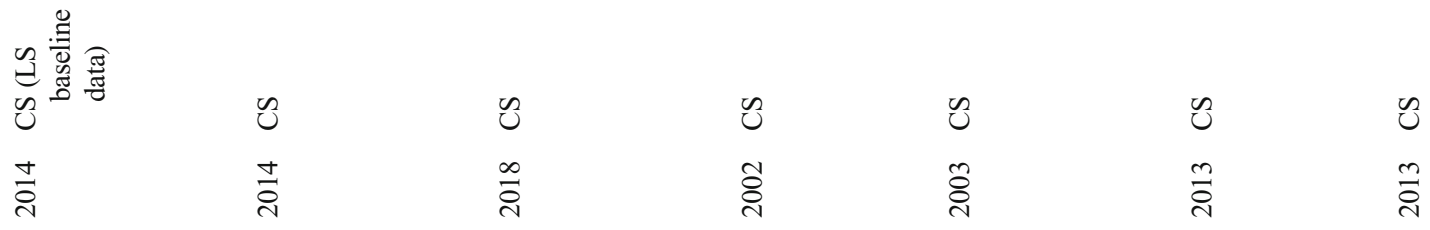

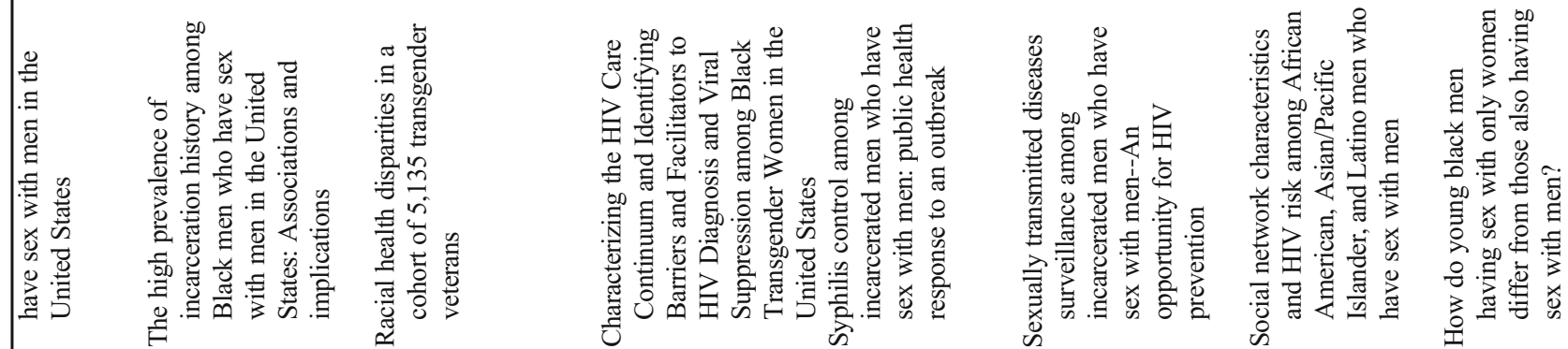

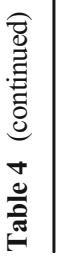

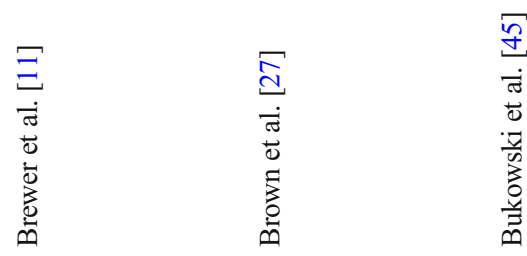

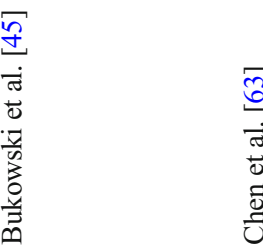

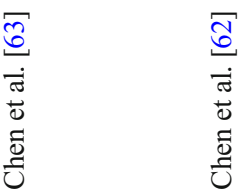

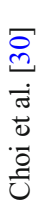

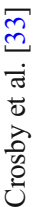



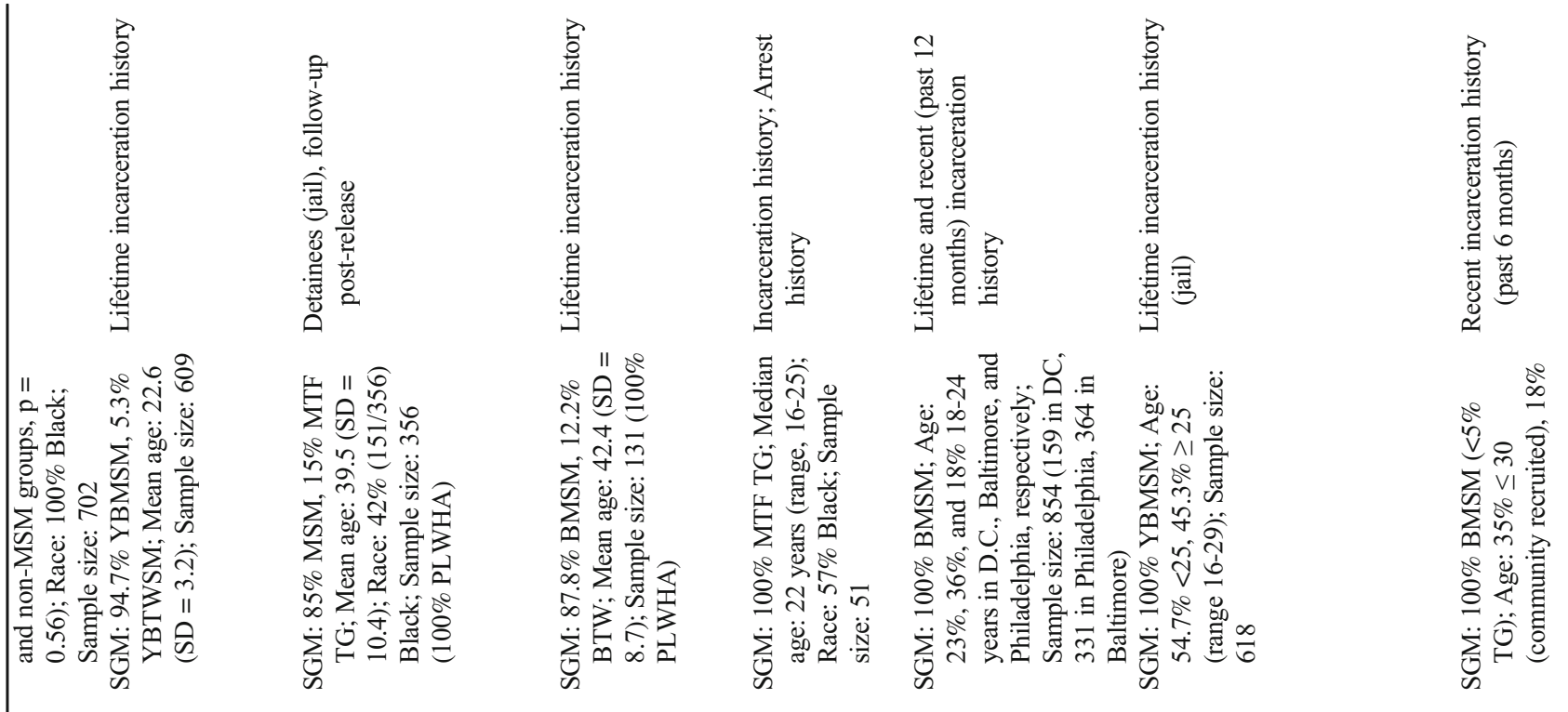<smiles>C=C=CC(=O)O</smiles><smiles>C#CCCCC</smiles>
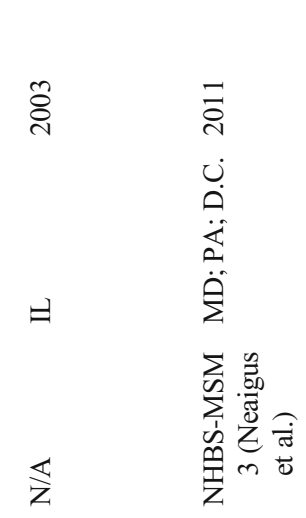

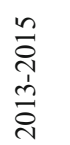

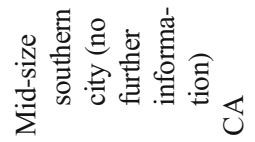
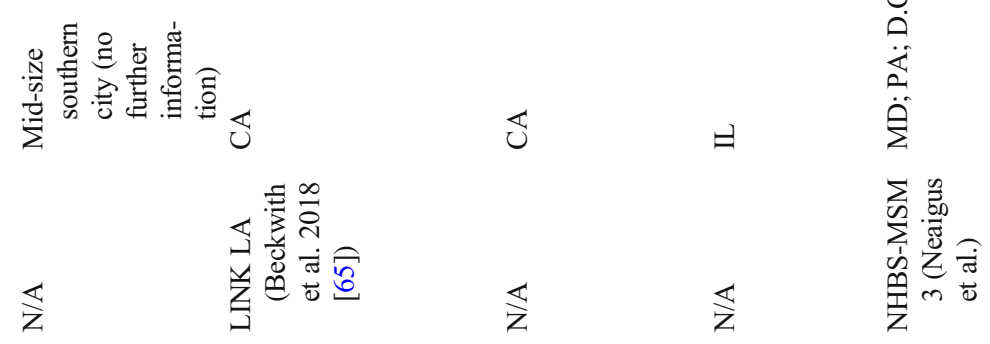

$=$

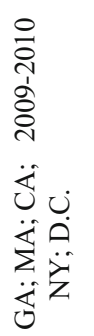

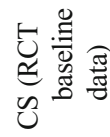
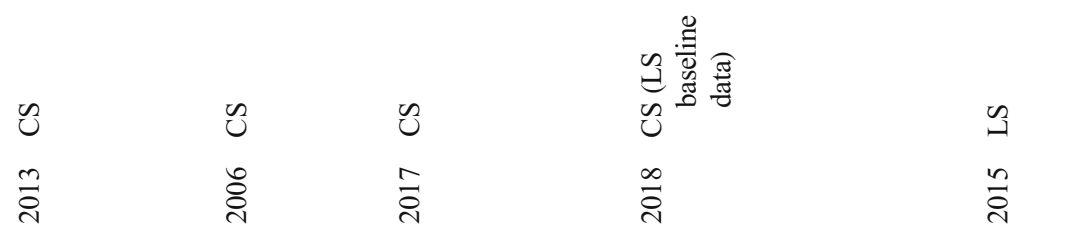

$\stackrel{\infty}{\circ}$
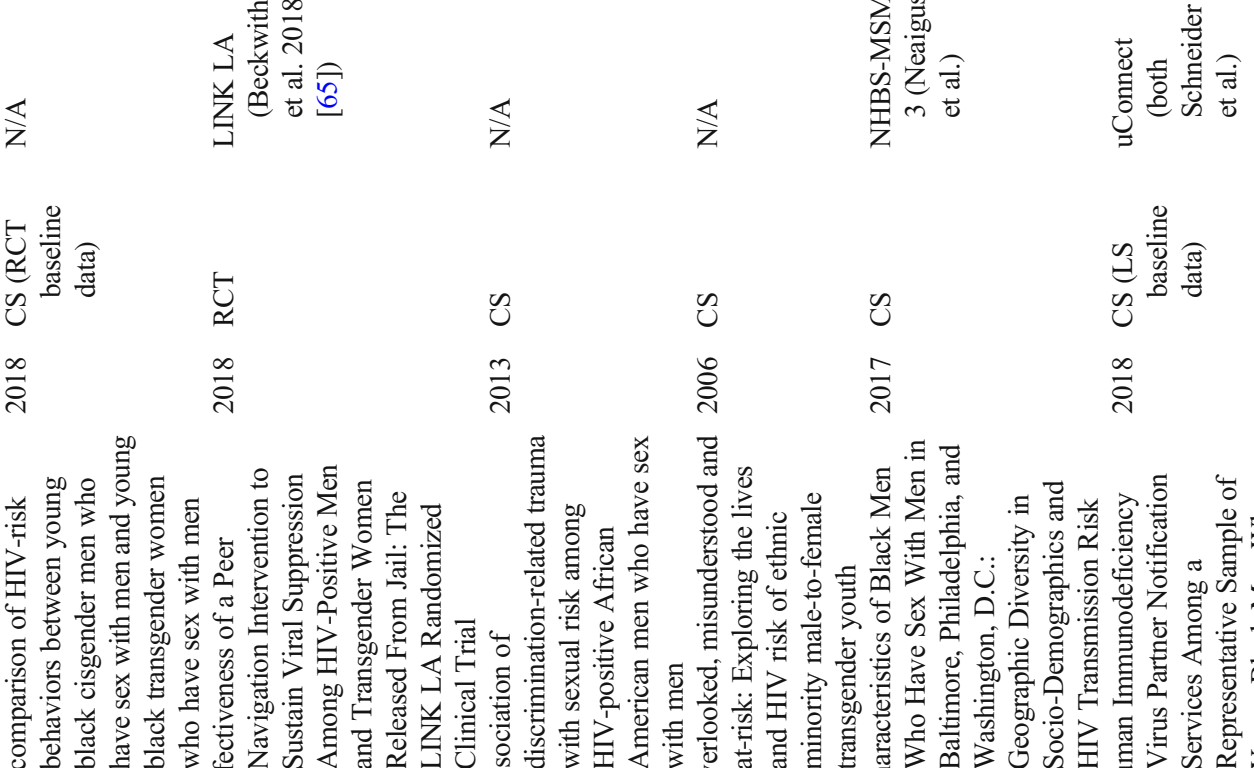

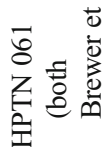
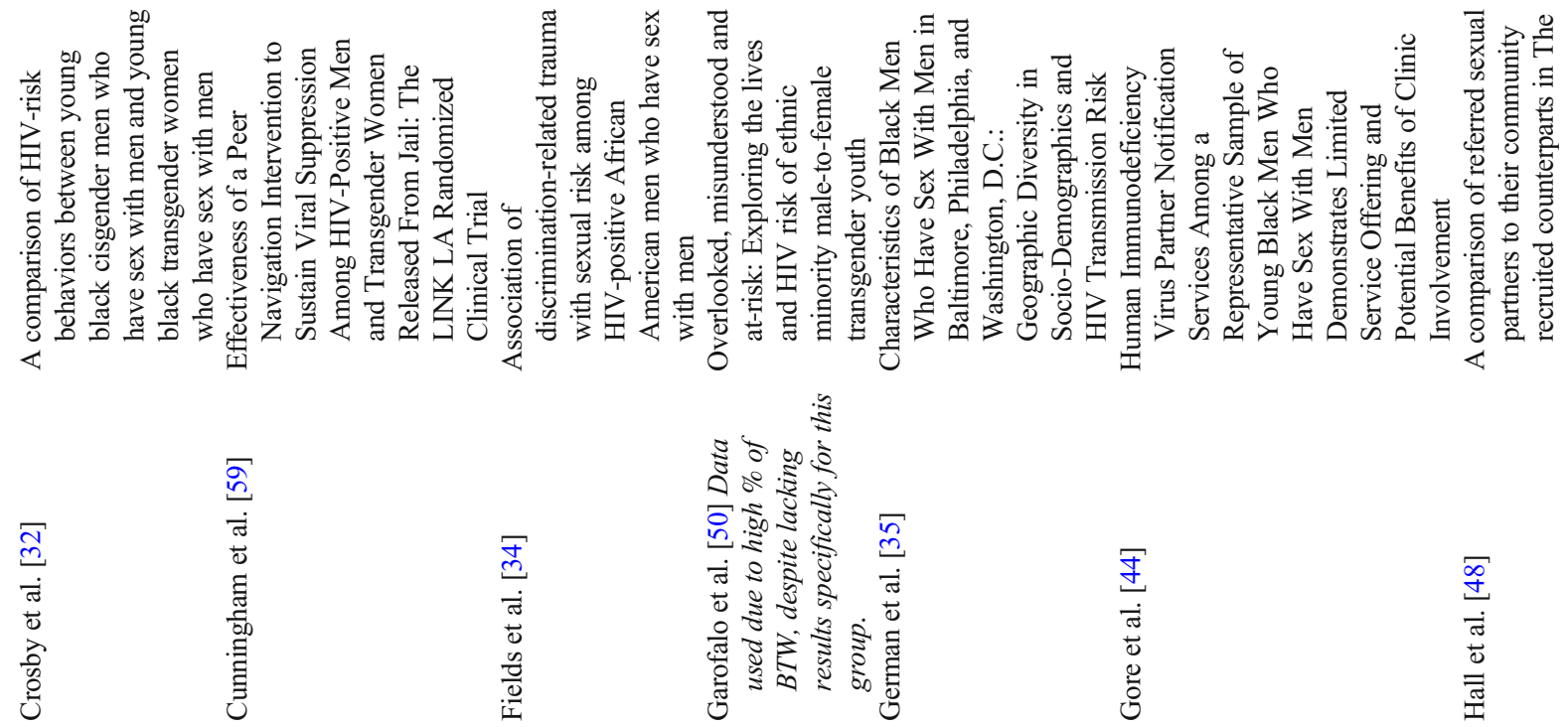


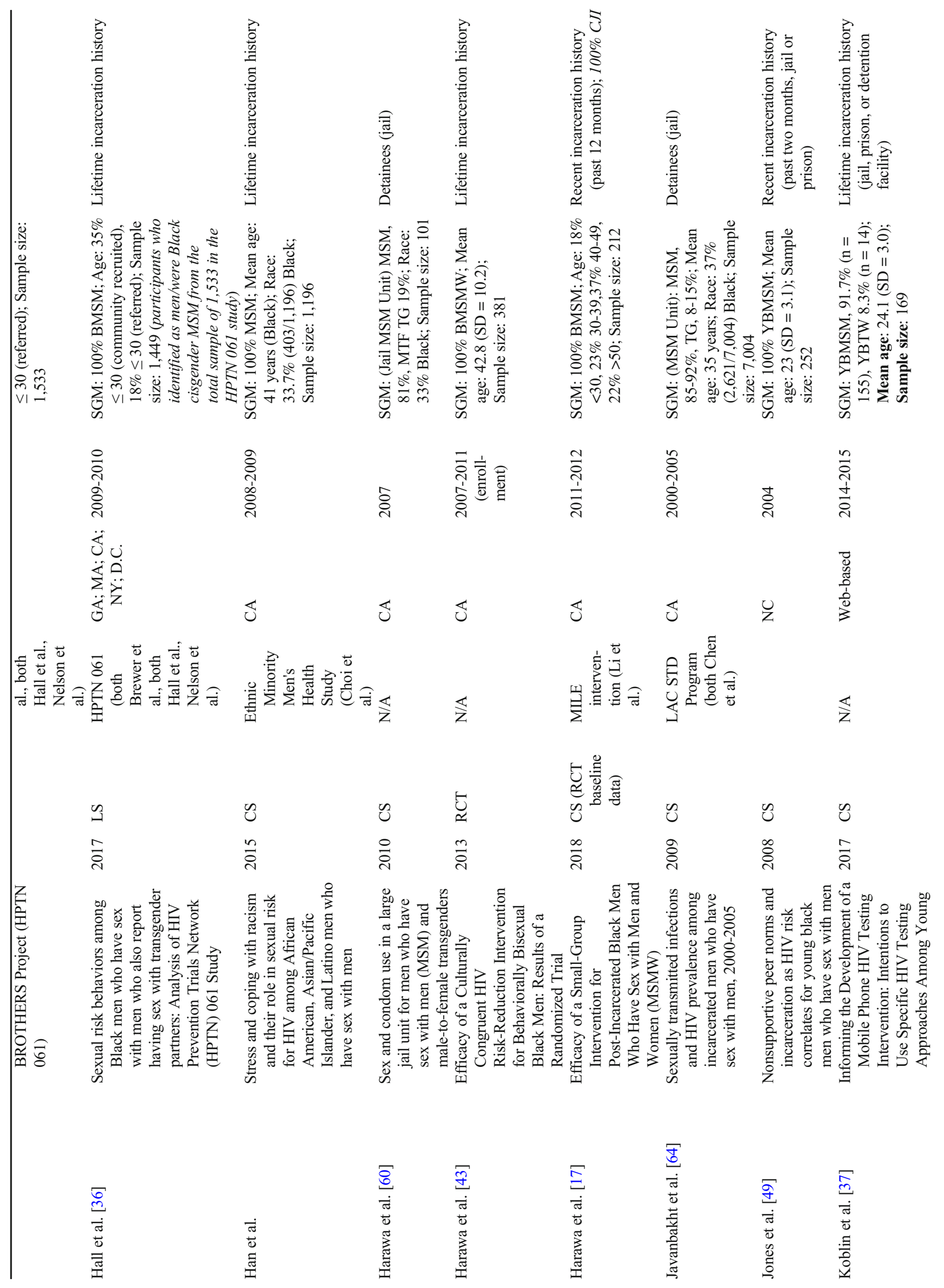



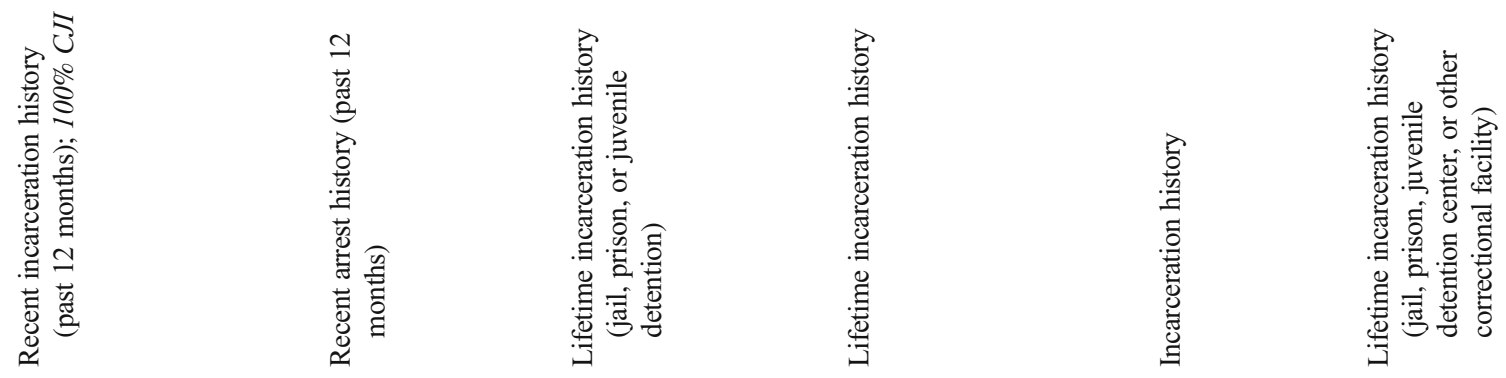

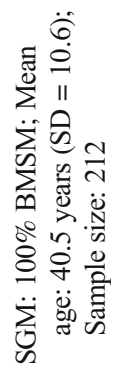

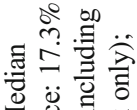

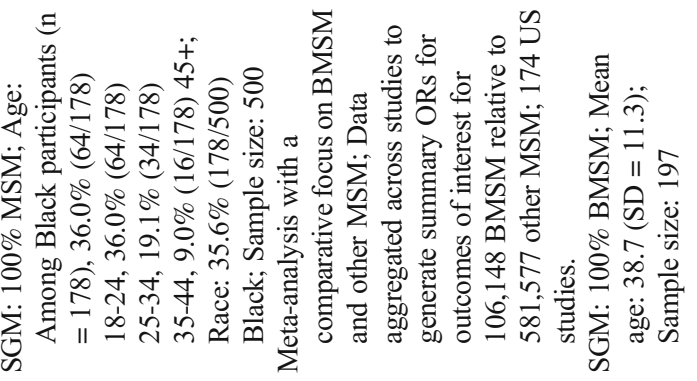

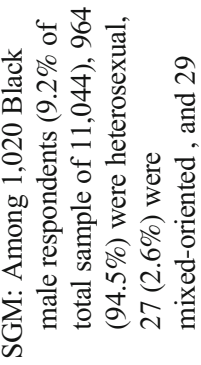

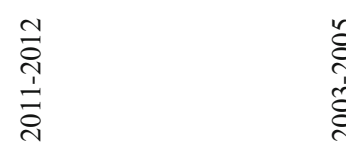

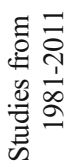

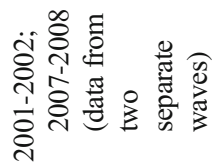

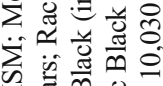

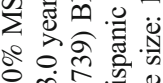

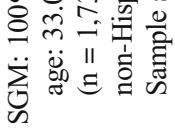

$\stackrel{\infty}{\stackrel{8}{~}}$

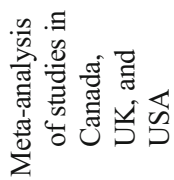

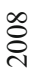

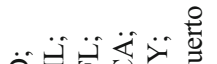

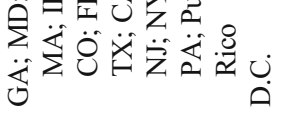

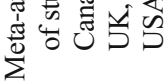

త゙

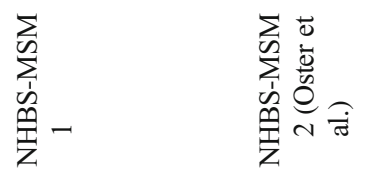

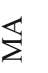

芯

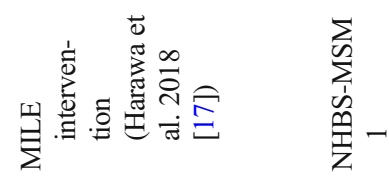

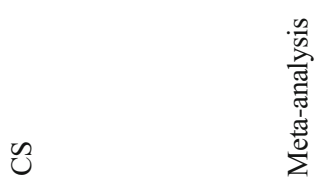

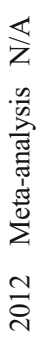

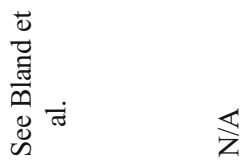

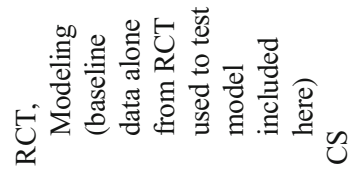

운

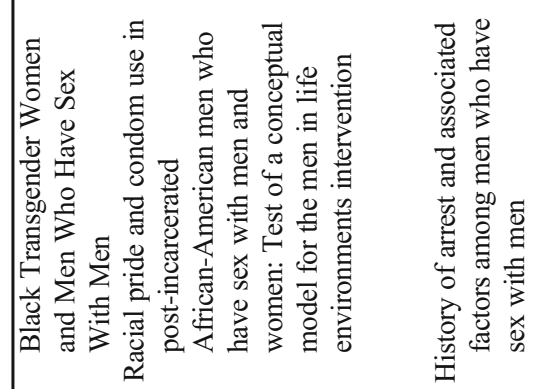
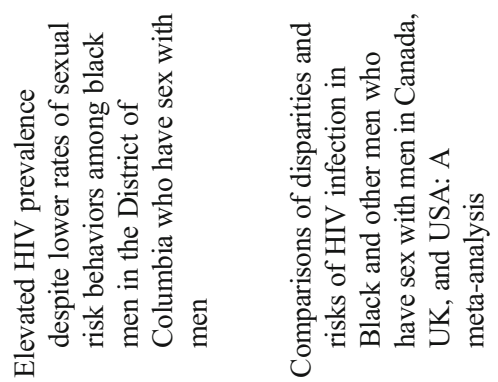

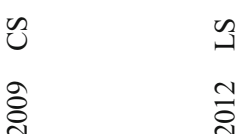

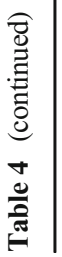
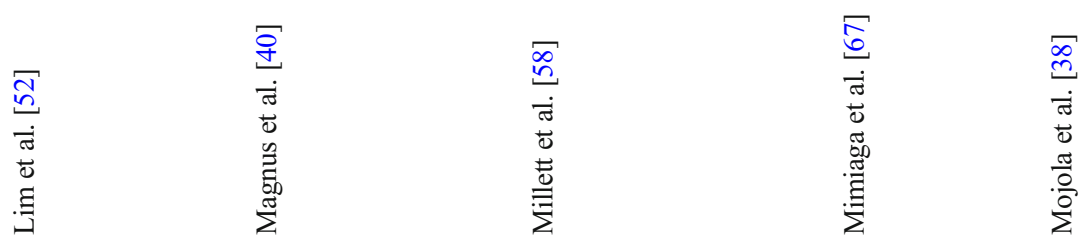

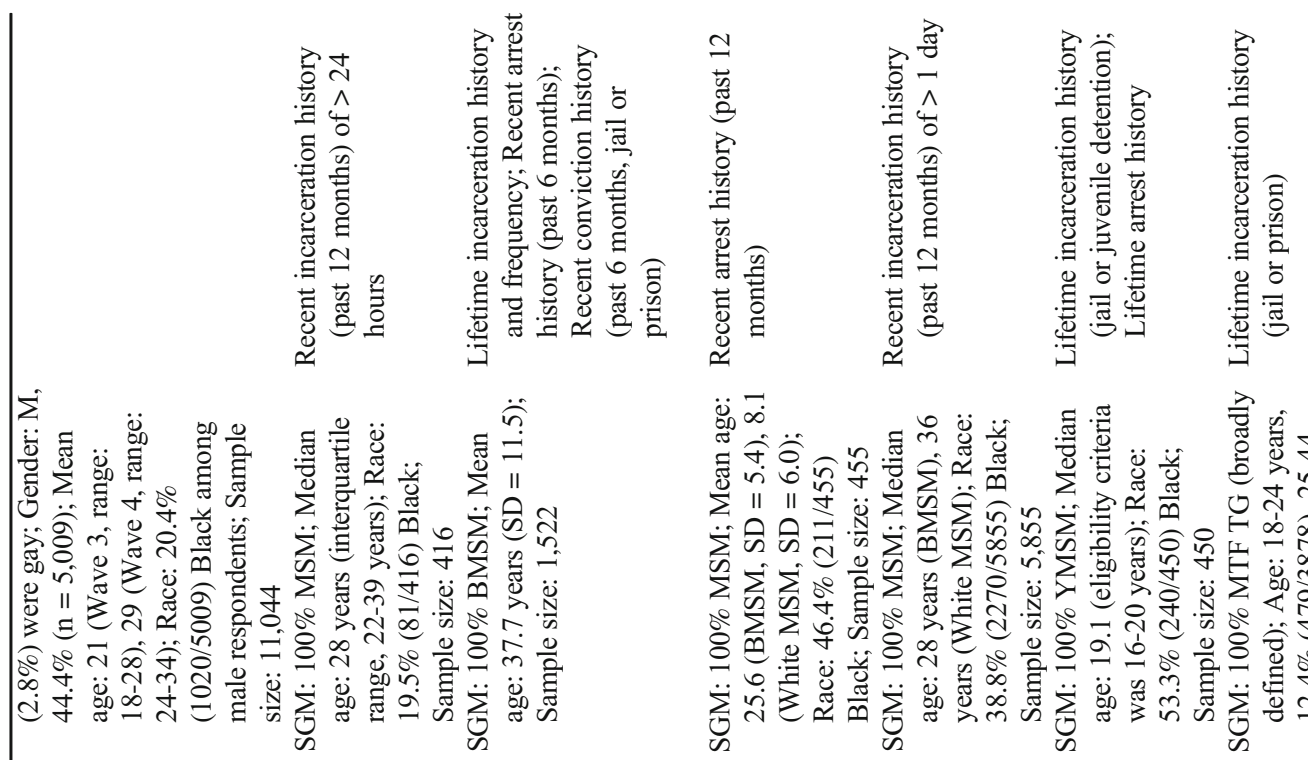

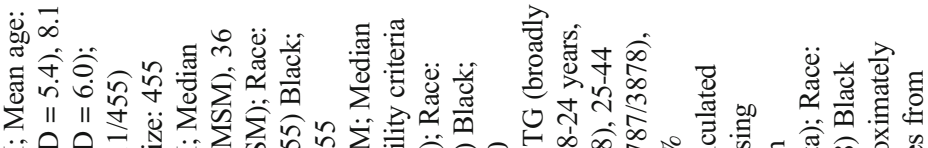

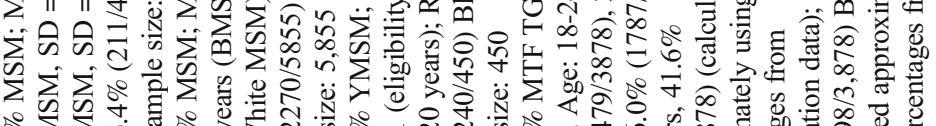

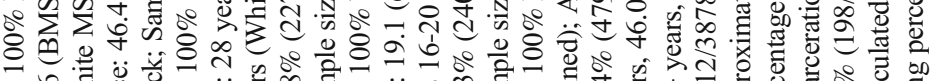

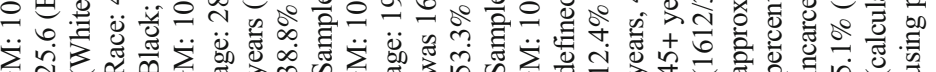

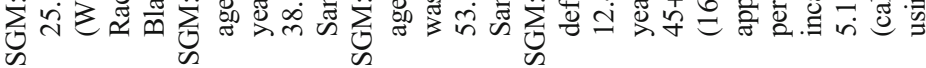
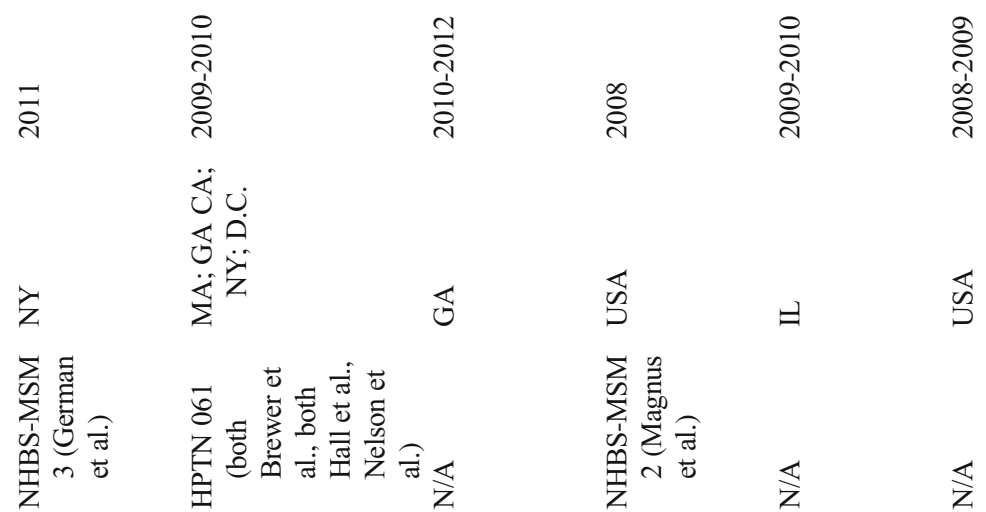

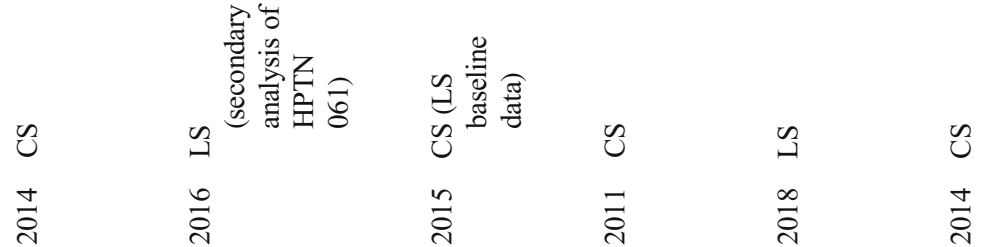

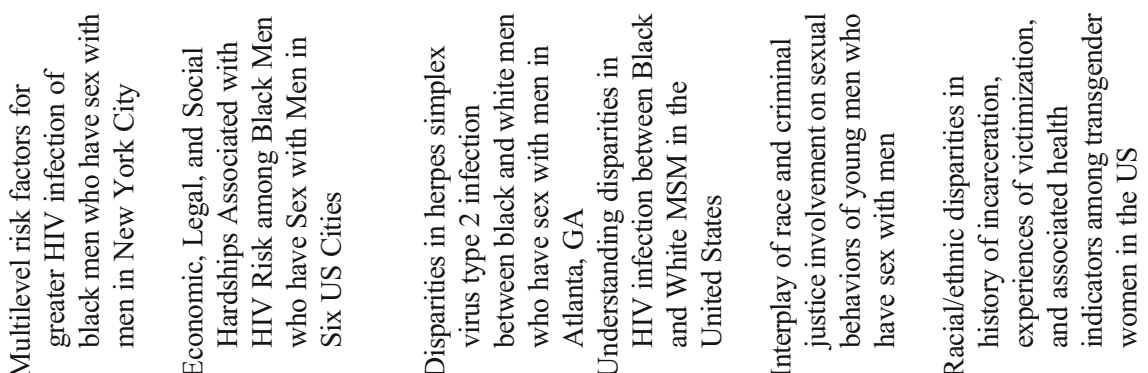

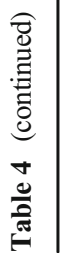

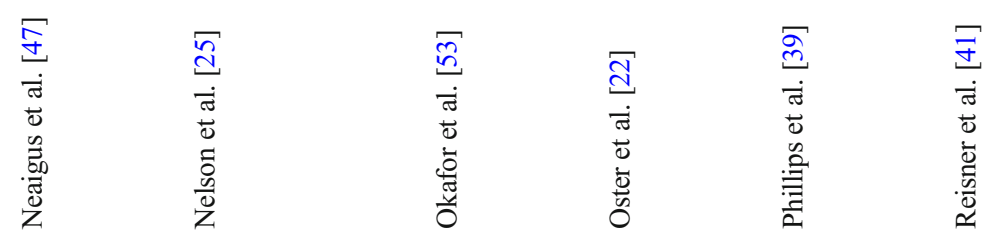



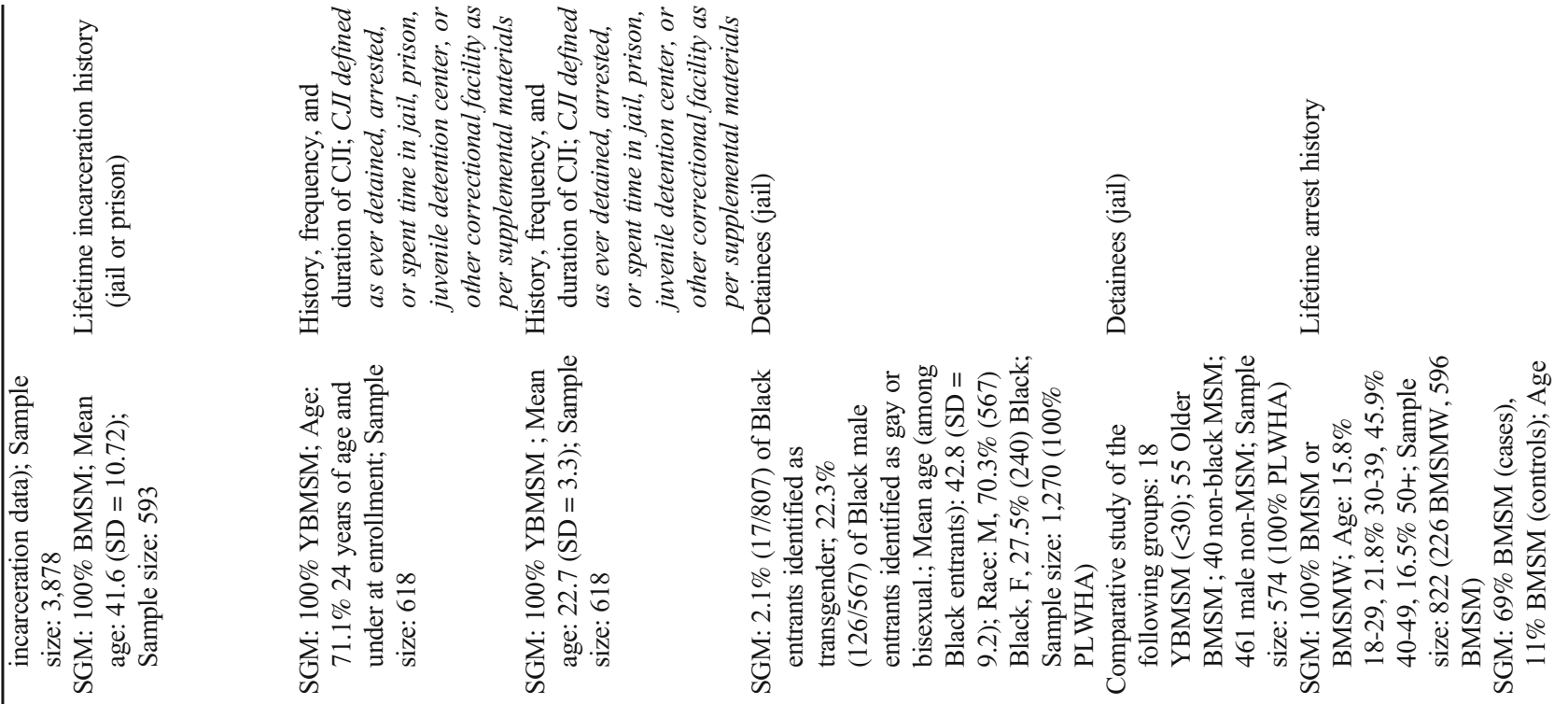

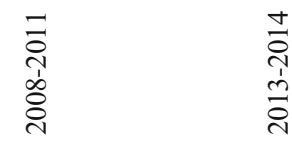

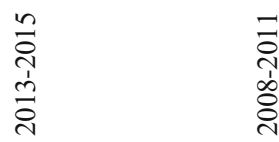

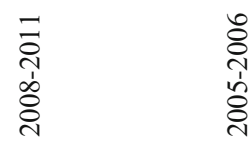

$\frac{\infty}{\frac{2}{2}}$

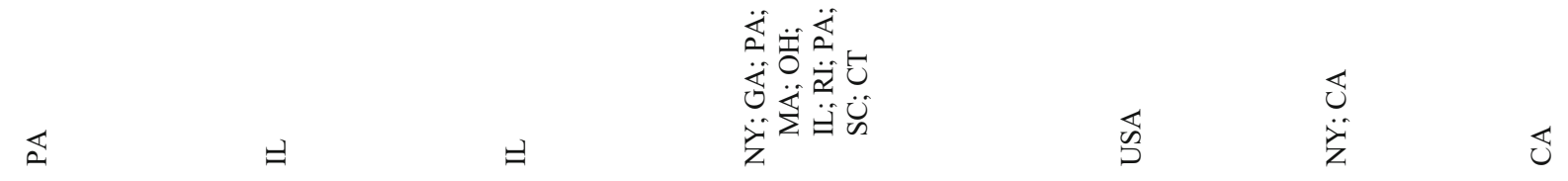

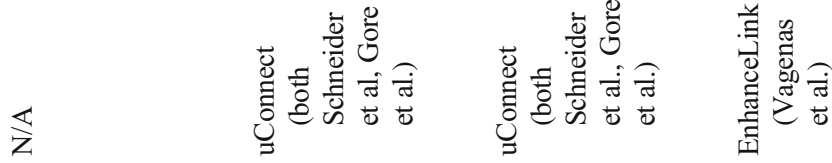

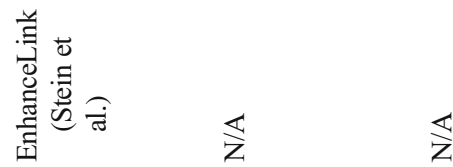

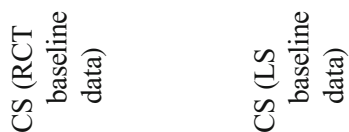

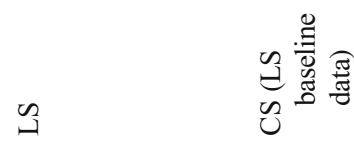

离

롱

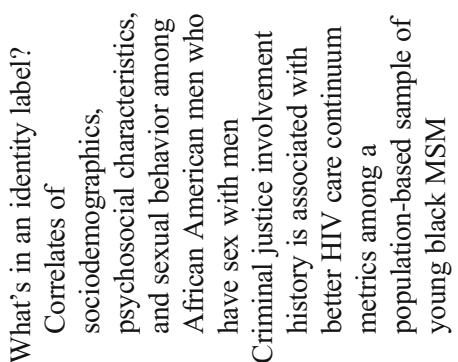

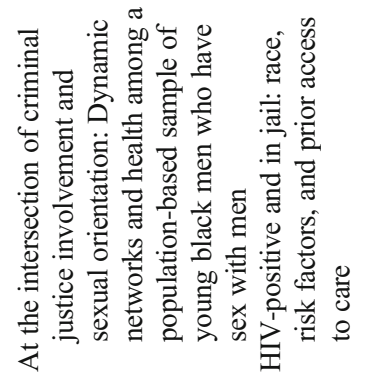

里

3

¿ำ

¿ั่
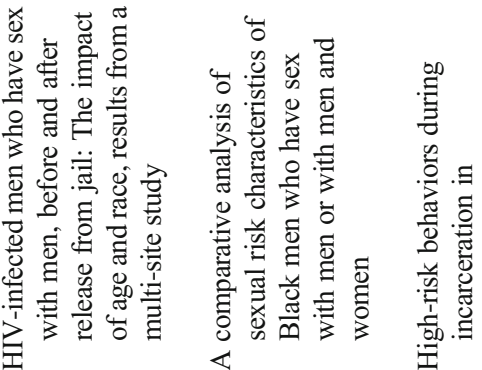

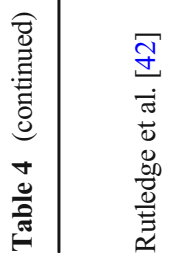

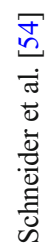

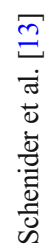

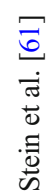

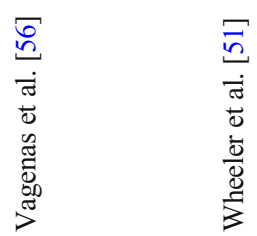

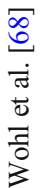




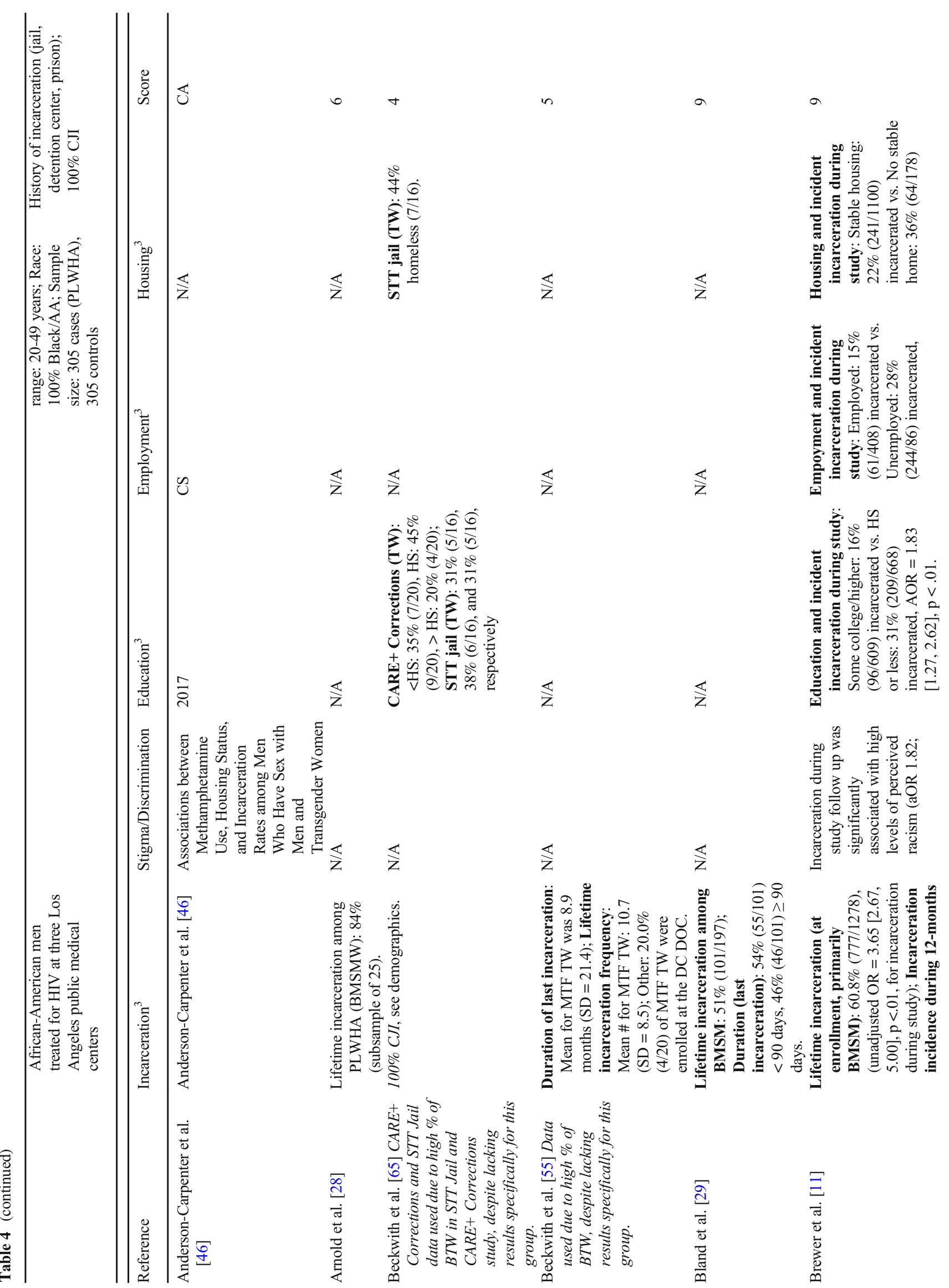




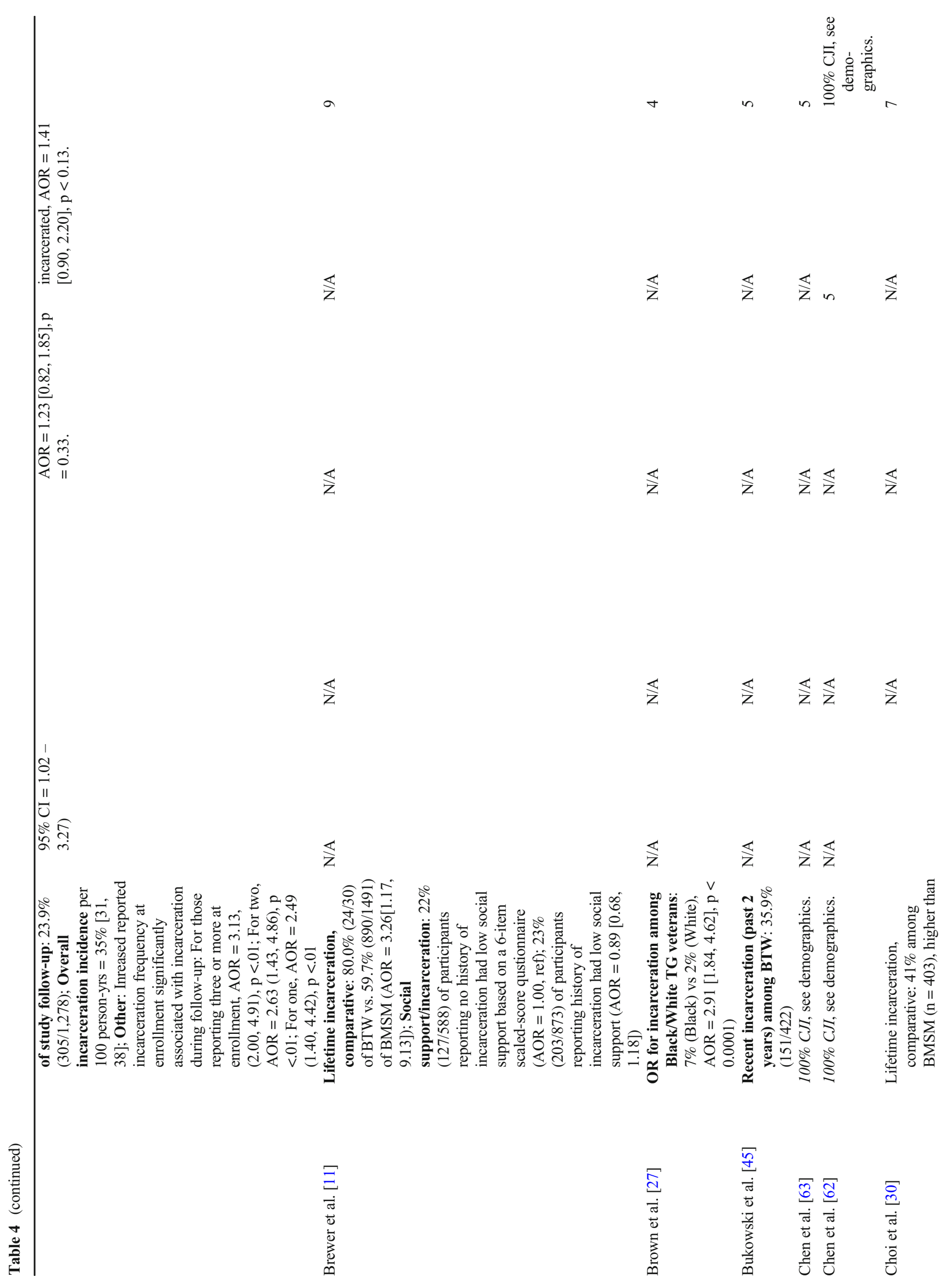




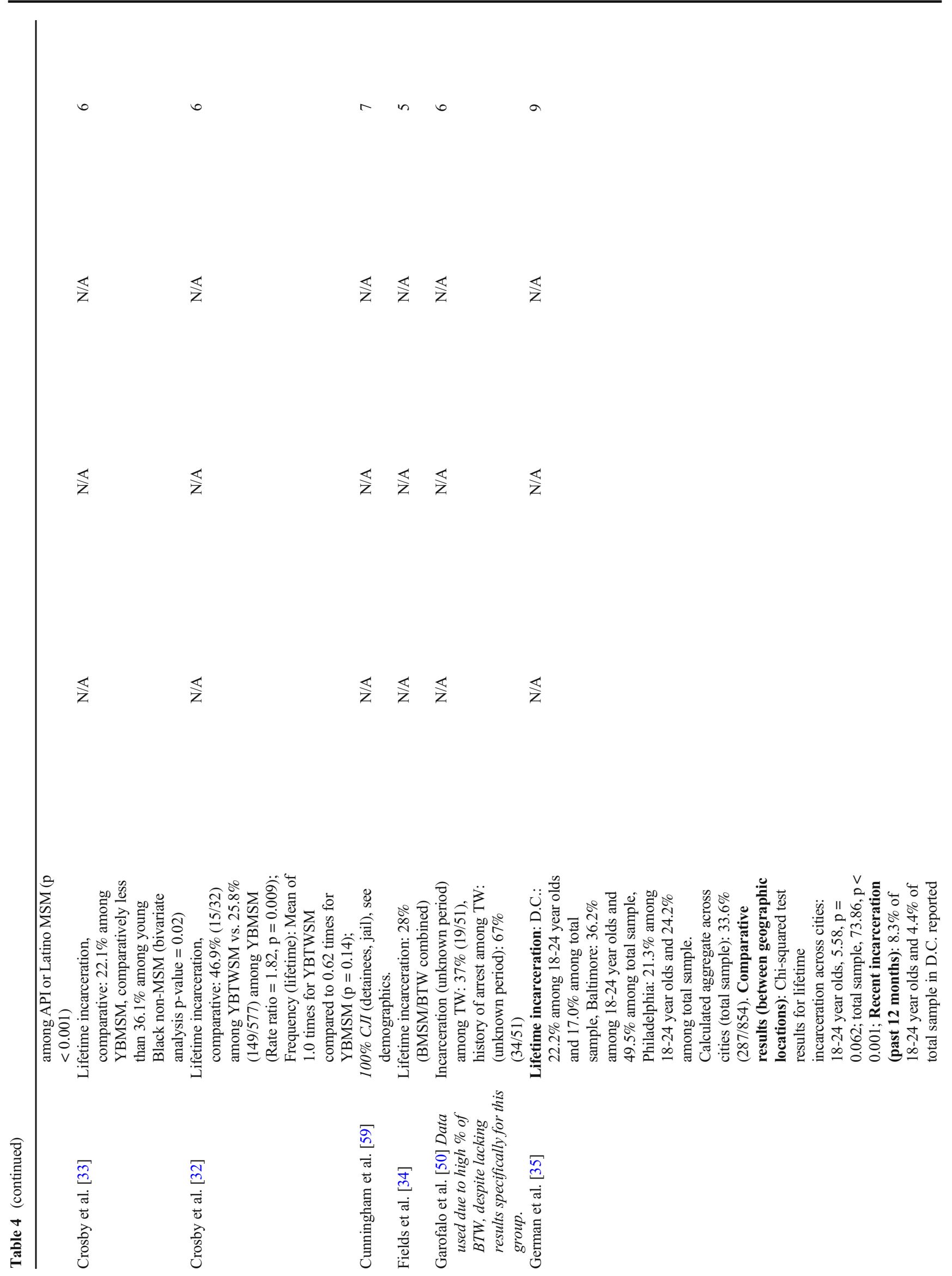




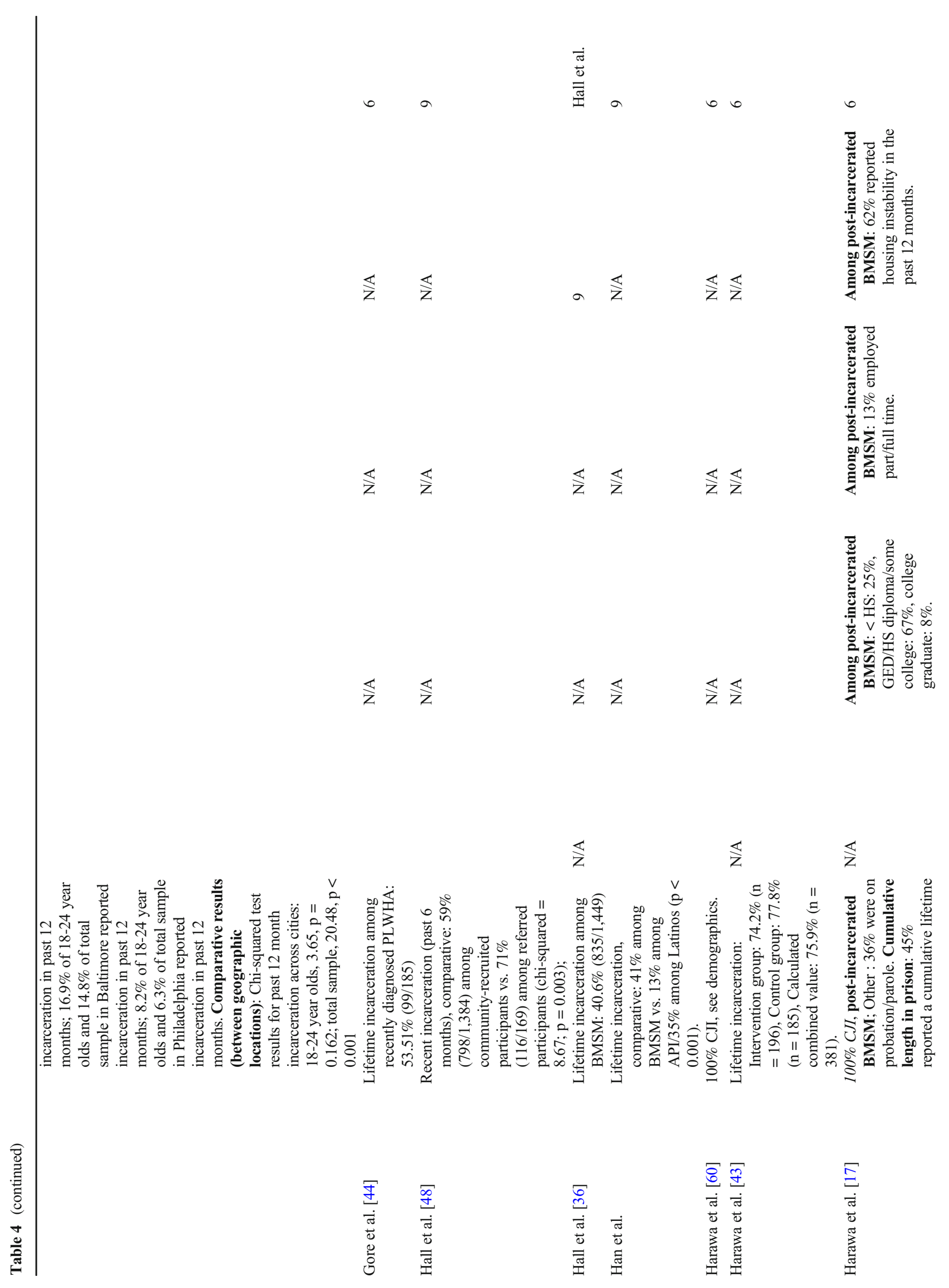




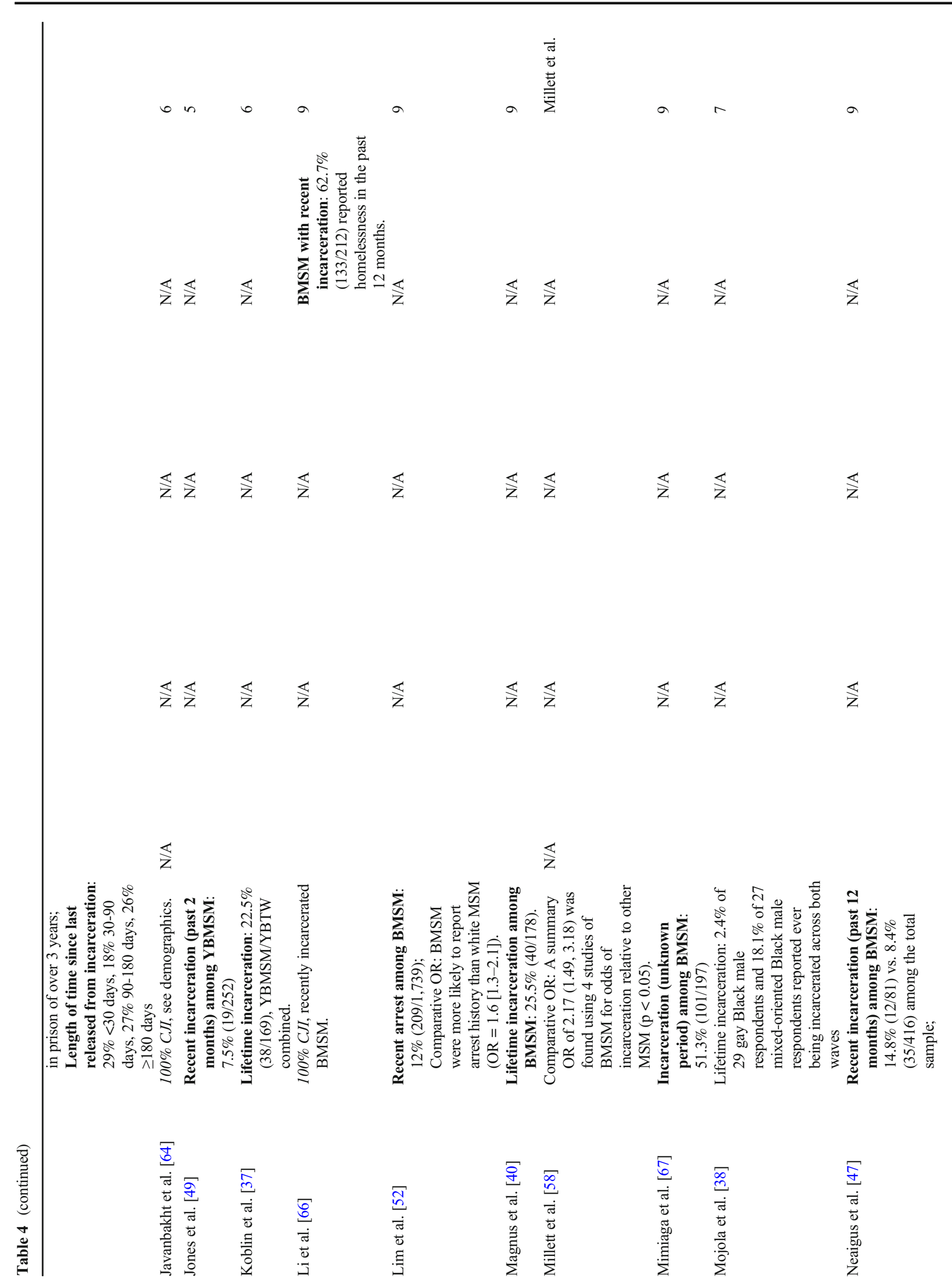




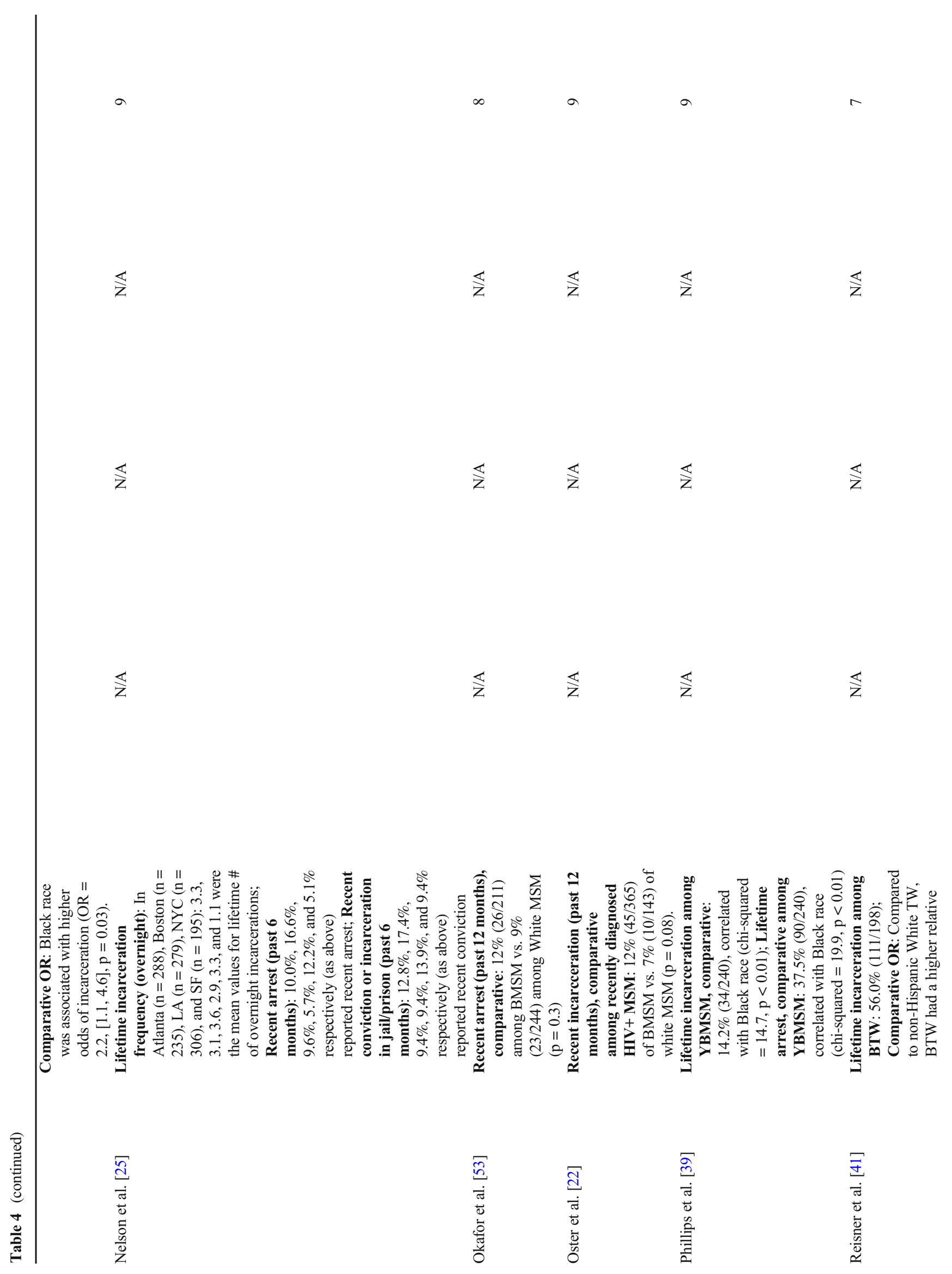



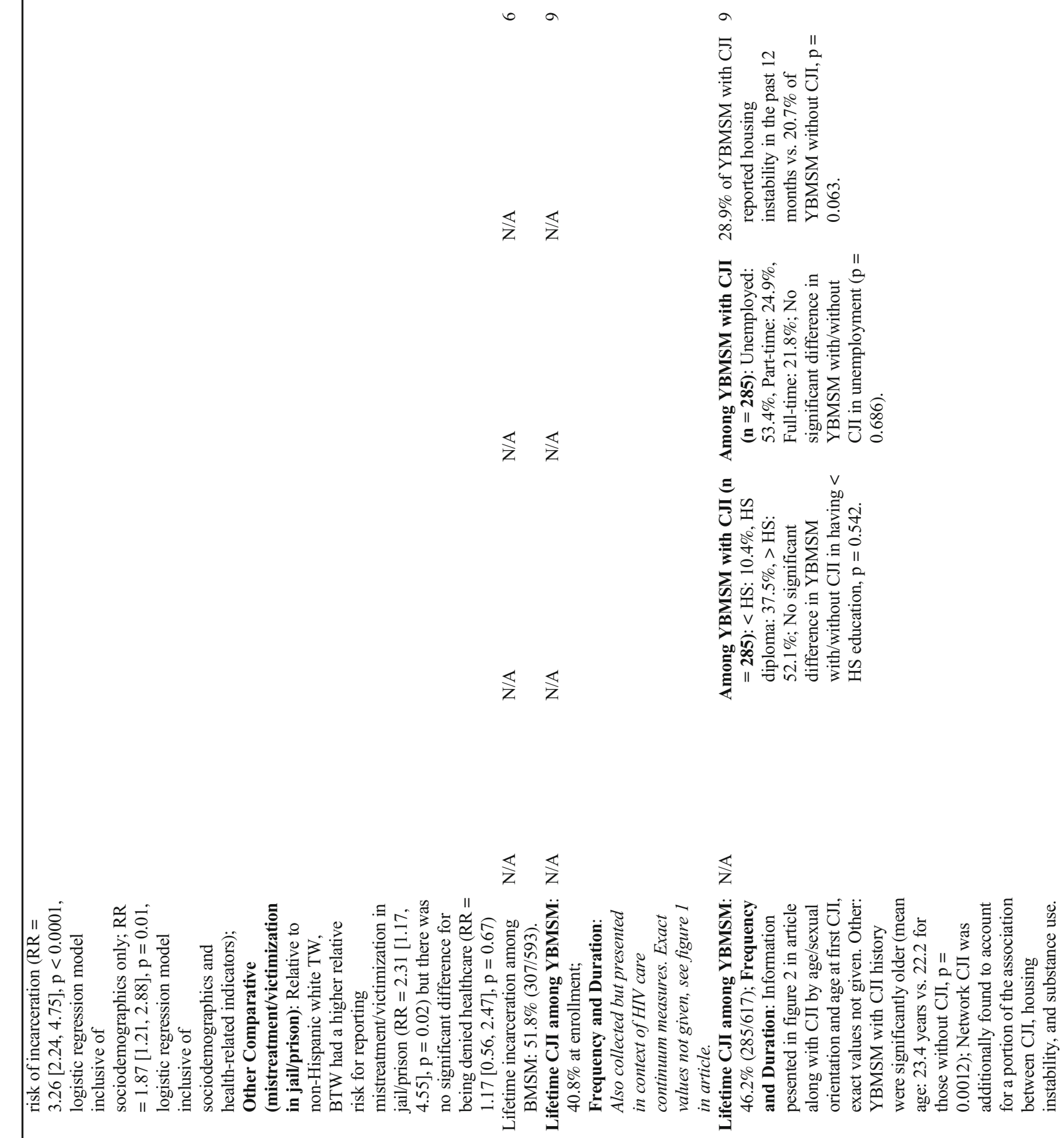

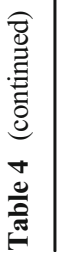

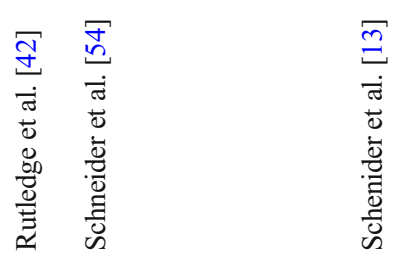




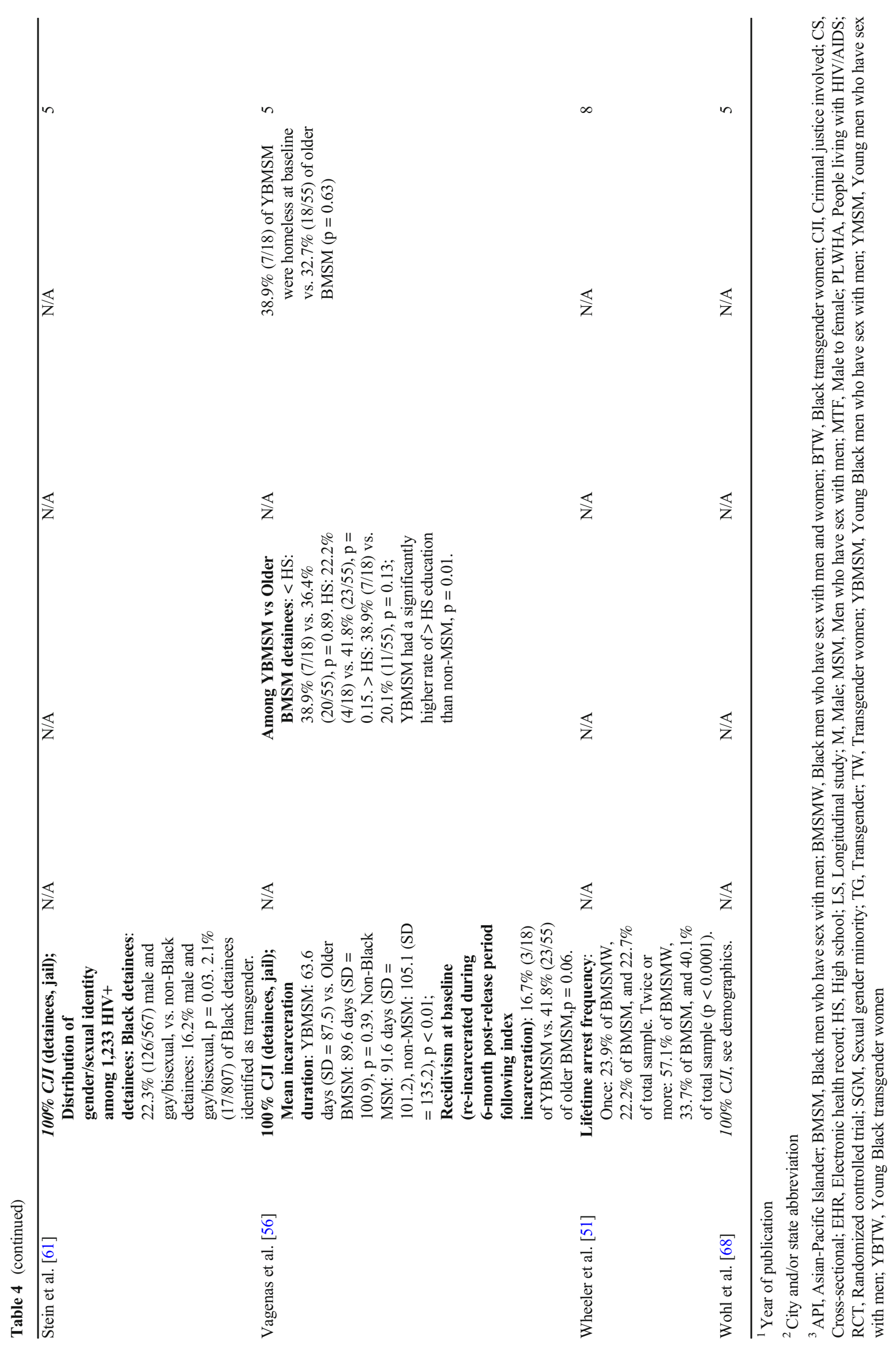


low rates of access to HIV treatment, retention in HIV care, and viral suppression among jail detainees including YBMSM. Thus, the relationship between criminal justice involvement and the HIV care continuum may be highly dependent upon the specific CJI measure assessed among BMSM. However, criminal justice settings may serve as a critical venue for HIV testing services for both BMSM and BTW.

\section{Key Findings Related to Criminal Justice Involvement and STIs Among BMSM and BTW}

Only 7 studies (15\%) examined the relationship between criminal justice involvement and STIs among the populations of interest. Three studies were among BMSM [25, 29, 67], one specifically among YBMSM [13], and three on the same jail population that consisted primarily of MSM [62-64]. None of the studies reported specific relationships between criminal justice involvement and STIs among BTW. However, three of 7 studies specifically examined the independent association between one or more STIs and criminal justice involvement among BMSM [13, 25, 29]. One article found a significant relationship between incarceration history and syphilis seropositivity, and another between incarceration and self-reported lifetime history of STIs (including syphilis, chlamydia, gonorrhea, or herpes) [13, 29]. Nelson et al. [25] reported a significant relationship between a recent conviction and any STI in the past 6 months $(\mathrm{aOR}=3.97, \mathrm{CI}=[1.58$, 9.94], $\mathrm{p}<0.05$ ). Contrary to the mixed findings between HIV and criminal justice involvement, these studies show that incarceration history is independently associated with a greater odds of STIs among BMSM with limited information particularly among BTW.

\section{Key Findings Related to Criminal Justice Involvement and Sexual Risk Behaviors Among BMSM and BTW}

Eleven of 47 articles (23\%) assessed sexual risk behaviors [11-13, 25, 29, 36, 49, 57, 65, 66, 68]. A range of sexual risk behaviors were assessed to include the following: exchange sex, three articles [57, 65, 68]; jail sex, two articles [57, 68]; history of condomless or unprotected sexual acts (e.g., any condomless sex and condomless insertive and/or receptive anal intercourse), six articles [12, 25, 29, 49, 57, 65]; frequency of condomless or unprotected sex, four articles $[36,57,66$, 68]; age of first intercourse, one article [11]; number of sexual partners, eight articles [12, 13, 25, 29, 36, 57, 65, 68]; and gender identity of sexual partners (i.e., male, female, transgender), seven articles $[12,25,29,36,57,66,68]$ with three transinclusive articles [36, 57, 65]. Overall, the analysis by Harawa et al. [57] was the most comprehensive assessment of sexual risk behaviors prior to entering a jail setting, but also surveyed the prevalence of sex within jail by partner gender. The analysis by Wohl et al. [68] was the most comprehensive assessment of sexual risk behaviors within a jail setting.

Only one study assessed sexual behaviors among transgender women and reported high rates $(\geq 65 \%)$ of condomless sex, exchange sex, and multiple partners in the past 90 days among small CJI samples of primarily BTW [65]. None of the included studies specifically examined the direct relationship between incarceration and sexual risk behaviors among BTW. However, findings on the relationship between incarceration and sexual risk behaviors among BMSM were mixed. Two articles did not find any significant relationship between lifetime incarceration and having multiple partners or unprotected and/or condomless sex in the past 6 months among BMSM $[29,36]$. Nelson et al. [25] actually reported a protective effect of lifetime incarceration for condomless receptive anal sex $(\mathrm{aOR}=0.73, \mathrm{CI}=[0.58,0.91], \mathrm{p}<0.05)$ among BMSM. However, two articles found a relationship between more recent incarceration and unprotected sex among BMSM [29, 49], and the same article by Nelson et al. [25] reported a significant relationship between recent conviction and multiple male partners in the past 6 months $(\mathrm{aOR}=0.56, \mathrm{CI}=$ [0.33, 0.93], $\mathrm{p}<0.01)$. Schneider et al. [13] also found a significant relationship between a history of criminal justice involvement and having a greater number of sexual partners among YBMSM (50.8\% among YBMSM with a history of criminal justice involvement vs. $66.1 \%$ with no history of criminal justice involvement; $p=0.0001$ ).

Interestingly, Schneider et al. [13] found that CJI YBMSM were more likely to have CJI homophily in their confidant and sexual networks such that 59\% of CJI YBMSM reported at least one sexual partner who had been in jail during the past 6 months compared to $26.5 \%$ of YBMSM without a history of criminal justice involvement $(\mathrm{p}<0.0001)$. Furthermore, network CJI history (i.e., confidants and sexual partners) was associated with greater encouragement of HIV/STI transmissible sexual behaviors [13].

\section{Key Findings Related to Criminal Justice Involvement and Substance Use/Misuse Among BMSM and BTW}

Nine studies (19.1\%) assessed substance use/misuse behaviors among study participants. These ranged from three studies $(6.4 \%)$ on general alcohol use $[12,56,65]$, one $(2.1 \%)$ on binge drinking $(n=1)$ [65], and nine $(19.1 \%)$ assessing substances such as marijuana, methamphetamine, crack/cocaine, opioids, stimulants, and multiple substances [11-13, 29, 46, $56,57,61,65]$. Two studies $(4.3 \%)$ also assessed whether participants received an alcohol/drug treatment program during custody [29, 57]. One article utilized the Addiction Severity Index $(n=1)$; the others did not address severity of substance use disorders [56]. Only one article had estimates focused primarily on BTW [65], finding high usage rates across a range of substances including crack/cocaine and 
binge alcohol, but in limited sample sizes of 20 or less. The remaining studies reported findings based on samples of all or nearly all BMSM and did not provide separate estimates for BTW. Overall, high levels of substance use were identified among BMSM and BTW.

Several studies found an independent association between previous criminal justice involvement and substance use among BMSM with no studies examining this relationship among BTW [11-13, 29, 41]. Bland et al. [29] found that incarceration history was significantly associated with injection drug use, lifetime history of substance use, and prior substance abuse treatment in a sample of 197 BMSM, with a higher odds among those incarcerated for $\geq 90$ days. Interestingly, BMSM with longer incarceration trajectories (i.e., $\geq 90$ days) were more likely to use crack cocaine during sex than those with shorter incarceration histories [24]. In Brewer et al.'s [12] two papers reporting on BMSM enrolled in the HIV Prevention Trials Network (HPTN) 061 study, any alcohol or drug in the past 6 months was significantly associated with a higher odds of lifetime incarceration history, while stimulant and marijuana use was linked to a higher odds of incident incarceration [11]. Vagenas et al. [56] examined age differences between younger and older BMSM, finding no significant differences between these groups in terms of drug type and addiction severity, except for cocaine usage, which was more frequent among older BMSM. Among YBMSM, network CJI history (i.e., confidants and sexual partners) was associated with a higher likelihood of drug use [13].

\section{Key Findings Related to Criminal Justice Involvement and Mental Health Outcomes Among BMSM and BTW}

Five articles (11\%) assessed mental health outcomes with no reported estimates specific to BTW even though they were enrolled in the larger cohort studies [11-13, 29, 56]. The most common condition measured were depressive symptoms using the Center for Epidemiologic Studies Depression Scale (CES-D). Two of the five papers were based on subsets of participants from the larger cohort of BMSM enrolled in the HPTN 061 study, with final analytic samples of 1278 and 1521 participants $[11,12]$. In these papers, the prevalence of depressive symptoms among BMSM reporting any incarceration during study follow-up or in their lifetime was $27 \%$ and $46 \%$, respectively $[11,12]$. One article was focused on a statewide sample of 197 BMSM and found a similarly high prevalence of depression (i.e., 46\%) among those incarcerated for $\geq 90$ days [29]. In short, relatively high levels of depressive symptoms among BMSM were reported.

Three of the five articles examined the relationship between a history of criminal justice involvement and depression among BMSM, with only one of the studies showing a statistically significant relationship between incarceration history ( $\geq 90$ days) and depressive symptoms $(\mathrm{AOR}=2.76, \mathrm{CI}=$
$[1.22,6.24], p=.01)[29]$. In terms of differences by age group, no significant differences between younger and older CJI BMSM were observed among included studies (50\% for younger vs. $58.2 \%$ for older, $\mathrm{p}=0.54$ ) [56]. However, interesting findings were observed for the relationship between network history of criminal justice involvement and depression, such that network stability was associated with a reduction in respondent depression [13]. In summary, the findings on the relationship between criminal justice involvement and depression among BMSM remain mixed.

For other mental health outcomes, among YBMSM specifically, a higher prevalence of criminal justice involvement history among network members (i.e., confidants and sexual partners) was associated with higher levels of anxiety and distress [13]. Schneider et al. [13] concluded that network criminal justice involvement history may limit access to the types of relationships that support and maintain mental health [69] and/or create situations of instability that further exacerbate mental health problems among non-institutionalized YBMSM [70].

\section{Key Findings Related to Criminal Justice Involvement and Other Socio-Structural Characteristics Among BMSM and BTW}

Only six studies (12.8\%) assessed one or more of the four other socio-structural characteristics of interest within the context of criminal justice involvement (i.e., stigma/discrimination, housing, employment, and education) $[11,13,56,57,65$, 66]. In terms of stigma/discrimination, among BMSM enrolled in the HPTN 061 study, incarceration during study follow-up was associated with high levels of perceived racism $(\mathrm{aOR} 1.82 ; 95 \% \mathrm{CI}=1.02-3.27)$ [11].

All six studies (12.8\%) documented high instances of housing instability among CJI BMSM ranging from 28 to $62 \%$ of samples $[11,13,56,57,65,66]$. Of these studies, two included estimates focused on YBMSM [13, 56]. Schneider et al. [13] found that CJI YBMSM were more likely to report unstable housing in the past 12 months compared with non-CJI YBMSM (28.9\% vs $20.7 \%$, $\mathrm{p}=0.063)$, though the difference was not significant. Among YBMSM, a history of criminal justice involvement was associated with housing instability. In addition, network criminal justice involvement history (i.e., confidants and sexual partners) was associated with a higher likelihood of housing instability [13]. Vagenas et al. [56] compared housing instability at baseline by age group among detained BMSM and did not find any significant differences (38.9\% among younger vs. $32.7 \%$ among older, $p=0.63$ ). Harawa et al. [57] and $\mathrm{Li}$ et al. [66] reported a high rate of housing instability of $62.7 \%$ in the past 12 months among post-incarcerated BMSM. Among BTW specifically, only one study reported a similarly high rate of housing instability (44\%) among a small sample of 16 predominantly HIV- 
positive BTW with a history of criminal justice involvement [65].

Five articles (10.6\%) provided estimates of educational attainment among CJI participants, including one focused on BTW [65], two on BMSM [11, 57], one on YBMSM [13], and one comparative analysis including estimates for older BMSM and YBMSM [56]. All five articles across these various groups reported over $10 \%$ (range $=10.4-38.9 \%$ ) of their samples not having completed a high school education [11, $13,56,57,65]$. The lowest estimate of $10.4 \%$ was in a sample of 285 CJI YBMSM, but all other estimates across groups (YBMSM, BMSM, and BTW), were $\geq 25 \%$. Of these articles, Harawa et al. [57] specified that having a GED, high school diploma, or some college were categorized as having completed a high school-level education, while the other four articles did not delineate a classification method.

Two articles $(4.3 \%)$ examined the relationship between criminal justice involvement and education level among BMSM. The study by Brewer et al. [11] showed that BMSM with less education were more likely to be incarcerated during study follow-up $(\mathrm{aOR}=1.83, \mathrm{CI}=[1.27,2.62], \mathrm{p}<$ 0.01). Schneider et al. [13], however, found no significant difference in education between CJI and non-CJI YBMSM at baseline. No studies examined the relationship between criminal justice involvement and education level among BTW.

Three studies $(6.4 \%)$ provided employment estimates for CJI BMSM but none were identified specifically for BTW $[11,13,57]$. All were quantitative studies with city/county (i.e., Los Angeles County and Chicago) and multi-state (i.e., six HPTN sites) samples of BMSM ranging from 212 to 1278 participants. The Chicago-specific study by Schneider et al. [13] did not find any significant differences in employment between CJI and non-CJI YBMSM at baseline which may be point to high level of need regardless of incarceration status. The multi-city HPTN study showed a greater odds of incarceration during study follow-up among men who were unemployed compared with those who were employed at baseline $(\mathrm{OR}=2.22,1.63-3.03)$ [35]. Thus, unemployment is a risk factor for future incarceration among BMSM. No studies examined the relationship between criminal justice involvement and employment among BTW.

\section{Discussion}

As of the date of this review, there was a paucity of research focused on the intersection of criminal justice involvement, HIV, and associated factors among BMSM and BTW. The objective of this systematic review was to provide a comprehensive overview of the intersections between criminal justice involvement, HIV, and HIV-related characteristics among BMSM and BTW. Included studies examined a wide range of criminal justice experiences, but the most common measure of criminal justice involvement was lifetime history of incarceration with a robust non-representative national sample composed primarily of BMSM enrolled in the HPTN 061 study reporting a high (i.e., 60\%) lifetime history of incarceration among BMSM with a greater likelihood of incarceration history among BTW [12].

The dearth of studies up to 2018 specifically focused on CJI BTW across all of the categories of interest is quite evident. Even though several studies enrolled BTW, specific analyses were not conducted and/or reported. A limited number of trans-inclusive published studies at the date of this review showed that criminal justice involvement may be more pronounced for BTW compared with BMSM. The geographic diversity of studies was additionally limited with most studies occurring in Los Angeles, CA and Chicago, IL. Geographic limitations may partly be explained by investigator interest and presence in those locales as well as the challenges associated with building and maintaining academic/criminal justice setting research collaborations, which may be even more pronounced during the COVID-19 pandemic [71].

Consistent with national data documenting the high prevalence of HIV among CJI persons, BMSM and BTW living with HIV had a high frequency of contact with the criminal justice system [72]. Even though we observed mixed findings as it relates to the independent association between criminal justice involvement and HIV infection, the current evidence favors no association between criminal justice involvement and HIV among BMSM with the largest cohort of BMSM to date not finding an association between recent incarceration and HIV acquisition. Findings related to the independent association between criminal justice involvement and sexual risk behaviors among BMSM were mixed. Criminal justice involvement was positively associated with substance use among BMSM with a strong network influence particularly among YBMSM such that network CJI history (i.e., confidants and sexual partners) was associated with a higher likelihood of drug use. Thus, network interventions may be appropriate for YBMSM.

In terms of STIs, we observed an independent relationship between criminal justice involvement and STI prevalence among BMSM, but inability to establish a temporal relationship precludes assessment of evidence for causality. Regardless, it is plausible that criminal justice settings provide an opportunity for increased STI testing services which are coupled with opt-out HIV testing within these settings [17]. Incarceration may also disrupt sexual relationships leading to an increase in casual sexual partnerships and associated increases in the likelihood of being exposed to STIs [25, 73]. As of the date of this review, there remains a dearth of information about the relationship between criminal justice involvement and STIs among BTW. 
A limited number of studies explored the relationship between criminal justice involvement and the HIV care continuum. Criminal justice-involved settings served as an important venue for HIV testing/diagnosis for both BMSM and BTW. The relationship between criminal justice involvement and the HIV care continuum particularly among BMSM seems highly dependent upon the specific CJI measure assessed. For example, any CJI history was associated with improved HIV care outcomes across the HIV care continuum. However incident jail stays and/or more frequent incarceration events may negatively impact HIV care. Interestingly, in one study of BTW living with HIV, those who were virally suppressed had significantly lower odds of lifetime incarceration compared to those who were virally unsuppressed. This may point to the syndemic nature of health disparities production among BTW [45] and existing barriers to viral suppression within criminal justice settings for this population [74-77]. For example, a qualitative study consisting primarily of transgender women of color described a non-affirming correctional culture in which their feminine identity was not recognized and a combination of provider bias, limited provider knowledge or inexperience caring for transgender patients, and restrictive correctional policies (e.g., sex-segregated environments based on genitalia and strict rules surrounding access to transition-related medical care) limited access to needed medical care [74].

In terms of the socio-structural characteristics, only one study examined the relationship between stigma/ discrimination and criminal justice involvement showing that incarceration during study follow-up was associated with perceived racism among BMSM. This is not a surprising finding given the pervasive nature of racial inequality and systemic racism in the US [78]. African Americans are more likely to be stopped by police and feel somewhat or very unsafe during their interactions with law enforcement, more likely to experience threats or use of physical force by law enforcement, and twice as likely to die from a fatal shooting by an on-duty police officer than their White counterparts [79-81]. Furthermore, BMSM's positioning at the intersection of multiple identities expose them to other forms of discrimination including homophobia $[5,82,83]$.

Few studies comprehensively assessed mental health outcomes among the CJI priority populations. Depressive symptoms were the most commonly assessed outcome, with high estimates of depressive symptoms among BMSM, but inconsistent associations with criminal justice involvement among BMSM. Network stability was identified as a protective factor in terms of mental health particularly for YBMSM. This finding also highlights the importance of network factors among YBMSM.

High rates of housing instability were found among CJI BMSM and BTW, with no statistically observed differences between CJI vs. non-CJI participants. However, criminal justice history was strongly connected to housing instability particularly among YBMSM. Findings indicated that more than $10 \%$ of BMSM and BTW with CJI have not completed a high diploma or GED. However, we note that, nationally, $15 \%$ of Black men ages 25 and higher have not completed high school [84]. While we did not observe differences in education level and employment for CJI YBMSM vs. nonCJI YBMSM [13], the largest multi-site cohort of BMSM did find an independent association between criminal justice involvement and education as well as criminal justice involvement and employment, particularly as it relates to incarceration incidence $[11,12]$. We note that research indicates that higher levels of both education and income offer relatively less protection against criminal justice involvement for African Americans than they do for Whites [85].

\section{Conclusion}

This systematic review provides some of the first comprehensive examinations of the burden of incarceration among Black sexual and gender minority populations as well as the intersection of criminal justice involvement, HIV, and associated factors among BMSM and BTW. Most studies were crosssectional in nature, limiting the ability to make causal inferences between criminal justice involvement, HIV, and associated factors. Our review is limited to published scientific studies up to 2018 in the three scientific databases used. Additional studies have been published after the cutoff date used for this systematic review. For this review, we did not include studies focused on HIV pre-exposure prophylaxis (PrEP). Thus, a future research area may include examining the relationship between criminal justice involvement and PrEP outcomes among BMSM and BTW. In spite of these limitations, this analysis provides a comprehensive overview of the state of the science as it relates to criminal justice involvement, HIV, and HIV-related characteristics among Black sexual and gender minority populations in the US. It highlights the need for more focused studies on BTW to include the relationship between CJI and STIs among this population as well as the importance of CJI network dynamics particularly among YBMSM. It also underscores the importance of the intersection between criminal justice involvement and HIV in any response to Ending the HIV Epidemic in the US $[86,87]$.

Supplementary Information The online version contains supplementary material available at https://doi.org/10.1007/s40615-021-01076-7.

Acknowledgements We thank Victoria Buckman for her assistance with locating and sorting articles. The authors take full responsibility for this 
work. The opinions and ideas expressed here are not necessarily those of the sponsor.

Author Contributions RB, SLR, AK, KF, JAS, AH, LW, NTH contributed to manuscript creation, design, analysis, and interpretation. RB, SLR, TE, JAS, and NTH contributed to data collection. All authors significantly revised the article. RB and SLR reviewed and completed the final version for publication. All authors have read and approved the final manuscript.

Funding This work was supported by HIV Intervention Models for Criminal Justice Involved Black MSM Networks (grant number R01DA039934). R Brewer's time was also supported by a grant from NIDA P30DA027828-08S1 and NIMH (R21MH121187). N. Harawa's time is also supported on grants from the California HIV/AIDS Research Program (CHRP) RP15-LA-007; OS17-LA-003 (PI, Harawa); the UCLA Clinical and Translational Science Institute (CTSI) NIH/NCATS grant UL1-TR001881 (PI, Dubinett); and the Center for HIV Identification, Prevention, and Treatment (CHIPTS) NIMH grant P30MH058107 (PI, Shoptaw).

\section{Declarations}

Ethical Approval All procedures performed in studies involving human participants were in accordance with the ethical standards of the institutional and/or national research committee and with the 1964 Helsinki declaration and its later amendments or comparable ethical standards.

Informed Consent Informed consent was not required for this systematic review.

Conflict of Interest The authors declare no competing interests.

\section{References}

1. Centers for Disease Control and Prevention. HIV and African American gay and bisexual men. 2019. Available at https://www. cdc.gov/hiv/group/msm/bmsm.html. Accessed 1/6/20.

2. Centers for Disease Control and Prevention. HIV and African Americans. 2019. Available at https://www.cdc.gov/hiv/group/ racialethnic/africanamericans/index.html. Accessed 1/6/20.

3. Maulsby C, Millett G, Lindsey K, Kelley R, Johnson K, Montoya $\mathrm{D}$, et al. HIV among Black men who have sex with men (MSM) in the United States: a review of the literature. AIDS Behav. 2014;18(1):10-25.

4. Millett GA, Peterson JL, Wolitski RJ, Stall R. Greater risk for HIV infection of Black men who have sex with men: a critical literature review. Am J Public Health. 2006;96(6):1007-19.

5. Poteat T, Reisner SL, Radix A. HIV epidemics among transgender women. Curr Opin HIV AIDS. 2014;9(2):168-73.

6. Herbst JH, Jacobs ED, Finlayson TJ, McKleroy VS, Neumann MS, Crepaz N. Estimating HIV prevalence and risk behaviors of transgender persons in the United States: a systematic review. AIDS Behav. 2008;12(1):1-17.

7. Beer L, Oster AM, Mattson CL, Skarbinski J. Disparities in HIV transmission risk among HIV-infected Black and White men who have sex with men, United States, 2009. Aids. 2014;28(1):105-14.

8. Hall HI, Frazier EL, Rhodes P, Holtgrave DR, Furlow-Parmley C, Tang $\mathrm{T}$, et al. Differences in human immunodeficiency virus care and treatment among subpopulations in the United States. JAMA Intern Med. 2013;173(14):1337-44.
9. Prevention CfDCa. HIV and transgender people. 2019; https:// www.cdc.gov/hiv/group/gender/transgender/index.html. Accessed $1 / 6 / 2020$.

10. Becasen JS, Denard CL, Mullins MM, Higa DH, Sipe TA. Estimating the prevalence of HIV and sexual behaviors among the US transgender population: a systematic review and meta-analysis. Am J Public Health. 2006-2017;2018:e1-8.

11. Brewer RA, Magnus M, Kuo I, Wang L, Liu T-Y, Mayer KH. Exploring the relationship between incarceration and HIV among Black men who have sex with men in the United States. JAIDS Journal of Acquired Immune Deficiency Syndromes. 2014;65(2): 218-25.

12. Brewer RA, Magnus M, Kuo I, Wang L, Liu T-Y, Mayer KH. The high prevalence of incarceration history among Black men who have sex with men in the United States: associations and implications. Am J Public Health. 2014;104(3):448-54.

13. Schneider JA, Lancki N, Schumm P. At the intersection of criminal justice involvement and sexual orientation: dynamic networks and health among a population-based sample of young Black men who have sex with men. Soc Networks. 2017.

14. Western B. Incarceration and social inequality. Daedalus. 2010;139(3):8-19.

15. Freudenberg N, Heller D. A Review of opportunities to improve the health of people involved in the criminal justice system in the United States. Annu Rev Public Health. 2016;37:313-33.

16. World Health Organization (WHO). Effectiveness of interventions to address HIV in prisons. Geneva: WHO-UNODC-UNAIDS 2007.

17. Harawa NT, Brewer R, Buckman V, Ramani S, Khanna A, Fujimoto K, et al. HIV, Sexually transmitted infection, and substance use continuum of care interventions among criminal justiceinvolved Black men who have sex with men: a systematic review. Am J Public Health. 2018;108(S4):e1-9.

18. Endnote $\mathrm{X} 7$ [computer program]. Thomson Reuters; 2015.

19. Hoy D, Brooks P, Woolf A, Blyth F, March L, Bain C, et al. Assessing risk of bias in prevalence studies: modification of an existing tool and evidence of interrater agreement. J Clin Epidemiol. 2012;65(9):934-9.

20. Hosek SG, Harper GW, Domanico R. Predictors of medication adherence among HIV-infected youth. Psychol Health Med. 2005;10(2):166-79.

21. Mugavero M, Ostermann J, Whetten K, Leserman J, Swartz M, Stangl D, et al. Barriers to antiretroviral adherence: the importance of depression, abuse, and other traumatic events. AIDS Patient Care STDs. 2006;20(6):418-28.

22. Oster AM, Wiegand RE, Sionean C, Miles IJ, Thomas PE, Melendez-Morales L, et al. Understanding disparities in HIV infection between Black and White MSM in the United States. AIDS. 2011;25(8):1103-12.

23. Levy ME, Wilton L, Phillips G II, Glick SN, Kuo I, Brewer RA, et al. Understanding structural barriers to accessing HIV testing and prevention services among Black men who have sex with men (BMSM) in the United States. AIDS Behav. 2014;18(5):972-96.

24. Mayer KH, Wang L, Koblin B, et al. Concomitant socioeconomic, behavioral, and biological factors associated with the disproportionate HIV infection burden among Black men who have sex with men in 6 U.S. cities. PLoS One. 2014;9(1):e87298.

25. Nelson LE, Wilton L, Moineddin R, et al. Economic, legal, and social hardships associated with HIV risk among Black men who have sex with men in six US cities. J Urban Health. 2016;93(1): $170-88$.

26. Walsh T, Bertozzi-Villa C, Schneider JA. Systematic review of racial disparities in human papillomavirus-associated anal dysplasia and anal cancer among men who have sex with men. Am J Public Health. 2015;105(4):e34-45. 
27. Brown GR, Jones KT. Racial health disparities in a cohort of 5,135 transgender veterans. J Racial Ethn Health Disparities. 2014;1(4): 257-66.

28. Arnold EA, Weeks J, Benjamin M, Stewart WR, Pollack LM, Kegeles SM, et al. Identifying social and economic barriers to regular care and treatment for Black men who have sex with men and women (BMSMW) and who are living with HIV: a qualitative study from the Bruthas cohort. BMC Health Serv Res. 2017;17(1):90.

29. Bland SE, Mimiaga MJ, Reisner SL, White JM, Driscoll MA, Isenberg D, et al. Sentencing risk: history of incarceration and HIV/STD transmission risk behaviours among Black men who have sex with men in Massachusetts. Cult Health Sex. 2012;14(3):329-45.

30. Choi K-H, Ayala G, Paul J, Boylan R, Gregorich SE. Social network characteristics and HIV risk among African American, Asian/ Pacific Islander, and Latino men who have sex with men. JAIDS Journal of Acquired Immune Deficiency Syndromes. 2013;64(5): 496-501.

31. C-s H, Ayala G, Paul JP, Boylan R, Gregorich SE, Choi K-H. Stress and coping with racism and their role in sexual risk for HIV among African American, Asian/Pacific Islander, and Latino men who have sex with men. Arch Sex Behav. 2015;44(2):411-20.

32. Crosby RA, Salazar LF, Hill B, Mena L. A comparison of HIV-risk behaviors between young Black cisgender men who have sex with men and young Black transgender women who have sex with men. Int J STD AIDS. 2018;29(7):665-72

33. Crosby R, Pasternak R, Salazar LF, Terrell I. How do young Black men having sex with only women differ from those also having sex with men? Sex Health. 2013;10(5):474-5.

34. Fields EL, Bogart LM, Galvan FH, Wagner GJ, Klein DJ, Schuster MA. Association of discrimination-related trauma with sexual risk among HIV-positive African American men who have sex with men. Am J Public Health. 2013;103(5):875-80.

35. German D, Brady K, Kuo I, et al. Characteristics of Black men who have sex with men in Baltimore, Philadelphia, and Washington, D.C.: Geographic Diversity in Socio-Demographics and HIV Transmission Risk. J Acquir Immune Defic Syndr. 2017;75(Suppl 3):S296-s308.

36. Hall G, Young A, Krakauer C, et al. Sexual risk behaviors among Black men who have sex with men who also report having sex with transgender partners: analysis of HIV Prevention Trials Network (HPTN) 061 Study. AIDS Educ Prev. 2017;29(5):418-31.

37. Koblin BA, Nandi V, Hirshfield S, Chiasson MA, Hoover DR, Wilton $\mathrm{L}$, et al. Informing the development of a mobile phone HIV testing intervention: intentions to use specific HIV testing approaches among young Black transgender women and men who have sex with men. JMIR Public Health Surveill. 2017;3(3): e45.

38. Mojola SA, Everett B. STD and HIV risk factors among US young adults: variations by gender, race, ethnicity and sexual orientation. Perspect Sex Reprod Health. 2012;44(2):125-33.

39. Phillips G, Birkett M, Salamanca P, et al. Interplay of race and criminal justice involvement on sexual behaviors of young men who have sex with men. Journal of Adolescent Health. 2018.

40. Magnus M, Kuo I, Phillips G 2nd, et al. Elevated HIV prevalence despite lower rates of sexual risk behaviors among Black men in the District of Columbia who have sex with men. AIDS Patient Care STDs. 2010;24(10):615-22.

41. Reisner SL, Bailey Z, Sevelius J. Racial/ethnic disparities in history of incarceration, experiences of victimization, and associated health indicators among transgender women in the US. Women Health. 2014;54(8):750-67.

42. Rutledge SE, Jemmott JB III, O'Leary A, Icard LD. What's in an identity label? Correlates of sociodemographics, psychosocial characteristics, and sexual behavior among African American men who have sex with men. Arch Sex Behav. 2018;47(1):157-67.

43. Harawa NT, Williams JK, McCuller WJ, et al. Efficacy of a culturally congruent HIV risk-reduction intervention for behaviorally bisexual Black men: results of a randomized trial. AIDS (London, England). 2013;27(12):1979-88.

44. Gore D, Ferreira M, Khanna AS, Schneider J. Human immunodeficiency virus partner notification services among a representative sample of young Black men who have sex with men demonstrates limited service offering and potential benefits of clinic involvement. Sex Transm Dis. 2018;45(9):636-41.

45. Bukowski LA, Chandler CJ, Creasy SL, Matthews DD, Friedman MR, Stall RD. Characterizing the HIV care continuum and identifying barriers and facilitators to HIV diagnosis and viral suppression among Black transgender women in the United States. J Acquir Immune Defic Syndr. 2018.

46. Anderson-Carpenter KD, Fletcher JB, Reback CJ. Associations between methamphetamine use, housing status, and incarceration rates among men who have sex with men and transgender women. J Drug Issues. 2017;47(3):383-95.

47. Neaigus A, Reilly KH, Jenness SM, Wendel T, Marshall DM, Hagan H. Multilevel risk factors for greater HIV infection of Black men who have sex with men in New York City. Sex Transm Dis. 2014;41(7):433-9.

48. Hall G, Li K, Wilton L, Wheeler D, Fogel J, Wang L, et al. A comparison of referred sexual partners to their community recruited counterparts in The BROTHERS Project (HPTN 061). AIDS Behav. 2015;19(12):2214-23.

49. Jones KT, Johnson WD, Wheeler DP, Gray P, Foust E, Gaiter J. Nonsupportive peer norms and incarceration as HIV risk correlates for young Black men who have sex with men. AIDS Behav. 2008;12(1):41-50.

50. Garofalo R, Deleon J, Osmer E, Doll M, Harper GW. Overlooked, misunderstood and at-risk: exploring the lives and HIV risk of ethnic minority male-to-female transgender youth. J Adolesc Health. 2006;38(3):230-6.

51. Wheeler DP, Lauby JL. Liu K-1, Van Sluytman LG, Murrill C. A comparative analysis of sexual risk characteristics of Black men who have sex with men or with men and women. Arch Sex Behav. 2008;37(5):697-707.

52. Lim JR, Sullivan PS, Salazar L, Spaulding AC, Dinenno EA. History of arrest and associated factors among men who have sex with men. J Urban Health. 2011;88(4):677-89.

53. Okafor N, Rosenberg ES, Luisi N, Sanchez T, Rio C, Sullivan PS, et al. Disparities in herpes simplex virus type 2 infection between Black and White men who have sex with men in Atlanta. GA Int J STD AIDS. 2015;26(10):740-5.

54. Schneider JA, Kozloski M, Michaels S, Skaathun B, Voisin D, Lancki N, et al. Criminal justice involvement history is associated with better HIV care continuum metrics among a population-based sample of young Black MSM. Aids. 2017;31(1):159-65.

55. Beckwith C, Castonguay BU, Trezza C, Bazerman L, Patrick R, Cates A, et al. Gender differences in HIV care among criminal justice-involved persons: baseline data from the CARE+ Corrections Study. PLoS One. 2017;12(1):e0169078.

56. Vagenas P, Zelenev A, Altice FL, di Paola A, Jordan AO, Teixeira $\mathrm{PA}$, et al. HIV-infected men who have sex with men, before and after release from jail: the impact of age and race, results from a multi-site study. AIDS Care. 2016;28(1):22-31.

57. Harawa NT, Guentzel-Frank H, McCuller WJ, et al. Efficacy of a small-group intervention for post-incarcerated Black men who have sex with men and women (MSMW). J Urban Health. 2018;95(2): 159-70.

58. Millett GA, Peterson JL, Flores SA, Hart TA, Jeffries WL 4th, Wilson PA, et al. Comparisons of disparities and risks of HIV infection in Black and other men who have sex with men in 
Canada, UK, and USA: a meta-analysis. Lancet. 2012;380(9839): 341-8.

59. Cunningham WE, Weiss RE, Nakazono T, Malek MA, Shoptaw SJ, Ettner SL, et al. Effectiveness of a peer navigation intervention to sustain viral suppression among HIV-positive men and transgender women released from jail: the LINK LA Randomized Clinical Trial. JAMA Intern Med. 2018;178(4):542-53.

60. Harawa NT, Sweat J, George S, Sylla M. Sex and condom use in a large jail unit for men who have sex with men (MSM) and male-tofemale transgenders. J Health Care Poor Underserved. 2010;21(3): 1071-87.

61. Stein MS, Spaulding AC, Cunningham M, et al. HIV-positive and in jail: race, risk factors, and prior access to care. AIDS Behav. 2013;17(Suppl 2):S108-17.

62. Chen JL, Bovee MC, Kerndt PR. Sexually transmitted diseases surveillance among incarcerated men who have sex with men-an opportunity for HIV prevention. AIDS Educ Prev. 2003;15(1 Suppl A):117-26.

63. Chen JL, Callahan DB, Kerndt PR. Syphilis control among incarcerated men who have sex with men: public health response to an outbreak. Am J Public Health. 2002;92(9):1473-4.

64. Javanbakht M, Murphy R, Harawa NT, Smith LV, Hayes M, Chien $\mathrm{M}$, et al. Sexually transmitted infections and HIV prevalence among incarcerated men who have sex with men, 2000-2005. Sex Transm Dis. 2009;36(2 Suppl):S17-21.

65. Beckwith CG, Kuo I, Fredericksen RJ, Brinkley-Rubinstein L, Cunningham WE, Springer SA, et al. Risk behaviors and HIV care continuum outcomes among criminal justice-involved HIV-infected transgender women and cisgender men: data from the Seek, Test, Treat, and Retain Harmonization Initiative. PLoS One. 2018;13(5):e0197730.

66. Li MJ, Frank HG, Harawa NT, Williams JK, Chou C-P, Bluthenthal RN. Racial pride and condom use in postincarcerated African-American men who have sex with men and women: test of a conceptual model for the men in life environments intervention. Arch Sex Behav. 2018:47(1):169-81.

67. Mimiaga MJ, Reisner SL, Bland S, Skeer M, Cranston K, Isenberg $\mathrm{D}$, et al. Health system and personal barriers resulting in decreased utilization of HIV and STD testing services among at-risk Black men who have sex with men in Massachusetts. AIDS Patient Care STDs. 2009;23(10):825-35.

68. Wohl AR, Johnson D, Jordan W, Lu S, Beall G, Currier J, et al. High-risk behaviors during incarceration in African-American men treated for HIV at three Los Angeles public medical centers. J Acquir Immune Defic Syndr. 2000;24(4):386-92.

69. Kawachi I, Berkman LF. Social ties and mental health. Journal of urban health : bulletin of the New York Academy of Medicine. 2001;78(3):458-67.

70. Christian J, Mellow J, Thomas S. Social and economic implications of family connections to prisoners. J Crim Just. 2006;34(4):443-52.

71. Apa ZL, Bai RY, Mukherejee DV, Herzig CTA, Koenigsmann C, Lowy FD, et al. Challenges and strategies for research in prisons. Public Health Nurs. 2012;29(5):467-72. https://doi.org/10.1111/j. 1525-1446.2012.01027.x.

72. Maruschak LM. HIV in prisons, 2001-2010. 2012. US Department of Justice NCJ 238877. Available at: https:// www.bjs.gov/content/ pub/pdf/hivp10.pdf. Accessed Jan 7, 2021.

73. Khan MR, Doherty IA, Schoenbach VJ, Taylor EM, Epperson MW, Adimora AA. Incarceration and high-risk sex partnerships among men in the United States. J Urban Health. 2009;86(4): 584-601.

74. Hughto JMW, Clark KA, Altice FL, et al. Creating, reinforcing, and resisting the gender binary: a qualitative study of transgender women's healthcare experiences in sex-segregated jails and prisons. Int J Prison Health. 2018;14(2):69-88.

75. Sevelius JM, Patouhas E, Keatley JG, et al. Barriers and facilitators to engagement and retention in care among transgender women living with human immunodeficiency virus. Ann Behav Med. 2014;47:5-16.

76. Bauer GR, Hammond R, Travers R, Kaay M, Hohenadel KM, Boyce M. "I don't think this is theoretical; this is our lives": how erasure impacts health care for transgender people. J Assoc Nurses AIDS Care. 2009;20:348-61.

77. Sanchez NF, Sanchez JP, DAnoff A. Health care utilization, barriers to care, and hormone usage among male-to-female transgender persons in New York City. Am J Public Health. 2009;99:713-9.

78. Hanks A, Solomon D, Weller CE. Systematic inequality. How America's structural racism helped create the Black-White wealth gap. Center for American Progress. 2018. Available at https://www. americanprogress.org/issues/race/reports/2018/02/21/447051/ systematic-inequality/. Accessed Jul 8, 2020.

79. U.S. Department of Justice. Bureau of Justice Statistics. Contacts between police and the public, 2015. 2018. Available at https:/ www.bjs.gov/content/pub/pdf/cpp15_sum.pdf. Accessed Jul 8, 2020.

80. Ballard J. Black Americans less likely to feel safe during police interactions. YouGov. 2018. Available at https://today.yougov. com/topics/politics/articles-reports/2018/11/13/black-americanspolice-safety-trust. Accessed Jul 8, 2020.

81. The Washington Post. Fatal Force. 2020. Available at https://www. washingtonpost.com/graphics/investigations/police-shootingsdatabase/. Accessed Jul 8, 2020.

82. Bowleg L. "Once you've blended the cake, you can't take the parts back to the main ingredients": Black gay and bisexual men's descriptions and experiences of intersectionality. Sex Roles. 2013;68(11-12):754-67.

83. Bogart L, Wagner GJ, Galvan FH, et al. Perceived discrimination and mental health symptoms among Black men with HIV. Cult Divers Ethn Minor Psychol. 2011;17(3):295-302. https://doi.org/ 10.1037/a0024056.

84. United States Census Bureau. 2018 ACS 1-year estimates. Available at https://www.census.gov/programs-surveys/acs/ technical-documentation/table-and-geography-changes/2018/1year.html. Accessed May 5, 2020.

85. Oliver P. Education, poverty, and rural vs. urban incarceration rates. 2020 Available at https://www.ssc.wisc.edu/soc/racepoliticsjustice/ 2017/07/14/education-poverty-and-rural-vs-urban-incarcerationrates/. Accessed on May 5, 2020.

86. Azar A. Ending the HIV Epidemic: A Plan for America. 2019; https://www.hhs.gov/blog/2019/02/05/ending-the-hiv-epidemic-aplan-for-america.html. Accessed 12/06/2019.

87. NASTAD. Ending the HIV epidemic: jurisdictional plans. 2019 https://www.nastad.org/maps/ending-hiv-epidemic-jurisdictionalplans. Accessed 12/06/2019.

Publisher's Note Springer Nature remains neutral with regard to jurisdictional claims in published maps and institutional affiliations. 